\title{
Venusian Habitable Climate Scenarios: Modeling Venus through time and applications to slowly rotating Venus-Like Exoplanets
}

\author{
M.J. Way ${ }^{1,2,3}$, and Anthony D. Del Genio ${ }^{1}$ \\ ${ }^{1}$ NASA Goddard Institute for Space Studies, 2880 Broadway, New York, NY, 10025, USA \\ ${ }^{2}$ GSFC Sellers Exoplanet Environments Collaboration \\ ${ }^{3}$ Theoretical Astrophysics, Department of Physics and Astronomy, Uppsala University, Uppsala,

$$
\text { SE-75120, Sweden }
$$

\section{Key Points:}

- Venus could have had habitable conditions for nearly 3 billion years.

- Surface liquid water is required for any habitable scenario.

- Solar insolation through time is not a crucial factor if a carbonate-silicate cycle is in action. 


\begin{abstract}
One popular view of Venus' climate history describes a world that has spent much of its life with surface liquid water, plate tectonics, and a stable temperate climate. Part of the basis for this optimistic scenario is the high deuterium to hydrogen ratio from the Pioneer Venus mission that was interpreted to imply Venus had a shallow ocean's worth of water throughout much of its history. Another view is that Venus had a long lived $(\sim$ 100 million year) primordial magma ocean with a $\mathrm{CO}_{2}$ and steam atmosphere. Venus' long lived steam atmosphere would sufficient time to dissociate most of the water vapor, allow significant hydrogen escape and oxidize the magma ocean. A third scenario is that Venus had surface water and habitable conditions early in its history for a short period of time $(<1 \mathrm{Gyr})$, but that a moist/runaway greenhouse took effect because of a gradually warming sun, leaving the planet desiccated ever since. Using a general circulation model we demonstrate the viability of the first scenario using the few observational constraints available. We further speculate that Large Igneous Provinces and the global resurfacing 100s of millions of years ago played key roles in ending the clement period in its history and presenting the Venus we see today. The results have implications for what astronomers term "the habitable zone," and if Venus-like exoplanets exist with clement conditions akin to modern Earth we propose to place them in what we term the "optimistic Venus zone."
\end{abstract}

\title{
Plain Language Summary
}

We have little data on our neighbor Venus to help us understand its climate history. Yet Earth and Venus are sister worlds: they initially formed close to one another, and have nearly the same mass and radius. Despite the differences in their current atmospheres and surface temperatures, they likely have similar bulk compositions, making comparison between them extremely valuable for illuminating their distinct climate histories. We analyze our present data on Venus alongside knowledge about Earth's climate history to make a number of exciting claims. Evaluating several snapshots in time over the past $4+$ billion years, we show that Venus could have sustained liquid water and moderate temperatures for most of this period. Cloud feedbacks from a slowly rotating world with surface liquid water reservoirs were the keys to keeping the planet clement. Contrast this with its current surface temperature of 450 degrees and an atmosphere dominated by Carbon Dioxide and Nitrogen. Our results demonstrate that it was not the gradual warming of the sun over the eons that contributed to Venus present hot-house state. Rather we speculate that large igneous provinces and the global resurfacing 100s of millions of years ago played key roles in ending the clement period in its history.

\section{Introduction}

The case for prolonged habitability of Venus has been made by a number of authors in recent years (e.g., Grinspoon \& Bullock, 2007; Way et al., 2016). If so, then if habitability was widespread and persisted over geological timescales (e.g. $10^{9}$ years), it is possible that organisms were capable of filling a large variety of environmental niches as occurred on Earth via evolutionary processes. This has led to speculation about possible remaining life-friendly niches (e.g., Morowitz \& Sagan, 1967; Grinspoon, 1997; Cockell, 1999; Schulze-Makuch \& Irwin, 2002; Schulze-Makuch et al., 2004; Dartnell et al., 2015; Limaye et al., 2018). These possibilities alone provide sufficient motivation to understand whether early Venus was habitable or not. However, Venus is also interesting from the perspective of the large number of rocky exoplanets discovered to date inside the traditional inner edge of the habitable zone but far enough from their host stars to maintain an atmosphere (Kane et al., 2019). If some of these planets in close proximity to their host stars have long periods of habitability it may overturn traditional notions of the habitable zone (e.g., Kopparapu et al., 2013) and influence target selection 
for characterization of the atmospheres of these planets. Hence, what appears to be a modern Venus-like world close to its parent star might host surface liquid water. We refer to such habitable worlds as residing in an "Optimistic Venus Zone," a subset of the planets in the "Venus Zone" described in Kane et al. (2014).

There are three primary requirements for the early habitability of Venus. The first is that temperatures were low enough that liquid water was capable of condensing on the surface of Venus. The second is that Venus had a sufficient inventory of water to create the conditions believed necessary for the rise of life on terrestrial worlds (e.g., Brack et al., 2010). Third, volatile cycling and a geologically active surface must exist to regulate the climate as possibly supported by the work of Noack et al. (2012). For surficial water reservoirs most research has focused on the poorly constrained measurement of the $\mathrm{D} / \mathrm{H}$ ratio of $\sim 150 \pm 30$ (times Earth's value) by the Pioneer Venus Mission

(https://nssdc.gsfc.nasa.gov/planetary/pioneer_venus.html) (Donahue et al., 1982, 1997). A number of other ground based measurements have been made (De Bergh et al., 1991; Marcq, 2006; Bjoraker et al., 1992; Fedorova et al., 2008) that have generally revealed values of $\mathrm{D} / \mathrm{H}$ greater than 100 . For a recent review of $\mathrm{D} / \mathrm{H}$ measurements of Venus see Section 6.3 of Marcq et al. (2017). We review the work of authors who have considered Venus' climate evolution below.

The first simple gray radiative transfer calculations of Venus' climate history suggested an early runaway greenhouse effect (e.g., Ingersoll, 1969; Rasool \& de Bergh, 1970). Any water would have remained in vapor form throughout Venus' early history until its loss to space via photodissociation processes (Goody \& Walker, 1972; Walker, 1975). $\mathrm{CO}_{2}$ would continue to be outgassed and would accumulate (offset by atmospheric loss over the last $4.5 \mathrm{Gyr}$ ) to the values we see today.

Pollack (1971) used a similar model but with non-gray radiative transfer. This was probably the first work to show that Venus could have hosted liquid water on its surface in its early history, but they also demonstrated that a runaway greenhouse was possible as well. The difference between the two outcomes was mostly due to to the specified cloud cover and water vapor content of the atmosphere. With $50 \%$ cloud fraction the result was usually a runaway greenhouse. For an $\mathrm{N}_{2}$ dominated atmosphere with a modern Earth water vapor profile, 100\% cloud cover, and a 30\% less luminous sun (akin to $\sim 4.5 \mathrm{Ga}$ ) he achieved surface temperatures $\sim 300 \mathrm{~K}$. These purely radiative models did not include convection, which would limit the water vapor mixing ratio by precipitation and limit the lapse rate of temperature to the moist adiabatic value (Rampino \& Caldeira, 1994) and lessen the strength of the greenhouse effect to some degree. Likewise, they did not include an atmospheric general circulation that would determine the cloud fraction self-consistently. Donahue and Pollack (1983) replicated some aspects of the Pollack (1971) work and again showed that clement conditions were possible in Venus' early history.

Kasting et al. (1984) used a 1-D radiative-convective model to demonstrate that

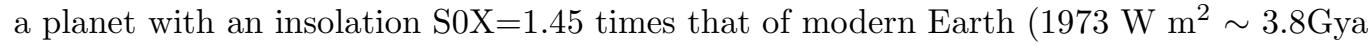
at Venus' orbit) would have temperatures $\sim 100^{\circ} \mathrm{C}$ for a 2 bar $\mathrm{N}_{2} \mathrm{H}_{2} \mathrm{O}$ atmosphere. This atmosphere contained a wet stratosphere, and thus photodissociation of $\mathrm{H}_{2} \mathrm{O}$ and subsequent escape of hydrogen (e.g., Goody \& Walker, 1972) could explain the long-term loss of Venus' primordial ocean and its present dry conditions. In a subsequent study Kasting (1988) claimed that clouds would cool the atmosphere enough to keep it in a moist greenhouse state, rather than the runaway state. At the same time the Kasting (1988) surface temperature for his "Early Venus" (Figure 7) cloud-free model was 500K and hovered just at the margin of the moist vs. runaway greenhouse states. Thus it was clear early on that maintaining liquid water on ancient Venus required high fractional cloud cover, but whether physical mechanisms exist to produce these cloudy conditions was not addressed. These early Venus habitability scenarios would have taken place within the first billion years of the planet's evolution limiting the possibility for complex life to 
evolve. Venus would have subsequently entered a moist/runaway greenhouse and left us with the state it is in today. For the curious reader Bullock and Grinspoon (1999) provide a nice review of the literature on the possibility of an early habitable Venus. Note that in a previous work (Way et al., 2016) it was shown that if habitable conditions were possible in early Venus' history that it likely remained so and that increasing solar insolation through time is not a deciding factor. In the present work we find the same, and hence believe that limited (in time) early habitability models are not supported by our simulations.

Grinspoon and Bullock, in a number of abstracts (e.g., Grinspoon \& Bullock, 2003; Grinspoon, 2008), described a Venus climate evolution scenario with long-lived surface habitability consistent with that described later in this paper. This work was never published, though, so the details of their calculations and the justifications for their conjectures are not documented.

The first three-dimensional (3-D) General Circulation Model (GCM) exploration of issues relevant to ancient Venus was that of Abe et al. (2011). Their study focused on land planets (analogous to the planet Arrakis of Dune) with no permanent surface water reservoirs, only limited fixed amounts of ground water. In some scenarios they found that "in principle Venus could have been a habitable land planet as recently as 1 billion years ago." Their conclusions resulted from the limited water vapor in the atmosphere caused by the modest subsurface reservoir, its limited greenhouse effect, and the albedo of the planet. Thereafter Leconte et al. (2013) used a 3-D GCM to look at climate scenarios for Gl581 c and HD 85512 b. HD 85512 b orbits a K-dwarf with a synchronous rotation period of $\sim 58$ days and receives approximately 1.86 times the insolation of present day Earth. This is slightly less than present day Venus' insolation (1.9), but its host star is a K-dwarf rather than a G-dwarf and hence the peak of its Planck blackbody spectrum is at longer wavelengths. They state, "if not for its thick atmosphere, Venus' climate would be very close to the one of HD 85512 b." They modeled a dry planet akin to that of Abe et al. (2011) using an $\mathrm{N}_{2}$ dominated atmosphere with $376 \mathrm{ppm} \mathrm{CO}_{2}$, and no water vapor. The model produced large temperate regions for a number of different atmospheric pressures (See Leconte et al. (2013) Figures 1, 2) for their land planet setup, but they also found similar behavior in their 'collapse' scenario with different atmospheric water vapor profile amounts.

A rationale for high albedo cloud cover on ancient Venus was first presented by Yang et al. (2014). Yang et al. (2014) was a large parameter study looking at the inner edge of the habitable zone around solar type stars using The National Center for Atmospheric Research (NCAR) Community Atmosphere Model (CAM) with comprehensive atmospheric physics but a thermodynamic ocean. A thermodynamic ocean, also known as a slab or mixed-layer ocean, is typically of limited depth (<100 meters) with a prescribed horizontal ocean heat transport, or no horizontal heat transport at all. The latter implies that the temperature of each ocean grid cell is determined solely by the atmosphere and incident sunlight directly above it. The shallow depth reduces the time lag between solar forcing and ocean response. See Way et al. (2017) Section 2.2.2 for details. In essence they stepped the sidereal rotation rate of an Earth-like world from 1 to 256 sidereal days. At the same time they increased the insolation from that of modern Earth to as much as 2.6 times the modern Earth for their most slowly rotating world of 256 sidereal days period. One of their key conclusions was that the slowest rotators would have had a daynight general circulation that would generate an optically thick contiguous cloud bank in the substellar region. This cloud deck would greatly increase the planetary albedo, keeping the surface temperature moderate even for quite high values of insolation. These results were later confirmed with a completely different 3-D GCM with a fully-coupled dynamic ocean (Way et al., 2018). Yang et al. (2014) also included a simulation with modern Venus orbital parameters, spin rate, insolation while using modern Earth topography and land/ocean mask, but again with a thermodynamic ocean. These studies pro- 
vide a possible rationale for the cloud cover needed to produce temperate surface conditions as first postulated by Pollack (1971). Finally Way et al. (2016, hereafter Paper I) took things one step further by exploring different topographies, insolations and rotation rates to put tighter constraints on possible habitable conditions for ancient Venus.

In this paper, we extend those parameter studies to consider a wider variety of planets and attempt to justify our modeling assumptions in light of possible scenarios for Venus' evolution. Sections $2-5$ review existing observational constraints and hypotheses about the composition, thickness, and evolution of Venus' atmosphere and water history; its surface and interior; and its rotation and obliquity. In Section 6 we draw upon this information to inform a series of 3-D global climate model simulations to illustrate possible scenarios for an early habitable Venus that transitioned to its current inhospitable state relatively late in its history. We discuss the implications of our results for the design of future missions to Venus and for the potential habitability of exoplanets inside the inner edge of the traditional "habitable zone" in Section 7. Finally, recently published complimentary work by Weller and Kiefer (2019) supports many of our conclusions.

\section{Atmospheric Composition and Pressure}

Assuming that Venus and Earth formed from the same parts of the protoplanetary disk and thus with similar compositions (e.g., Raymond et al., 2004), we are guided by the history of Earth whose early atmosphere was likely $\mathrm{CO}_{2}$-rich and possibly cool, but not frozen due to the faint young sun for the late Hadean and early Archean (4.2-4.0 Ga) (e.g., Owen et al., 1979; Kasting, 1993; Zahnle \& Sleep, 2002; J. W. Valley et al., 2002; Zahnle, 2006; Zahnle et al., 2010; Kunze et al., 2014; Catling \& Kasting, 2017; KrissansenTotton et al., 2018; Mello \& Friaa, 2019; S. J. Mojzsis et al., 2019). The picture of a "Cool Early Earth" promoted in the early 2000s by J. W. Valley et al. (2002); J. Valley (2005) and with more recent zircon data (Valley et al., 2014) may also be applicable to Venus' early evolutionary history if Venus survived its magma ocean (MO) phase with some liquid surface water. Chassefière et al. (2012) was probably the first to make the comparison of Hadean Earth with Venus, calling his hypothesis a "cool early Venus."

The prospects for a cool early Earth and Venus hypothesis have improved in recent years, while the likelihood for their end in a cataclysmic "late instability" known as the Late Heavy Bombardment (LHB) may have started to fall out of favor. The LHB is important because its intensity was imagined so intense that the surface temperatures of Earth would return to those before the cool early Earth period, perhaps evaporating the oceans and/or raising surface temperatures to values exceeding $100^{\circ} \mathrm{C}$. However, in recent years a number of studies have started to question the timing and strength of the LHB (e.g. Boehnke \& Harrison, 2016; Zellner, 2017; Morbidelli et al., 2018; Quarles \& Kaib, 2019; S. J. Mojzsis et al., 2019). For a brief overview of the latest work on the LHB see Mann (2018) and Voosen (2020). An "early instability" has started to gain favor in what is termed an "accretion tail" scenario. This accretion tail scenario has recently been promoted in the works of Morbidelli et al. (2018, Figure 1) and S. J. Mojzsis et al. (2019, Figure 1). In these works a late or early heavy bombardment is triggered by a period of orbital 'instability' experienced by the giant planets as described in de Sousa Ribeiro et al. (2020). More recent work by de Sousa Ribeiro et al. (2020) demonstrates that the instability has a median timescale of $36.78-61.5 \mathrm{Myr}$ and is within $136 \mathrm{Myr}$ in $75 \%$ of their cases. de Sousa Ribeiro et al. (2020) say the timing of an early instability fits in nicely with the survival of the Patroclus-Menoetius Jupiter Trojan as a primordial binary from the Kuiper Belt (Nesvorny et al., 2018) and is a good match to other solar system properties (e.g. Clement et al., 2019), but they explicitly discuss the many limitations of their model. In the spirit of an early instability and accretion tail scenario, Figure 4 of S. J. Mojzsis et al. (2019) suggests that Venus accreted less than $0.01 \mathrm{wt} \%$ between 4.3 and $4.1 \mathrm{Ga}$, about the same as Earth. As S. J. Mojzsis et al. (2019) notes, "Results show that an abating impact flux from late accretion is inadequate to sterilize the surface zone." These works 
demonstrate the possibility that the cool early Earth continued through the originally proposed time period of the LHB from $\sim 3.8-4.1 \mathrm{Ga}$. Hence we will begin our most ancient Venus simulations with $\mathrm{CO}_{2}$ dominated atmospheres at $\sim 4.2 \mathrm{Ga}$ (during the J. W. Valley et al. (2002) cool early Earth period) that evolves over time to $\mathrm{N}_{2}$ dominated atmospheres. If the LHB were a real event we would want to begin our simulations at $3.8 \mathrm{Ga}$, rather than 4.2Ga, as others have speculated previously (e.g., Rampino \& Caldeira, 1994; Lammer et al., 2018). There are still many unanswered questions regarding the early postMO history of the atmospheres of Venus, Earth and Mars. Even though we have far more information to discern Earth's early post-MO atmosphere it remains a complicated story yet to be fully resolved (e.g., Hirschmann, 2012; Nikolaou et al., 2019) and may depend on atmospheric pressure more than previously assumed (e.g., Gaillard \& Scaillet, 2014; Bower, Dan J. et al., 2019).

The carbonate-silicate cycle (e.g., Walker et al., 1981; Stewart et al., 2019) is the key to keeping most of Earth's $\mathrm{CO}_{2}$ locked up in rocks for much of its history rather than in the atmosphere as on present day Venus. The carbonate-silicate cycle on Earth functions via subductive-type plate tectonics, the presence of a hydrosphere and continental crust. For Earth there are several lines of evidence to suggest these may go back to the Hadean (e.g., S. Mojzsis et al., 2001; Hopkins et al., 2008; Harrison, 2009; Korenaga, 2013; Harrison et al., 2017; O'Neill et al., 2017; Rozel et al., 2017; Kusky et al., 2018; Korenaga, 2018; Maruyama et al., 2018, and references therein). Dehant et al. (2019) reviews the literature for a later beginning of plate tectonics on Earth (Section 3.2). The requirements for how plate tectonics begins are still not fully understood and hence remains an active area of research (e.g., Lenardic et al., 2019). If Venus had a similar early atmospheric and interior evolution to that of Earth then early volatile cycling via some form of plate tectonics is a viable hypothesis. In fact recent work demonstrates convection regimes like that of plate tectonics in Venus' recent history (Gillmann \& Tackley, 2014; Davaille et al., 2017). Dehant et al. (2019) reviews plate tectonic mechanisms that may not require as much water as previously believed, which may be relevant if Venus retained some water but less than Earth. Hence in our scenario a carbonate silicate cycle is hypothesized for Venus after the magma ocean phase and well before its resurfacing period to keep $\mathrm{CO}_{2}$ largely sequestered in crustal carbonates as on modern Earth.

We are motivated to choose 1 bar atmospheres for our epochs of interest based on geological atmospheric pressure proxies for Earth that imply an atmospheric density of 0.25-1.1bar for most of the past 4 billion years (Nishizawa et al., 2007; Goldblatt et al., 2009; D. Som S. Catling et al., 2012; S. Som et al., 2016; Marty et al., 2013; Avice et al., 2018). However, some models of Nitrogen cycling imply that the atmospheric pressure could have been higher in the Archean (Johnson \& Goldblatt, 2015; Mallik et al., 2018). Differences in $\mathrm{N}_{2}$ of factors of a few have relatively small net impacts on climate, primarily due to small decreases/increases in the pressure broadening of $\mathrm{CO}_{2}$ lines and partly offsetting decreases/increases in Rayleigh scattering. Given the likely similar geochemistry and volatile histories of Venus and Earth (e.g., Ringwood \& Anderson, 1977; Lécuyer et al., 2000; Treiman, 2009; Chassefière et al., 2012; Rubie et al., 2015), a similar evolution in their early composition and pressure histories is plausible. Although whether they did indeed start out with similar volatile inventories is still an open research question (e.g. Horner et al., 2009).

Additional work demonstrates that the present day $\mathrm{CO}_{2}$ and $\mathrm{N}_{2}$ inventories of Earth and Venus may be similar (Donahue \& Pollack, 1983; Goldblatt et al., 2009) if Venus is more degassed than Earth as Donahue and Pollack (1983) speculated. Early work by Rasool and de Bergh (1970) and Kasting (1988) estimated nearly as much $\mathrm{CO}_{2}$ was locked up in carbonate rocks on Earth as exist in the atmosphere of Venus. Since there is no carbonate-silicate cycle active on Venus today most of the $\mathrm{CO}_{2}$ that would otherwise be locked up in the interior is in the atmosphere, having degassed over the past several hundred million years (at least). As well, nearly 4 times as much $\mathrm{N}_{2}$ is found in Venus' present 
day atmosphere as in Earth's when scaled by planetary mass. Earth's internal $\mathrm{N}_{2}$ budget is estimated at $\sim 7 \pm 4$ times that of the atmospheric mass (Johnson \& Goldblatt, 2015).

However, Argon (Ar) modeling studies (Kaula, 1999; ORourke \& Korenaga, 2015) imply that Venus is less degassed than Earth, although see Donahue and Pollack (1983) and Halliday (2013) for alternative explanations for the current ${ }^{40} \mathrm{Ar}$ abundance difference between Earth \& Venus. Watson et al. (2007) claims that ${ }^{40} \mathrm{Ar}$ is not a reliable indicator of degassing, although "the interpretation of their data is controversial" according to ORourke and Korenaga (2015). Halliday (2013) also mentions that Venus' radiogenic ${ }^{40} \mathrm{Ar}$ implies Venus is less degassed than Earth, but he notes that Venus' atmospheric non-radiogenic ${ }^{36} \mathrm{Ar}$ has concentrations roughly two orders of magnitude greater than Earth's and that "this is hard to explain unless it (Venus) is heavily degassed with a larger inventory of primordial volatiles." In further support of a degassed Venus Halliday (2013) notes that the similar Earth and Venus budgets of $\mathrm{C}$ and $\mathrm{N}$ support a degassed Venus while helping to explain the high ${ }^{20} \mathrm{Ne}$ and ${ }^{36} \mathrm{Ar}$ budgets of Venus. One of the largest stumbling blocks in deciding whether the ${ }^{40} \mathrm{Ar}$ modeling inference is correct is a proper measurement of $\mathrm{K} / \mathrm{U}$ on Venus, which is presently highly unconstrained. For this reason modeling studies generally use Earth values. Namiki and Solomon (1998) use He to confirm the ${ }^{40} \mathrm{Ar}$ estimates, but they require a Venus in-situ mission to make the appropriate $\mathrm{Th}$ and $\mathrm{U}$ abundance measurements to characterize the geochemistry necessary for He production. One also needs to consider He escape, an under-explored area of research given that it depends not only on the ability of He to remain charged or neutral, but also whether Venus had a past magnetic field and how present day measurements can distinguish in situ He in the upper atmosphere from solar wind deposition.

Another limiting factor in comparing Earth and Venus is the lack of good constraints on the bulk water content of Earth. Some papers refer only to surface water amounts of $0.023 \mathrm{wt} \%$ of the Earth's total mass, but there are compelling arguments for possibly deep reservoirs within the lower mantle or core (e.g., Raymond et al., 2006; Schmandt et al., 2014; Genda, 2016; Ikoma et al., 2018). For Venus, interior water amount estimates are mostly speculation and are restricted to planetary formation studies (e.g., Ikoma et al., 2018).

\section{Venus' Early Evolution \& Evidence for Water}

Venus \& Earth likely received similar initial water inventories during their formation histories, as has been shown in a number of works (e.g., Raymond et al., 2006). It is also tied to their composition in general, as discussed above in Section 2.

The Pioneer Venus mass spectrometer measured a very high D/H ratio of $150 \pm 30$ times that of terrestrial water (Donahue et al., 1997) in a trapped droplet of sulfuric acid. It is the only such published in-situ measurement. Other non in-situ measurements have been made as noted in Section 1, and work continues apace (e.g. Tsang et al., 2017). The original Venus D/H discovery paper by Donahue et al. (1982) was titled "Venus was Wet: A measurement of the Ratio of Deuterium to Hydrogen." This was a tantalizing prospect, but limited by our knowledge of atmospheric escape processes (Donahue \& Pollack, 1983; Donahue \& Russell, 1997; Donahue, 1999) and the D/H of delivered materials over the aeons.

It is possible that the $\mathrm{D} / \mathrm{H}$ ratio is not an indicator of large amounts of water in Venus' ancient history. Grinspoon (1993) pointed out that a short residence time for water in the present atmosphere of Venus works against the primordial ocean hypothesis. Grinspoon (1993) also noted that updated theoretical calculations at that time that implied higher deuterium escape efficiency put constraints on the $\mathrm{D} / \mathrm{H}$ source water of 10 15. That would rule out source material such as meteorites, comets and dust particles 
with high D/H ratios (e.g., Irvine et al., 2000; Charnley \& Rodgers, 2009). As well, measurements of D/H and Xenon isotopes in Comet 67P (Altwegg et al., 2015; Marty et al., 2017) imply that Earth's ocean has a much lower contribution from cometary objects than previously thought. This would also likely rule out a large cometary contribution to the high $\mathrm{D} / \mathrm{H}$ ratio measured on Venus.

A number of authors have tried to model changes in the $\mathrm{D} / \mathrm{H}$ fractionation over time (Kasting \& Pollack, 1983; Gurwell \& Yung, 1993; Gurwell, 1995; Hartle et al., 1996) to put some constraints on when the water was lost. Given the lack of data from Venus it is equally difficult to constrain or move these models forward.

The possibility that the high $\mathrm{D} / \mathrm{H}$ ratio implies long-lived surface water is also limited by in-situ measurements. There is some circumstantial evidence of past surface water from surface emissivity observations from the Galileo NIMS instrument (Hashimoto et al., 2008) and the Venus Express VIRTIS instrument (Mueller et al., 2008). These observations may imply that the highland "tessera" regions are mostly composed of felsic rocks, and if they are indeed granitic they would have required surface water to form (Campbell \& Taylor, 1983). M. S. Gilmore et al. (2015); M. Gilmore et al. (2017) find that at least one tessera region observed with VIRTIS (Alpha Regio) appears to be more felsic than surrounding plains. This also suggests that these older stratigraphic units (Ivanov \& Basilevsky, 1993; M. S. Gilmore et al., 1997) are granitic crustal remnants, but recent work by Wroblewski et al. (2019) shows that parts of the Ovda Regio highland tessera are not in fact of granitic origin. However, it is not yet possible to generalize the work of Wroblewski et al. (2019) to the entirety of tessera.

Nikolayeva (1990) and Shellnutt (2019) analyzed surface rock measurements from Venera 8. As Shellnutt (2019) explains "it is possible that the Venera 8 probe encountered a fragment of crust that resembles a terrestrial greenstone belt." Zolotov et al. (1997) and Johnson and Fegley (2000) have also demonstrated that signatures of water in hydrous minerals may persist on the surface of Venus for long periods even after the surface morphology has changed. This motivates an in-situ mission to Venus to search for such materials, if they exist. Watson et al. (2007) tried to demonstrate that the ${ }^{40} \mathrm{Ar}$ in Earth's atmosphere is related to the hydration of the oceanic lithosphere consisting of relatively Ar-rich olivine and orthopyroxene. If the results from Watson et al. (2007) are correct, (and there is skepticism (Ballentine, 2007)), this would lead one to believe that the ${ }^{40} \mathrm{Ar}$ in Venus' atmosphere today implies that water oceans could have persisted for some time.

An outstanding unsolved and understudied problem is what happened in the epoch of Venus' MO as it cooled, as this may greatly affect the long-term water inventory of the planet. The timescale of the MO crystallization could be of order a few million years (Myr) as for Earth (e.g., Katyal et al., 2019; Nikolaou et al., 2019) or greater than 100 Myr (Hamano et al., 2013; Lebrun et al., 2013). The longevity of the MO and associated hot steam and $\mathrm{CO}_{2}$ atmosphere is vital to understanding the volatile history of Venus (e.g. Salvador et al., 2017). If the MO and steam atmosphere persist too long then much of the primordial water inventory of Venus could have been lost in its very early history from a stronger solar wind (Chassefière, 1997; Lichtenegger et al., 2016). An attractive feature of the extended MO hypothesis is that it naturally solves the problem of the lack of oxygen in the present day Venusian atmosphere. This would be accomplished by sequestering the $\mathrm{O}_{2}$ left behind by $\mathrm{H}_{2} \mathrm{O}$ dissociation in the magmatic crust and upper mantle (e.g. Lebrun et al., 2013; Gillmann et al., 2009; Lichtenegger et al., 2016; Lammer et al., 2018). We discuss how large quantities of $\mathrm{O}_{2}$ can be lost after a significant period of habitability in bullet 6 of Section 8 , in lieu of early MO losses. It is possible that the high D/H ratio we see today (Donahue et al., 1982, 1997) is a relic of the early MO period. If the MO cooled quickly, then there was an opportunity to build up a surface ocean and atmosphere as is believed to have happened in Earth's early history. The question is whether Venus' surface conditions as a result of its closer proximity to the Sun would 
prevent the condensation of water on its surface or not. The answer is more complicated than it may seem since water can condense under hot high pressure multi-bar atmospheres. Matsui and Abe (1986) allow for temperatures up to 600K, while later work by Liu (2004) allow temperatures approaching $720 \mathrm{~K}$.

Additionally the answer may reside in the planet's rotation history, what role clouds played, and the outgassing rates of $\mathrm{H}_{2} \mathrm{O}$ and $\mathrm{CO}_{2}$. As we will show in Section 5 it is possible for Venus to reach a tidally locked state in less than a few hundred Myr using constant phase lag dissipation theory, suggesting that the planet's rotation rate could have been slow early on. As shown in previous work (Way et al., 2016, 2018) as long as a planet is in the slowly rotating regime (length of day greater than $~ 16$ Earth sidereal days) its climate dynamics work to allow liquid water to persist on the surface for insolations up to $\sim 2.6$ times that of present day Earth. This is due a large contiguous dayside cloud deck that significantly increases the planetary albedo as discussed in Section 4.

The timing of the MO termination is critical in more than one way. If the steam and $\mathrm{CO}_{2}$ atmosphere cooled sufficiently for $\mathrm{MO}$ crystallization to occur by the time of the Late Veneer (also referred to as "Late Accretion") then even if Venus lost most/all of its primordial $\mathrm{H}_{2} \mathrm{O}$ through escape processes (Gillmann et al., 2009; Hamano et al., 2013; Lichtenegger et al., 2016) there may have been a second chance to obtain a surface ocean, albeit a shallow one. Recent work by Greenwood et al. (2018) implies that Earth may have received as much as $30 \%$ of its $\mathrm{H}_{2} \mathrm{O}$ inventory in post-accretion impact delivery, consistent with research that shows that the entire $\mathrm{H}_{2} \mathrm{O}$ budget cannot come from the late veneer (Morbidelli \& Wood, 2015). Halliday (2013) concludes that if veneers were common they should be proportional to planetary mass, and hence Venus would have received a percentage of late veneer $\mathrm{H}_{2} \mathrm{O}$ similar to that of Earth. If Venus was left dry after a long-lived magma ocean phase (Hamano et al., 2013), then this amount of $\mathrm{H}_{2} \mathrm{O}$ veneer also fits within the error bounds of Venus' measured D/H ratio (Donahue et al., 1982, 1997). It should be noted that the work of Greenwood et al. (2018) can also fit within the Ruthenium studies of Fischer-Gödde and Kleine (2017). For a contrary point of view see Gillmann et al. (2019), who claim that most of the late veneer impactors would have been Enstatite/ordinary chondrites which are water-poor, as opposed to water-rich carbonaceous chondrites that would have been a mere $0-2 \%$ of the total chondrite delivery. These contrary points of view come about because different geochemical measurements give different answers as pointed out in a number of recent works (e.g. Albarède, 2009; Fischer-Gödde \& Kleine, 2017; Dauphas, 2017; McCubbin \& Barnes, 2019; Zahnle et al., 2019). There are two other important caveats to consider regarding the late veneer. First the water content depends upon the composition of the accreting bodies. For example, if the late veneer was made up of a few large bodies then the variations could have been greater than if it was due to a large collection of smaller bodies. Second, the definition of the late veneer is important since it is typically associated with the accretion of bodies after the last giant impact. Jacobson et al. (2017) has suggested that the last giant impact on Venus could have been much earlier than on Earth and this obviously affects the composition of objects making up the late veneer.

At the same time, work by Gillmann et al. (2009), Morbidelli et al. (2000), and Raymond et al. (2006) shows that Venus' initial water inventory at formation could be as much as two terrestrial ocean's worth while large planetary embryos could deliver much more within 200 Myr of formation. If true, and if the magma ocean lifetime on Venus was shorter rather than longer, then our estimates of the water content on Venus from Pioneer Venus $\mathrm{D} / \mathrm{H}$ ratios (Donahue et al., 1982, 1997) should be more toward the higher end, $\sim 16 \%$ of a present day Earth's ocean (Donahue et al., 1997). However, it is not clear whether Venus' primordial water content can readily be constrained by the D/H ratio (Grinspoon, 1987; Grinspoon, 1993) due to a lack of knowledge of sources and sinks over the lifetime of the planet. 
Another hypothesis (e.g., Rampino \& Caldeira, 1994) states that because of its proximity to the Sun, Venus could never condense water on its surface and hence its surface temperature has always been $300 \mathrm{~K}$ or higher (see Figure 1 in Rampino \& Caldeira, 1994) and that most of this water was lost by photodissociation (Goody \& Walker, 1972). At the same time the lack of water prevents silicate rock weathering (on Earth this removes $\mathrm{CO}_{2}$ from the atmosphere), hence the $\mathrm{CO}_{2}$ builds up in the atmosphere driving temperatures ever higher due to the greenhouse effect as seen today.

\section{Surface History, Impactors and Climate Evolution}

Understanding the surface history of Venus is crucial to constraining any theory of its long-term climate evolution. Smrekar et al. (2018) reviews the literature on Venus' internal structure and dynamics. In this section we mostly focus on implications for the surface features we see today and how those might be consistent with a hypothesis for the long-term habitability of Venus and a transition to a more recent ( 1Gyr) hothouse state.

Up to $80 \%$ of the Venus surface has volcanic plains and tectonic structures emplaced over a relatively short geological interval as determined from crater counts (Ivanov \& Head, 2013, 2015). The cratering record seen in the plains regions imply surface ages ranging, for example, from $\sim 180 \mathrm{Ma}$ (Bottke et al., 2016), to $\sim 300 \mathrm{Ma}$ (Strom et al., 1994 ) to $\sim 750 \mathrm{Ma}$ (McKinnon et al., 1997). The relative youth of most of Venus' surface may be the result of a large scale lithospheric overturn known as the Global Resurfacing Event (GRE), or it may be due to the latest GRE in a long sequence of episodic resurfacing events (e.g., Turcotte, 1993; Strom et al., 1994). For example, Kaula (1999) constructed a simple model with outgassing events staggered at time periods of 4.1, 3.8, 3.5, 3.1, 2.6, 2.1, 1.5 and $0.7 \mathrm{Ga}$ constrained by ${ }^{40} \mathrm{Ar}$ measurements. The other hypothesis for the young surface of Venus is from continuous volcanic resurfacing (e.g. Basilevsky et al., 1997; Bjonnes et al., 2012; King, 2018).

The highland tesserae may be one of the keys to understanding this history. They are of particular interest because they may contain information about past crustal differentiation and other processes prior to the loss of any surface water. Some crater age estimates from the Magellan Mission imply that the tesserae are $\sim 40 \%$ older than the plains (Ivanov \& Basilevsky, 1993; M. S. Gilmore et al., 1997). However, Strom et al. (1994) did not agree with this conclusion. Additional work by V. Hansen and López (2010) points to the possibility that the Ribbon Tessera Terrain are older than the surface units identified with the GRE. Later analysis by Ivanov and Head (2013) implied that tessera are the oldest stratigraphic unit and that they were created near the beginning of Venus' surface observable history during the "tectonically dominated regime."

However, how the large basaltic plains were emplaced remains controversial. A number of authors (e.g., Herrick, 1994; Strom et al., 1994; Basilevsky \& Head, 1996) postulated a nearly global $(\sim 80 \%)$ geologically instantaneous $(10-100 \mathrm{Myr})$ thick $(>1 \mathrm{~km})$ deposition of basaltic material from volcanic type outflows (GIBVO) that would have buried older craters we cannot observe today (akin to the GRE mentioned above). The outflow depth requirements are determined by the size of the largest impact craters that would have to be completely covered. However, as Ivanov and Head (2013) point out it is possible that the cratering record previous to GIBVO could have also been erased in some manner. The GIBVO model was later augmented and became known as the global stratigraphy hypothesis (e.g., Basilevsky \& Head, 1996; Basilevsky et al., 1997; Basilevsky \& Head, 1998; Head \& Basilevsky, 1998). Yet another hypothesis to explain the Venus surface record was initially put forward by Phillips et al. (1992) and is termed the Equilibrium Resurfacing Model (ERM). In this model the number of craters observed on Venus today is the result of an equilibrium between constant crater formation (via impacts) and the removal of such craters via on-going tectonic or volcanic methods. Monte Carlo cal- 
culations by Bullock et al. (1993) and Strom et al. (1994) demonstrated why the ERM was not feasible. Strom et al. (1994) decided that the GIBVO was a better fit to their data, while Bullock et al. (1993) preferred a longer timeline of 550Myr. More recent Monte Carlo calculations by Bjonnes et al. (2012) show that the ERM is able to fit the observations.

V. Hansen and Young (2007) strove to demonstrate why none of these hypotheses fit all available observational constraints. V. Hansen and Young (2007) then proposed what they termed the Spatially Isolated Time-Transgressive Equilibrium Resurfacing (SPITTER) hypothesis to explain more of the observational constraints. It is not clear that the Venus geological community has settled on any of these hypotheses. Perhaps one of the largest problems with the global lava hypothesis is the timescale, volume and depth of the basaltic flows required, none of which have been observed on any present or previously active volcanic body in the solar system (including in Earth's past). The largest known outflow to date in Earth's history is the mid-Cretaceous Superplume (Larson, 1991), which is small by comparison to those envisioned to describe Venus' resurfacing. At the same time the superplume hypothesis for Venus is compelling as large amounts of $\mathrm{CO}_{2}$ could have been released at the same time as the plume event (Caldeira \& Rampino, 1991). Large overturn events have been proposed as an explanation for Venus' present surface state, but in such a scenario it is possible to sequester large amounts of $\mathrm{CO}_{2}$ in fresh flood basalt outflows due to enhanced planetary weatherability (e.g., Goddris et al., 2003; Cox et al., 2016). Large Igneous Provinces (LIPs), on the other hand, can release copious amounts of $\mathrm{CO}_{2}$ sequestered in some sedimentary materials (e.g., Ganino \& Arndt, 2009) while avoiding the sequestration issues of a large overturn event. LIPs have been proposed as an explanation for Venus' present day state as we will discuss below.

Previous simulations by Way et al. (2016) showed that Venus could have had temperate conditions for nearly 2 billion years providing it had a shallow ocean of $310 \mathrm{~m}$ in depth, slow rotation rate, and modern orbital elements. Venus might even have experienced more stable conditions than Earth in its early history since studies by Correia and Laskar (2001) and J. W. Barnes et al. (2016) have shown that low obliquity states (like that of modern Venus) may be stable over billions of years and we know that the much shorter Milankovich cycles have had a strong influence on Earth's climate through time. Deitrick et al. (2018) reviews the influence of such cycles on the climate of Earth and possible influences on exoplanets. In addition, Weller et al. (2018) has also shown from geological models that early Venus could have avoided glaciations more easily than early Earth, which experienced several partial or total snowball periods in its history. If long-term stable surface conditions are a requirement for life, Venus might have been more stable and allowed primitive life to fill more ecological niches more quickly than on Earth. This gives rise to the possibility that life may still exist in Venus' upper atmosphere (Limaye et al., 2018).

Ernst et al. (2017) speculate that "On Venus, voluminous LIP volcanism produced high levels of $\mathrm{CO}_{2}$ that led to run-away greenhouse effect, and high levels of $\mathrm{SO}_{2}$ that caused acid rain," but with little supporting evidence. Bullock and Grinspoon (2001) present a similar hypothesis that involves outgassing of $\mathrm{SO}_{2}$ and $\mathrm{H}_{2} \mathrm{O}$ that eventually drive the planet, over 100s of $M y r$, into a runaway greenhouse state, but do not mention $\mathrm{CO}_{2}$. If Venus had LIP volcanism then $\mathrm{CO}_{2}$ as well as $\mathrm{SO}_{2}$ can be outgassed if trapped in sediments in the crust as is seen on Earth (e.g., J. W. Head III \& Coffin, 1997; V. L. Hansen, 2007; Ernst et al., 2017; Ernst \& Youbi, 2017). Hence if Venus had an earlier epoch of liquid water habitability then it is logical to assume that $\mathrm{CO}_{2}$ would have been trapped in the crust of the planet in the same way it is trapped on Earth today and LIP volcanism would have been the means to release that $\mathrm{CO}_{2}$ into the atmosphere.

However, as noted in Macdonald and Wordsworth (2017) when the surface temperature is warmer $(\mathrm{T}>300 \mathrm{~K}$, see their Figure 2$)$ more water vapor is injected into the stratosphere, which stabilizes the lapse rate. Such warm climates (as seen in the Venus 
models herein) would prevent the largest plumes from injecting $\mathrm{SO}_{2}$ into the stratosphere, allowing $\mathrm{CO}_{2}$ warming without offsetting cooling by $\mathrm{H}_{2} \mathrm{SO}_{4}$ aerosols.

Another well known mechanism to get Venus from a cool clement state to its present day hot and dry state was proposed by a number of authors (e.g. Ingersoll, 1969; Kasting \& Pollack, 1983; Kasting et al., 1984; Kasting, 1988; Taylor \& Grinspoon, 2009) who speculated that water loss via upper atmospheric dissociation and then hydrogen escape would have eventually made the planet dry. Then, as stated in Taylor and Grinspoon (2009) "With the loss of water, the removal mechanism for $\mathrm{CO}_{2}$ would be eliminated, and carbonate rocks on the surface would presumably eventually be subducted and lost to thermal decomposition, with the $\mathrm{CO}_{2}$ being irreversibly returned to the atmosphere through outgassing." This model fits in with more recent research by R. D. Wordsworth (2016a) who states that the oxygen left over would eventually find its way to oxidize the mantle and change its redox state, allowing for enhanced nitrogen outgassing which is compatible with the nearly 3 bars of $\mathrm{N}_{2}$ we see in Venus' atmosphere today (also see review by Lammer et al. (2018)). However, an alternative hypothesis is proposed by Gillmann et al. (2009), who suggest that the oxidation of the mantle occurred in the first $100 \mathrm{Myr}$ of Venus' history. They assume the surface was never cool enough to allow liquid water to condense. The water would again be photodissociated and the hydrogen would have been lost to space (Lichtenegger et al., 2016). The leftover oxygen would have dissolved in the magma ocean.

Genda and Abe (2005) have proposed that the lack of water on Venus and in Venus' protoplanetary impactors in its early history (in contrast to that of Earth and its water rich impactors) would explain differences in most of the noble gas abundances between Venus and Earth because oceanic protoplanets would enhance atmospheric loss, implying that Venus' original noble gas abundant proto-atmosphere survived to present day on Venus, unlike that of Earth. A lack of water being detrimental to subductive plate tectonics (see Section 8). Sakuraba et al. (2019) have also attempted to get the presently observed nitrogen and noble gas abundances via impact degassing and atmospheric erosion (also see work by, Pham et al., 2011), but unlike Genda and Abe (2005) they believe late accretion may have further influenced the atmosphere of Venus.

More recent work by Gillmann et al. (2016) show that large impactors (400-800km in diameter) can cause atmospheric erosion and escape and deposit energy in the crust and mantle. They believe the latter can cause a thermal anomaly in the crust and mantle triggering large scale volcanic events at the impact region and the antipode. This in turn may deplete the upper mantle of volatiles and lead to water loss in the early atmosphere, or conversely provide a volatile heavy atmosphere with extreme temperatures for billions of years. In a sense this is similar to a theory by Davies (2008) who propose a mega-collision (akin to that of the Earth's moon-forming impact) to dry out the interior of the planet. But thus far no large Venus impactor simulations have been utilized to examine such a scenario, as has been done for Earth's moon-forming collision (e.g., Canup, 2004).

To summarize, a number of mechanisms exist by which early Venus could have condensed liquid water on its surface. The key ingredient is that it must have been cool enough for long enough in its early history. As shown by Yang et al. (2014); Way et al. (2016, 2018), the rotation rate of a planet greatly affects its climate dynamics. Specifically, for very slow rotation a large contiguous water cloud forms at the substellar point, increasing the Bond albedo markedly and keeping surface temperatures moderate for insolation values up to nearly three times that of modern Earth's $1361 \mathrm{~W} \mathrm{~m}^{-2}$. In Paper I Way et al. (2016) we demonstrated that early Venus could have had consistently habitable conditions throughout its early history if it began with sufficiently slow rotation. In the next section we review what is understood about the possible evolution of Venus' spinorbit state. 
In our scenario, early Venus' has the earliest consistent liquid water habitability in the solar system followed by Earth and then Mars. This is a broader statement of the Faint Young Sun Paradox (FYSP), the challenge of explaining how early Earth, not to mention Mars, could have been warm and wet early in their histories when the Sun was 25-30\% dimmer than today (e.g., Feulner, 2012). There is still debate in the ancient Earth GCM community about the actual composition and thus temperature of early Earth's atmosphere given observational proxies for $\mathrm{CO}_{2}$ that span orders of magnitude, though models suggest that the range encompasses several viable scenarios (e.g., Charnay et al., 2013; Wolf \& Toon, 2013; Kunze et al., 2014; Le Hir et al., 2014; Charnay et al., 2017; Krissansen-Totton et al., 2018). These GCM studies and most proxies (e.g., Spencer, 2019) are from the Archean rather than the late Hadean, but there is some evidence that habitable surface conditions existed well back into the Hadean (e.g., Harrison, 2009; Arndt \& Nisbet, 2012).

It is interesting to note that recent atmospheric pressure proxies from the late Archean imply an atmospheric pressure less than half that of today (D. Som S. Catling et al., 2012; S. Som et al., 2016). Atmospheres thinner than modern Earth's are less likely to avoid snowball conditions, yet the literature above notes that there is geological evidence that Earth was not in a snowball state during much of the late Archean that the pressure proxies correspond to. Regardless, for this reason we feel is it necessary to explore the possibilities of lower atmospheric surface pressures in Venus' climatic history as described for Simulations 26-30 in Section 6.

The FYSP for Mars remains difficult to resolve (e.g., R. D. Wordsworth, 2016b) partly due to the fact that 3-D GCMs have traditionally struggled to consistently sustain large-area liquid water conditions over millions of years (e.g., Goldblatt et al., 2009; Kasting, 2010; Kienert et al., 2012; Feulner, 2012; Haqq-Misra et al., 2008) without snowball type conditions. Long-standing solutions involving large amounts of atmospheric $\mathrm{CO}_{2}$ are inconsistent with unobserved carbonate deposits expected from such $\mathrm{CO}_{2}$ dominated atmospheres (Shaw, 2018) and are insufficient in isolation to produce above-freezing conditions. One possible solution to the lack iof surface carbonates was proposed by Kasting (2012). Other solutions to Mars' FYSP exist that involve $\mathrm{H}_{2}$ with $\mathrm{CO}_{2}$ as the background gas (e.g. R. Wordsworth et al., 2017; Ramirez, Kopparapu, Zugger, et al., 2014; Ramirez \& Craddock, 2018; Haberle et al., 2019), although presently there appears to be little consensus in the community.

\section{Rotation and Obliquity evolution}

To the best of our abilities we would like to constrain the obliquity and rotational history of Venus to better constrain these important inputs for climate models. This is limited by the absence of any direct information about Venus' initial rotation and obliquity and the fact that impacts likely play a significant role in the early rotational history of the terrestrial planets (e.g., Lissauer \& Kary, 1991; Dones \& Tremaine, 1993). On Earth a variety of means exist to obtain some constraints using dynamical modeling combined with geological data when available (e.g., Hays et al., 1976; Park \& Herbert, 1987; Imbrie et al., 1992; Matthews et al., 1997; Petit et al., 1999; Pälike \& Shackleton, 2000; Pälike et al., 2004; Olsen et al., 2019) and there has been modest success doing the same for Mars (e.g., Cutts \& Lewis, 1982; Laskar et al., 2002, 2004; Byrne, 2009; Dickson et al., 2015; Bierson et al., 2016). For Earth, an additional constraint is provided by the Moon, which has predictably affected the evolution of Earth's rotation and damped obliquity excursions over its history (Zahnle \& Walker, 1987; Lissauer \& Chambers, 2011). However, until and unless geological observables become available to constrain dynamical models, only plausible scenarios for the rotational and obliquity history of Venus can be defined. 
Hoolst (2015) summarizes much of the literature on the rotational evolution of Venus throughout its history. We summarize some of the work on this subject below and add some additional estimates. First we look at the history of studies of the possible spin evolution of Venus.

In the 1960-70s several authors investigated the possibility that Venus' rotation period was correlated with its synodic period (Goldreich \& Peale, 1966; Gold \& Soter, 1969, 1979). Goldreich and Peale (1966) states, "the presence of the Earth may have stabilized the sidereal rotation period of Venus at the value of 243.16 days retrograde." An equilibrium between the atmospheric and body tide of Venus was first proposed by Gold and Soter (1969) to explain Venus' non-synchronous rotation period, based on the incorrect belief at that time that Venus always showed the same face at each inferior conjunction with Earth as proposed by Goldreich and Peale (1966).

The first work to analytically look at Venus' rotation rate and the role of atmospheric tides was by Ingersoll and Dobrovolskis (1978) who extended the earlier work of Lord Kelvin Thomson (1882), Chapman and Lindzen (1970) and Munk and MacDonald (1960). They mention that "Venus probably originated with a retrograde rotation in order to have evolved to the current retrograde state." In the 1980s this work was further extended in a series of papers (Dobrovolskis \& Ingersoll, 1980; Dobrovolskis, 1980, 1983). It was clear that Venus' rotation rate was probably determined by a balance between the solid body tidal dissipation and the thermal tides of its thick atmosphere with the sun. Core-mantle friction (CMF) can also play an important role in slowing the spin rate of Venus, as first explored by Goldreich and Peale (1970). Goldreich and Peale (1970) were also the first to demonstrate that core-mantle viscous coupling can drive the obliquity to $0^{\circ}$ when less than $90^{\circ}$ and to $180^{\circ}$ if it is greater than $90^{\circ}$ over time.

This remained the state of understanding of Venus' rotational history until the early 2000s when the long-term evolution of its spin state of Venus was investigated in a series of papers by Correia and Laskar (2001); Correia et al. (2003); Correia and Laskar (2003), who suggested that Venus may have rotated faster in the past, and possibly prograde. It also became clear that at faster spin rates CMF plays an important role in slowing the rotation of the planet, but less so at slower spin rates.

Once a planet is spinning more slowly CMF may play an important role in obliquity variations (e.g., Correia et al., 2003). Correia and Laskar (2001) explored a number of stable obliquity and spin states of Venus while more recent work by J. W. Barnes et al. (2016) has investigated how stable the obliquity of Venus might be though time.

The work on the thermal tides of Venus had led researchers to assume that its effects would be minor (as it is for Earth) for atmospheres of modest density (e.g. 1 bar). However, more recent work by Leconte et al. (2015) has demonstrated that thermal tides arising from even 1 bar atmospheres can be significant depending on the distance to the host star and the host star's mass. Leconte et al. (2015) show that even if modern Venus had a 1 bar atmosphere the tidal torques would still be quite significant.

R. Barnes (2017) used an equilibrium tide model with a constant phase lag (CPL) to find that Earth could have ended up tidally locked today (after 4.5Gyr) had it started with a rotation rate of 3 Earth Days or longer (the latter more likely if Earth had no satellite). We have applied the same Equilibrium Tide Model (EqTide https://github.com/RoryBarnes/EqTide) from R. Barnes (2017) to Venus to explore how long it would take Venus to reach a tidally locked state only from solid body tides. As shown in Figure 1 using CPL theory we find that Venus could have been tidally locked within $684 M y r$ if it started with a prograde rotation period of 3 Earth days and zero obliquity. Unfortunately the EqTide model we utilize does not support retrograde spin states, but we expect the differences to be minor. We will continue to explore these issues in a future work using the simulator vplanet (R. Barnes et al., 2019) once this functionality is added. Figure 1 gives further exam- 
ples for CPL and Constant Time Lag (CTL) theory results using EqTide. For input parameters we assume that the tidal dissipation factor $\mathrm{Q}=12$ and Love number of degree $2 \mathrm{k}_{2}=0.3$. These are the same numbers used for the modern Earth in R. Barnes (2017). Recent work by Henning and Hurford (2014) demonstrates that our choice for Q may not be unreasonable for Venus. Henning and Hurford (2014) give estimates of Q for Earthlike planets (see their Fig 15, top-center-row plot) with orbital periods from 0 to 200 days. Venus' $224 \mathrm{~d}$ period is slightly outside the range they explore (but can be anticipated from the trend visible in their figure). Our assumption of $Q=12$ is not far off the Henning and Hurford (2014) 'Warm Earth 2' estimate in their Fig 15. As an aside, Q and $k_{2}$ are poorly constrained for present-day Venus. We have even fewer constraints on these values for an ancient Venus, but perhaps those values would be more Earth-like than present day Venus. For example, present day Venus' time lag may not be the same as Earth's because of higher internal temperatures (MacDonald, 1962; Henning \& Hurford, 2014). Historically Goldreich and Soter (1966) estimated that $\mathrm{Q}<17$ for Venus, Lago and Cazenave (1979) had values up to $\mathrm{Q} \sim 40$ while Leconte (2018) estimate $\mathrm{Q} \sim 100$.

More recently Venus' tidal love number was estimated by Konopliv and Yoder (1996) using Magellan and Pioneer Venus Orbiter data to be $\mathrm{k}_{2}=0.295 \pm 0.066$ implying the core is liquid (Yoder, 1997). Work by Zhang (1992); Xia and Xiao (2002) have estimated $\mathrm{k}_{2}=0.18$ $\sim 0.26$. A smaller value $\left(\mathrm{k}_{2}=0.17\right)$ would imply a solidified iron core which is not consistent with Konopliv and Yoder (1996). Modeling work by Dumoulin et al. (2017) are consistent with the work of Konopliv and Yoder (1996) as well as our own modeling choices (discussed above) of $\mathrm{Q}=12$ and Love number of degree $2 \mathrm{k}_{2}=0.299$ (see Table 3 in Dumoulin et al. (2017)). Regardless, if one uses higher values of $Q$ and/or lower values of $k_{2}$ for ancient Venus it is sufficient to say that equilibrium tide theory predicts that the CPL and CTL for Venus estimates for tidal locking will be longer than those presented in Figure 1. The values in Figure 1 then represent lower limits to tidal locking for a given starting rotational period. As a caveat there is a debate in the dynamics community about the appropriateness of the CPL and CTL approaches (Efroimsky \& Williams, 2009; Efroimsky \& Makarov, 2013; Touma \& Wisdom, 1994; Greenberg, 2009). so these tidal locking timescales should be viewed with some caution in the context of the CPL and CTL models used herein. Of course we do not take into account magnetic braking to see how the Sun's natural spin-down might affect the tidal evolution of Venus, nor do we assume that Venus' orbital characteristics would have changed over the timescale of our calculations, the latter being one of the criticism when applying CPL/CTL to evolving systems (Efroimsky \& Williams, 2009; Efroimsky \& Makarov, 2013).

Recent work (Green et al., 2019) has investigated the influence of a hypothetical shallow ocean on Venus (water equivalent layers of $\sim 330$ meters deep and $830 \mathrm{~m}$ ) using present day topography and a range of initial rotation periods. The most dissipative scenario predicts a slow down of 72 days per million years. The latter result may be surprising until one recalls that tidal dissipation in Earth's oceans is larger than that of the Earth's solid body tides (e.g., Munk \& MacDonald, 1960).

It is likely that Venus was initially a prograde spinning body like the other 3 terrestrial planets in our solar system. The prograde hypothesis goes back at least to (Alfvn, 1964) and more recent work by Lissauer and Kary (1991); Dones and Tremaine (1993); Kary and Lissauer (1995) would also support the idea of a primordial prograde Venus, barring the effects of a late large impactor as discussed in those works and that below. From that starting point we find the following perhaps the most compelling answer to Venus' present day spin state. As shown above there are models that can drive the planet toward a tidally locked state rather quickly. Core-mantle friction damps obliquity perturbations which drive the spin rate to sub-synchronous prograde rotations. Then atmospheric tides would reverse the spin to a retrograde equilibrium. These atmospheric tides continue to prevent the planet from being tidally locked and that is the state the 


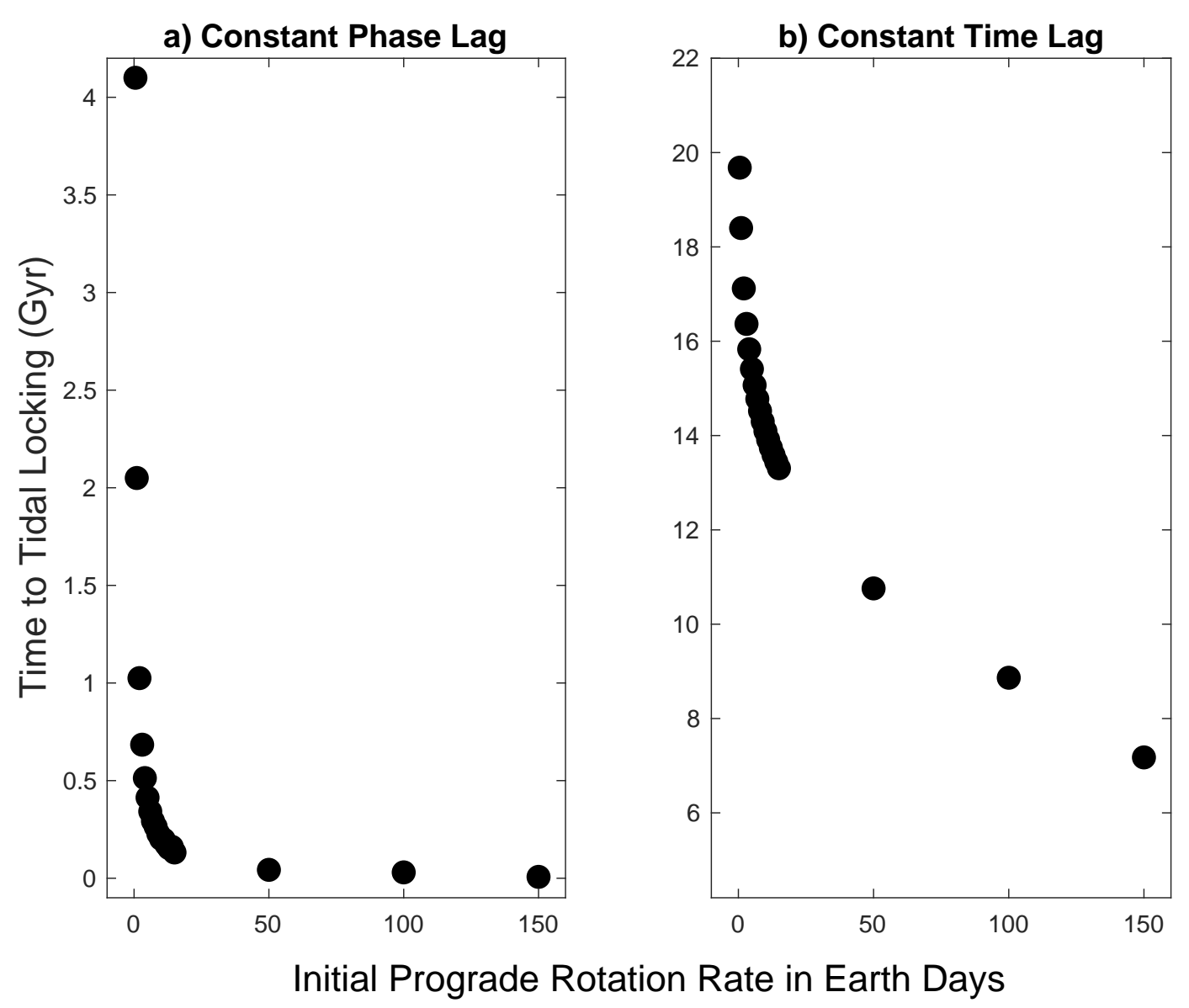

Figure 1. Venus tidal locking timescales using equilibrium tide constant phase (a) and time (b) lag theory. Note that the y-axes have different limits.

planet has been in since that time as shown in some of the work of Correia and Laskar (2001).

Yet it has long been speculated that Venus' current retrograde rotation state is the result of a large impactor early it its history (McCord, 1968; Singer, 1970; French \& Singer, 1971; Counselman, 1973; Burns, 1973; Ward \& Reid, 1973; Harris, 1978; Alemi \& Stevenson, 2006; Davies, 2008). The large impactor hypothesis may also explain a possibly very dry Venus interior, a lack of oxygen in the atmosphere and reconcile the ${ }^{40} \mathrm{Ar}$ results that imply it is less degassed than Earth (Davies, 2008). However, as pointed out in Ward and Reid (1973) it is possible for a small impactor (less than 1\% of the Moon's mass) to drive Venus retrograde if the planet has already spun down considerably due to tidal dissipation with the Sun (Figure 1).

Unfortunately, there is little hope that we will ever truly know the rotation rate of Venus through time without a way to either measure its "Geological Orrery" as on Earth (Olsen et al., 2019) and tie that to dynamical models, or find evidence that an impactor played a role in its rotational and hence geochemical evolution as seen in investigations on Earth related to late accretion and its effect on different isotope abundances (e.g., Varas-Reus et al., 2019). In fact Brasser et al. (2016) and S. J. Mojzsis et al. (2019) prefer the hypothesis that the Earth's Late Veneer was mainly delivered by a single Plutoor Ceres-sized impactor. Hence if a larger object was involved in the late evolution of 
Venus' spin or obliquity it may be possible to detect its geochemical fingerprints in a future in-situ mission.

For most of our climate simulations we assume, rightly or wrongly as discussed above, that Venus has had the same retrograde rotation and its present day obliquity for the past $4.2 \times 10^{9}$ years. We have included a few faster rotation rates that approach the 'fast rotators' described in Yang et al. (2014); Way et al. (2018), meaning sidereal day lengths of 16 and 64 times that of present day Earth.

\section{Methods}

All our simulations use ROCKE-3D (Way et al., 2017) a three-dimensional (3-D) General Circulation Model (GCM) developed at the NASA Goddard Institute for Space Studies (GISS). Radiative transfer in ROCKE-3D uses k-coefficients derived from the HITRAN 2012 line list, as well as the MT-CKD 3.0 water vapor continuum and CO2 collisionally-induced absorption and sub-Lorentzian line shapes, as described in references cited in (Del Genio, Way, et al., 2019). HITRAN 2012 is accurate for temperatures below $350 \mathrm{~K}$, as shown by (Kopparapu et al., 2013). As we will discuss below, a small number of our simulations exhibit a growing radiation imbalance with time, indicative of continually rising temperatures and a transition to a runaway greenhouse. If our objective were to determine the threshold for a runaway, we would need to use the more comprehensive HITEMP line list for these simulations, as discussed by (Kopparapu et al., 2013). Our purpose, though, is simply to identify such cases and exclude them from further analysis.

Most simulations use modern Venus' current orbital parameters, slow retrograde rotation period (-243 Earth sidereal days in length) and orbital period (224 sidereal days). In Paper I (plotted herein with ID $=\mathrm{B}$ ) we looked at a faster rotation period (16 $\mathrm{x}$ modern Earth's sidereal day length) to see how the planet's early climate might have responded, and we also look at 16 \& 64 day retrograde rotation periods in Venus' early history in this work. Our focus is on changing insolation, topography, land/sea mask, surface water availability and atmospheric constituents. We motivate our choices below.

All simulations discussed below are outlined in Table 1. Our focus is on the retention and stability of surface liquid water on Venus over time. Therefore we simulate four types of planets with surfaces that differ in the amount of water they contain and how that water is allowed to interact with the atmosphere. ROCKE-3D allows for 3 types of surface water: Soil moisture at and beneath the surface with no standing bodies of water; "dynamic" lakes whose depth and area vary with time and that can appear or disappear as the competition between precipitation and evaporation dictates; and deeper oceans with permanent boundaries and an effectively infinite source of water for the atmosphere. All planets with oceans are fully dynamic. For more details on the capabilities of such oceans see Way et al. (2017).

- Arid Venus: This planet has modern Venus topography, but only contains $20 \mathrm{~cm}$ of water in the subsurface soil layers, soil consisting of $100 \%$ sand, and no surface standing water at the start of the simulation. The atmosphere is initialized with zero water vapor and an isothermal temperature profile at $300 \mathrm{~K}$. This initial condition is similar to that of Kodama et al. (2019); Abe et al. (2011) who attempt to limit the amount of water vapor in the atmosphere (a strong greenhouse gas) and subsequently push the inner edge of the habitable zone farther inward. However, Kodama et al. (2019); Abe et al. (2011) use modern Earth's rotation rate for all their experiments.

- 10m-Venus: Uses modern Venus topography and places a 10 meter liquid waterequivalent layer in the lowest lying topographic areas. These are treated by the 
model as lakes, which have no circulation. The soil is a 50/50 sand/clay mix as used in Yang et al. (2014); Way et al. (2016, 2018).

- $310 \mathrm{~m}$-Venus: Similar to $10 \mathrm{~m}$-Venus, except with a 310 meter water equivalent layer again spread in the lowest lying regions. This is the same topography used in Way et al. (2016) simulations A,B and D.

- 158m-Aqua: This is a simple aquaplanet configuration that is commonly used in the exoplanet community. It uses a fixed 158 meter deep ocean, which corresponds to the bottom of the fifth layer of the ROCKE-3D ocean model. It is a bit shallower than the mean depth of the $310 \mathrm{~m}$-Venus ocean, and therefore comes into equilibrium a bit faster while still having a similar heat capacity, while including horizontal heat transport as well as wind-driven and thermohaline overturning circulations.

- 310m-Earth: Similar to 310m-Venus, but using a modern Earth-like land/sea mask with a $310 \mathrm{~m}$ deep bathtub dynamic ocean (i.e., every ocean grid cell is of a fixed depth of $310 \mathrm{~m})$. We call this an Earth-like land/sea mask since it is not exactly modern Earth, but has some modest changes as shown in Way et al. (2018) Figure 8 .

The five planets above are then given four types of atmospheres and four different insolations as described below:

- Simulations 1-5: These have a 10 bar $100 \% \mathrm{CO}_{2}$ atmosphere using a solar spectrum and insolation from $4.2 \mathrm{Ga}$ from the work of Claire et al. (2012). $\mathrm{CO}_{2}$ was probably the dominant gas in Earth's early atmospheric evolution (e.g., Kasting, 1993). We pick atmospheric pressures of 1 bar (see next bullet point) and 10 bar to cover the Kasting (1993) ranges (see their Fig 2). Our 10 bar results either equilibrate at a temperature beyond that at which our radiative transfer is accurate, or do not reach equilibrium and the temperatures attained at the time the experiments were terminated are already beyond the upper limits of our radiation tables. We report the results of these experiments in Table 2 below simply as a guide for future research, but we exclude them from our analysis in Figs. 2-8. The 10 bar simulations use a modern Venus rotation rate and obliquity.

- Simulations 6-10: Similar to Simulations 1-5, but these use a 1 bar $97 \% \mathrm{CO}_{2}$ and $3 \% \mathrm{~N}_{2}$ atmosphere at $4.2 \mathrm{Ga}$.

- Simulations 11-15: As in Simulations 6-10 but with a rotation period of -16 sidereal Earth days to place the planet on the edge of the fast rotator regime as described in Yang et al. (2014); Way et al. (2018). This allows us to explore the possibility that the planet was rotating more quickly in its early history than today. The choice of a retrograde rotation rate was chosen to be consistent with the present day retrograde rotation, but unpublished simulations with prograde rotation rates with these values produce very similar temperatures. Note that the work of Correia and Laskar $(2001,2003)$ indicate that prograde rotation rates of 16 days for Venus put its spin axis (obliquity) in a possibly chaotic regime. However, other work by J. W. Barnes et al. (2016) indicate that low obliquity retrograde rotation rates generally have more stable spin axes. Even if there are spin axis variations on geological timescales, it is not possible for us to model those here given that ROCKE3D simulations are limited to $<10,000$ years in length.

- Simulations 16-20: As in Simulations 6-10 but with a rotation period of -64 sidereal Earth days. This allow us to explore the possibility that the planet was rotating somewhat more quickly in its early history but still in the slowly rotating dynamical regime. Again, prograde rotation rates were also used in unpublished results and have similar global surface temperature values.

- Simulations 21-25: These simulations use an atmospheric composition and pressure very similar to modern Earth, namely an $\mathrm{N}_{2}$-dominated atmosphere with 400ppmv $\mathrm{CO}_{2}$ and 1 ppmv $\mathrm{CH}_{4}$ with a $1013 \mathrm{mb}$ surface pressure. They also use a solar spec- 
trum and insolation at $2.9 \mathrm{Ga}$ from Claire et al. (2012). The rotation rate is the same as modern Venus.

- Simulations 26-30: Similar to Simulations 21-25, but with a lower atmospheric surface pressure of $250 \mathrm{mb}$. This is again in the interest of comparative climatology since the Archean atmospheric pressure proxy work of D. Som S. Catling et al. (2012); S. Som et al. (2016) suggests that Earth may have had a surface pressure similar to $250 \mathrm{mb}$ at this time.

- Simulations 31-35: Similar to Simulations 21-25, but now using a solar spectrum and insolation from 0.715Ga from the work of Claire et al. (2012).

- Simulations 36-40: Again, similar to Simulations 21-25, but now using a modern solar spectrum and insolation.

- Simulations 41-45: Similar to Simulations 21-25, but now using a modern solar spectrum, but with insolation set to 1.26 times Venus' present day insolation (2.4 times modern day Earth's insolation) to test the boundaries of the inner edge of the habitable zone as in Way et al. (2018). Two of these simulations are also out of radiation balance and trending toward a runaway greenhouse state, and thus we do not analyze them further.

Most simulations except $158 \mathrm{~m}$-Aqua use a fixed ground albedo of 0.2 (thermal conductivity $=0.26 \mathrm{~W} \mathrm{~m}^{-1} \mathrm{~K}^{-1}$ ) and 50/50 mix of sand/clay soil following the work of Yang et al. (2014); Way et al. (2016, 2018). The Arid-Venus simulation uses the same albedo (0.2), but utilizes a $100 \%$ sand soil, rather than the sand/clay mix in other simulations. The advantage of using sand is that it more quickly loses and absorbs water. This allows the ground hydrology to come into balance more quickly than other soil types. This is because in the Arid-Venus simulations we are focused on water availability to/from the atmosphere from/to the soil and hence the amount of total water vapor acting as a greenhouse gas in the atmosphere.

\section{Results and Discussion}

Simulations 1-5, all with a 10 bar pure $\mathrm{CO}_{2}$ atmosphere and $4.2 \mathrm{Ga}$ insolation, are uniformly uninhabitable regardless of the surface water reservoir and topography (see Table 2 in the Supplementary Information). The driest planet (Arid Venus) does reach equilibrium, but with a surface temperature of $262^{\circ} \mathrm{C}$, well above the accuracy limits of the radiation parameterization used by ROCKE-3D. The other four planets are also well above $100^{\circ} \mathrm{C}$ at the point at which they were terminated and are not converging to equilibrium. Given the greater water reservoirs in these simulations, they are likely to be approaching a runaway greenhouse state.

In Figure 2 we show several different possible evolutionary scenarios for Venus derived from the other experiments in Table 1. In all such scenarios we assume that Venus had surface liquid water in varying amounts at model start, as described in Section 6 . The colors in this figure differentiate groups of simulations with different insolation, rotation, surface pressure, and/or atmospheric compositions, while the numbers 1-5 and corresponding symbols for each color delineate the range of climates obtained for different surface water reservoir and topography assumptions.

\section{$7.1 \quad 4.2 \mathrm{Ga}$}

Since there are major uncertainties about what Venus' initial rotation rate was (See Section 5) we explored early post-magma ocean scenarios at $4.2 \mathrm{Ga}$ with three different retrograde initial rotation periods in the left hand part of Figures 2,3,4: -16 days (gray; experiments 6-10), -64 days (magenta; experiments 11-15) and -243 days (red; experiments 16-20). Each assumes a 1 bar $\mathrm{CO}_{2}$-dominated atmosphere. As one would expect from the studies of Yang et al. (2014); Way et al. (2018) the faster spin rate simulations 
Table 1. Experiments

\begin{tabular}{|c|c|c|c|c|c|c|c|c|c|}
\hline ID & Topography $^{a}$ & $\begin{array}{l}\text { Epoch } \\
\text { Ga }\end{array}$ & $\begin{array}{l}\text { Insolation }{ }^{b} \\
\text { SoX/W m }\end{array}$ & $\begin{array}{l}\mathrm{P}^{c} \\
\text { bar }\end{array}$ & $\begin{array}{l}\text { Spin } \\
\text { days }\end{array}$ & $\begin{array}{c}\mathrm{N}_{2} \\
\text { ppmv }\end{array}$ & $\begin{array}{l}\mathrm{CO}_{2} \\
\text { ppmv }\end{array}$ & $\begin{array}{c}\mathrm{CH}_{4} \\
\text { ppmv }\end{array}$ & $\begin{array}{c}\text { Soil } \\
\text { Type }^{d}\end{array}$ \\
\hline $\begin{array}{l}01 \\
02 \\
03 \\
04 \\
05\end{array}$ & $\begin{array}{l}\text { Arid-Venus } \\
10 \mathrm{~m} \text {-Venus } \\
310 \mathrm{~m} \text {-Venus } \\
158 \mathrm{~m} \text {-Aqua } \\
310 \mathrm{~m} \text {-Earth }\end{array}$ & $\begin{array}{l}4.2 \\
" \\
" \\
" \\
"\end{array}$ & $\begin{array}{l}1.396 / 1913.6 \\
" \\
" \\
"\end{array}$ & $\begin{array}{l}10 \\
" ” \\
"\end{array}$ & $\begin{array}{c}-243 \\
" \\
" \\
" \\
"\end{array}$ & $\begin{array}{l}0 \\
" \\
" \\
"\end{array}$ & $\begin{array}{c}1000000 \\
" \\
" \\
" \\
"\end{array}$ & $\begin{array}{l}0 \\
" \\
" \\
"\end{array}$ & $\begin{array}{c}\mathrm{S} \\
\mathrm{S} / \mathrm{C} \\
\mathrm{S} / \mathrm{C} \\
- \\
\mathrm{S} / \mathrm{C}\end{array}$ \\
\hline $\begin{array}{l}06 \\
07 \\
08 \\
09 \\
10\end{array}$ & $\begin{array}{l}\text { Arid-Venus } \\
10 \mathrm{~m} \text {-Venus } \\
310 \mathrm{~m} \text {-Venus } \\
\text { 158m-Aqua } \\
310 \mathrm{~m} \text {-Earth }\end{array}$ & $\begin{array}{l}4.2 \\
" \\
" \\
"\end{array}$ & $\begin{array}{l}1.396 / 1913.6 \\
" \\
" \\
"\end{array}$ & $\begin{array}{l}1 \\
" \\
" \\
"\end{array}$ & $\begin{array}{l}-16 \\
", \\
" \\
"\end{array}$ & $\begin{array}{l}43000 \\
" \\
" \\
" \\
"\end{array}$ & $\begin{array}{c}970000 \\
" \\
" \\
" \\
"\end{array}$ & $\begin{array}{l}0 \\
" \\
" \\
"\end{array}$ & $\begin{array}{c}\mathrm{S} \\
\mathrm{S} / \mathrm{C} \\
\mathrm{S} / \mathrm{C} \\
- \\
\mathrm{S} / \mathrm{C}\end{array}$ \\
\hline $\begin{array}{l}11 \\
12 \\
13 \\
14 \\
15\end{array}$ & $\begin{array}{l}\text { Arid-Venus } \\
10 \mathrm{~m} \text {-Venus } \\
310 \mathrm{~m} \text {-Venus } \\
158 \mathrm{~m} \text {-Aqua } \\
310 \mathrm{~m} \text {-Earth }\end{array}$ & $\begin{array}{l}4.2 \\
" \\
" \\
"\end{array}$ & $\begin{array}{l}1.396 / 1913.6 \\
" \\
" \\
"\end{array}$ & $\begin{array}{l}1 \\
" \\
" \\
"\end{array}$ & $\begin{array}{l}-64 \\
" \\
" \\
" \\
"\end{array}$ & $\begin{array}{l}43000 \\
" \\
" \\
" \\
"\end{array}$ & $\begin{array}{c}970000 \\
" \\
" \\
" \\
"\end{array}$ & $\begin{array}{l}0 \\
" \\
" \\
"\end{array}$ & $\begin{array}{c}\mathrm{S} \\
\mathrm{S} / \mathrm{C} \\
\mathrm{S} / \mathrm{C} \\
- \\
\mathrm{S} / \mathrm{C}\end{array}$ \\
\hline $\begin{array}{l}16 \\
17 \\
18 \\
19 \\
20\end{array}$ & $\begin{array}{l}\text { Arid-Venus } \\
10 \mathrm{~m} \text {-Venus } \\
310 \mathrm{~m} \text {-Venus } \\
158 \mathrm{~m} \text {-Aqua } \\
310 \mathrm{~m} \text {-Earth }\end{array}$ & $\begin{array}{l}4.2 \\
" \\
" \\
"\end{array}$ & $\begin{array}{l}1.396 / 1913.6 \\
" \\
" \\
"\end{array}$ & $\begin{array}{l}1 \\
, \\
" \\
"\end{array}$ & $\begin{array}{c}-243 \\
" \\
" \\
" \\
"\end{array}$ & $\begin{array}{l}43000 \\
" \\
" \\
" \\
"\end{array}$ & $\begin{array}{c}970000 \\
" \\
" \\
" \\
"\end{array}$ & $\begin{array}{l}0 \\
" \\
" \\
"\end{array}$ & $\begin{array}{l}\mathrm{S} \\
\mathrm{S} / \mathrm{C} \\
\mathrm{S} / \mathrm{C} \\
- \\
\mathrm{S} / \mathrm{C}\end{array}$ \\
\hline $\begin{array}{l}21 \\
22 \\
23 \\
24 \\
25\end{array}$ & $\begin{array}{l}\text { Arid-Venus } \\
10 \mathrm{~m} \text {-Venus } \\
310 \mathrm{~m} \text {-Venus } \\
158 \mathrm{~m} \text {-Aqua } \\
310 \mathrm{~m} \text {-Earth }\end{array}$ & $\begin{array}{l}2.9 \\
" \\
" \\
"\end{array}$ & $\begin{array}{l}1.47 / 2001.0 \\
" ” \\
"\end{array}$ & $\begin{array}{l}1 \\
" \\
" \\
"\end{array}$ & $\begin{array}{c}-243 \\
" \\
" \\
" \\
"\end{array}$ & $\begin{array}{c}1012599 \\
" \\
" \\
" \\
"\end{array}$ & $\begin{array}{l}400 \\
" \\
" \\
"\end{array}$ & $\begin{array}{l}1 \\
, \\
,\end{array}$ & $\begin{array}{c}\mathrm{S} \\
\mathrm{S} / \mathrm{C} \\
\mathrm{S} / \mathrm{C} \\
- \\
\mathrm{S} / \mathrm{C}\end{array}$ \\
\hline $\begin{array}{l}26 \\
27 \\
28 \\
29 \\
30\end{array}$ & $\begin{array}{l}\text { Arid-Venus } \\
10 \mathrm{~m} \text {-Venus } \\
310 \mathrm{~m} \text {-Venus } \\
158 \mathrm{~m} \text {-Aqua } \\
310 \mathrm{~m} \text {-Earth }\end{array}$ & $\begin{array}{l}2.9 \\
" \\
" \\
"\end{array}$ & $\begin{array}{l}1.47 / 2001.0 \\
" ” \\
"\end{array}$ & $\begin{array}{l}0.25 \\
" \\
" \\
" \\
"\end{array}$ & $\begin{array}{c}-243 \\
" \\
" \\
" \\
"\end{array}$ & $\begin{array}{c}1012599 \\
" \\
" \\
" \\
"\end{array}$ & $\begin{array}{l}400 \\
" \\
" \\
"\end{array}$ & $\begin{array}{l}1 \\
" \\
"\end{array}$ & $\begin{array}{c}\mathrm{S} \\
\mathrm{S} / \mathrm{C} \\
\mathrm{S} / \mathrm{C} \\
- \\
\mathrm{S} / \mathrm{C}\end{array}$ \\
\hline $\begin{array}{l}31 \\
32 \\
33 \\
34 \\
35\end{array}$ & $\begin{array}{l}\text { Arid-Venus } \\
10 \mathrm{~m} \text {-Venus } \\
310 \mathrm{~m} \text {-Venus } \\
158 \mathrm{~m} \text {-Aqua } \\
310 \mathrm{~m} \text {-Earth }\end{array}$ & $\begin{array}{l}0.715 \\
" \\
" \\
"\end{array}$ & $\begin{array}{l}1.71 / 2358.9 \\
" ” \\
"\end{array}$ & $\begin{array}{l}1 \\
" \\
" \\
"\end{array}$ & $\begin{array}{c}-243 \\
" \\
" \\
" \\
"\end{array}$ & $\begin{array}{c}1012599 \\
" \\
" \\
" \\
"\end{array}$ & $\begin{array}{l}400 \\
" \\
" \\
"\end{array}$ & $\begin{array}{l}1 \\
" \\
" \\
"\end{array}$ & $\begin{array}{c}\mathrm{S} \\
\mathrm{S} / \mathrm{C} \\
\mathrm{S} / \mathrm{C} \\
- \\
\mathrm{S} / \mathrm{C}\end{array}$ \\
\hline $\begin{array}{l}36 \\
37 \\
38 \\
39 \\
40\end{array}$ & $\begin{array}{l}\text { Arid-Venus } \\
10 \mathrm{~m} \text {-Venus } \\
310 \mathrm{~m} \text {-Venus } \\
158 \mathrm{~m} \text {-Aqua } \\
310 \mathrm{~m} \text {-Earth }\end{array}$ & $\begin{array}{l}0.0 \\
" \\
" \\
" \\
"\end{array}$ & $\begin{array}{l}1.9 / 2601.0 \\
" \\
" \\
"\end{array}$ & $\begin{array}{l}1 \\
" \\
" \\
"\end{array}$ & $\begin{array}{c}-243 \\
" \\
" \\
" \\
"\end{array}$ & $\begin{array}{c}1012599 \\
" \\
" \\
" \\
"\end{array}$ & $\begin{array}{l}400 \\
" \\
" \\
"\end{array}$ & $\begin{array}{l}1 \\
" \\
,\end{array}$ & $\begin{array}{c}\mathrm{S} \\
\mathrm{S} / \mathrm{C} \\
\mathrm{S} / \mathrm{C} \\
- \\
\mathrm{S} / \mathrm{C}\end{array}$ \\
\hline $\begin{array}{l}41 \\
42 \\
43 \\
44 \\
45\end{array}$ & $\begin{array}{l}\text { Arid-Venus } \\
\text { 10m-Venus } \\
310 \mathrm{~m} \text {-Venus } \\
158 \mathrm{~m} \text {-Aqua } \\
310 \mathrm{~m} \text {-Earth }\end{array}$ & $\begin{array}{l}\text { Future } \\
" \\
" \\
"\end{array}$ & $\begin{array}{l}2.4 / 3266.0 \\
" \\
" \\
"\end{array}$ & $\begin{array}{l}1 \\
" \\
" \\
"\end{array}$ & $\begin{array}{c}-243 \\
" \\
" \\
" \\
"\end{array}$ & $\begin{array}{c}1012599 \\
" \\
" \\
" \\
"\end{array}$ & $\begin{array}{l}400 \\
" \\
" \\
"\end{array}$ & $\begin{array}{l}1 \\
" \\
" \\
"\end{array}$ & $\begin{array}{c}\mathrm{S} \\
\mathrm{S} / \mathrm{C} \\
\mathrm{S} / \mathrm{C} \\
- \\
\mathrm{S} / \mathrm{C}\end{array}$ \\
\hline $\mathrm{D}^{d}$ & $310 \mathrm{~m}$-Venus & 2.9 & $1.47 / 2001.0$ & 1 & -16 & 1012599 & 400 & 1 & $\mathrm{~S} / \mathrm{C}$ \\
\hline
\end{tabular}

${ }^{a}$ Topography: Arid-Venus=Only Ground Water, no surficial reservoirs, $20 \mathrm{~cm}$ water in soil, with modern Venus topography; 10m-Venus=10m Water Equivalent Layer (WEL) spread in lowest elevations as lakes with modern Venus topography; $310 \mathrm{~m}$-Venus $=310 \mathrm{~m}$ deep ocean with modern Venus topography; 310m-Earth=Modern Earth-like topography with $310 \mathrm{~m}$ deep ocean; $158 \mathrm{~m}$-Aqua $=158 \mathrm{~m}$ deep aquaplanet.

${ }^{b}$ Insolation: SOX = multiple of amount that Earth receives today in insolation $\left(\mathrm{S} 0=1361 \mathrm{~W} \mathrm{~m}^{-1}\right)$.

${ }^{c}$ Pressure in bar. ${ }^{d} \mathrm{~S}=100 \%$ Sand, $\mathrm{S} / \mathrm{C}=50 / 50 \%$ Sand/Clay, - = Not Applicable, 100\% ocean.

${ }^{d}$ Simulation D from Paper 1 (Way et al., 2016). Most similar to ID 8.

generally have higher temperatures because of the cloud processes discussed in those papers, but almost all of them reach equilibrium at a habitable global mean surface temperature. However, the clouds also differ to some degree because of water availability. Contrary to the work of Abe et al. (2011); Kodama et al. (2019) the Arid-Venus cases all have higher surface temperatures than their counterparts. This is because those previous works used modern Earth's rotation rate, whereas the cloud processes on these slower rotating worlds better regulate the climate, more so the more water that is available for 


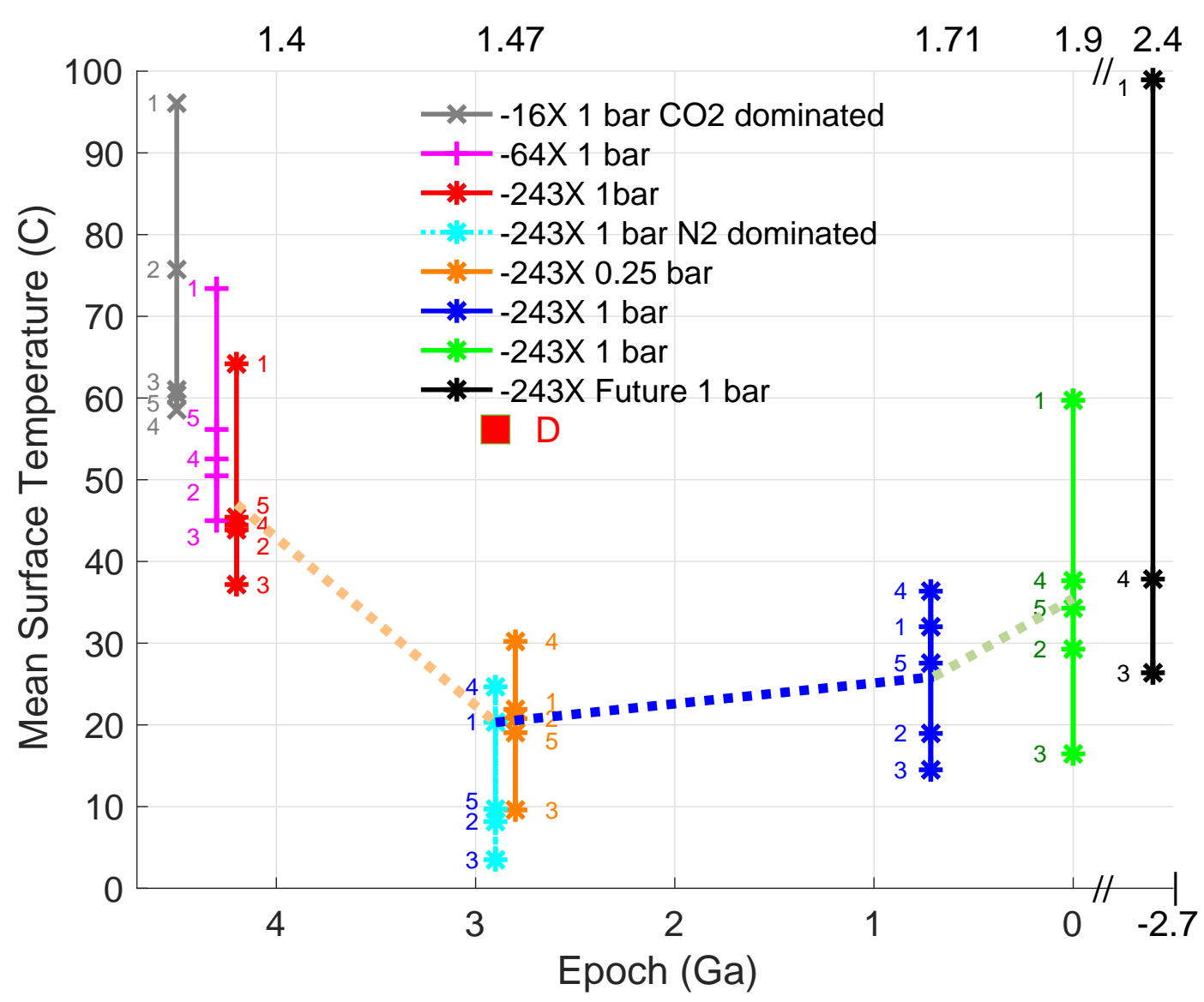

Figure 2. Atmospheric evolutionary scenarios for Venus. Top $\mathrm{x}$-axis is insolation relative to modern Earth $\left(1.4=1.4 \times 1361 \mathrm{~W} \mathrm{~m}^{-2}\right)$. Note that the gray, magenta and red data in the leftmost section of this plot are all for 4.2 Ga simulations. They are separated purely for visual effect and do not reflect differences in epoch or insolation. The same is true for the cyan, and orange data, all of which correspond to $2.9 \mathrm{Ga}$. The numbers oriented vertically along each set of simulations correspond to the different water reservoir/topography types: $1=$ Arid-Venus, $2=10 \mathrm{~m}$-Venus, $3=310 \mathrm{~m}$-Venus $4=158 \mathrm{~m}$-Aqua, $5=310 \mathrm{~m}$-Earth. See Table 2 .

cloud formation. This analysis is backed up by Figure 3 where we plot the shortwave cloud radiative forcing (SWCRF). The Arid-Venus simulations have the smallest (in magnitude) values, because a drier planet has less reflective clouds with less condensed water. In Figure 4 we show the percentage of high level clouds (PCLDH), the dominant of the three cloud types (high, medium, low) in Table 2. Here the distinction between the AridVenus simulations and the others is not consistent across the different rotation periods, suggesting that in some cases middle and/or low level clouds make important contributions to SWCRF.

\section{$7.2 \quad 2.9 \mathrm{Ga}$}

Here we plot two different sets of simulations for $\mathrm{N}_{2}$-dominated atmospheres: 1 bar (cyan; simulations 21-25) and 250mb (orange; simulations 26-30). In effect these portray representative possible atmospheres for an ancient Venus with liquid water that has evolved from an early $\mathrm{CO}_{2}$-dominated atmosphere to a more Earth-like composition via the carbonatesilicate cycle feedback that is believed to regulate $\mathrm{CO}_{2}$ on planets with liquid water. In 


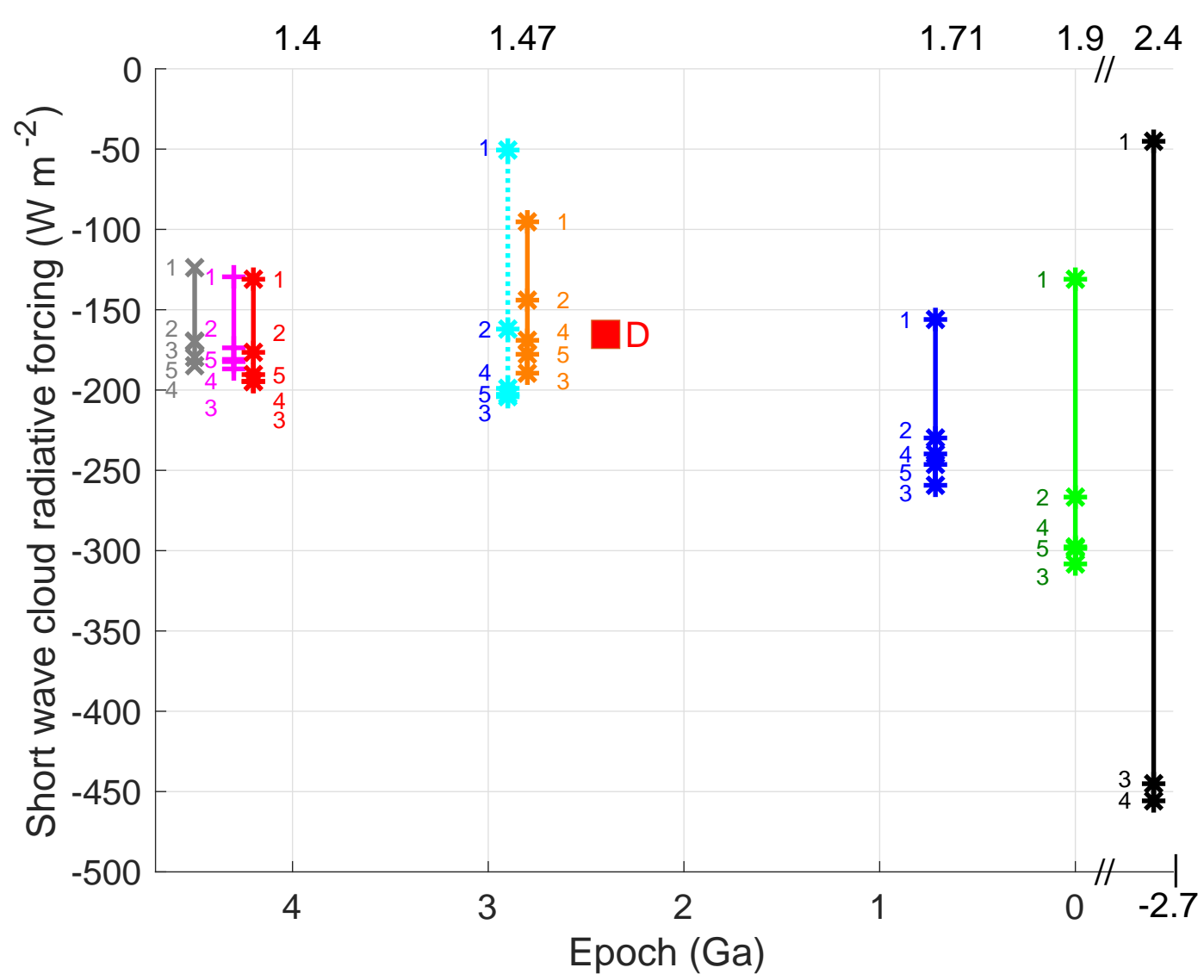

Figure 3. Shortwave cloud radiative forcing for the same evolutionary scenarios, defined as the difference between the solar radiation actually absorbed by the planet and how much would be absorbed if clouds were transparent. This is an estimate of how effective the clouds are at shielding the planet from the star's intense radiation.

both cases the Aqua-158m simulations have the highest mean surface temperatures with the Arid-Venus a close second, but all 10 simulations have moderate surface temperatures fairly similar to modern Earth. However as for simulations 6-20 the shortwave cloud radiative forcing is again the smallest for the Arid-Venus simulations (Figure 3) while also having less high cloud in (Figure 4) than the simulations with more surface water. Unsurprisingly, the thin 250mb atmospheres (simulations 26-30) have cooler surface temperatures in Figure 2. Simulations $27 \& 28$ have lower mean surface temperatures than modern Earth. The surface temperature field for simulation 28 is plotted in Figure 5 for reference. It exhibits fairly uniformly warm oceans, a signature of slowly rotating planets. Continental temperatures are cooler, slightly below freezing on average, due to nighttime cooling that offsets daytime warming. We also plot Simulation D from Paper I. The other 3 simulations from Paper I have similar values to their corresponding simulations herein. Simulation $\mathrm{D}$ is an $\mathrm{N}_{2}$-dominated atmosphere, but is otherwise similar to ID 8 (a $\mathrm{CO}_{2}$ dominated atmosphere) in Tables 1 and 2. It has a lower mean surface temperature than ID 8 as expected, but is significantly higher than the other simulations with larger rotation periods ( $\mathrm{ID}=21-30)$ at $2.9 \mathrm{Ga}$. It has less short wave cloud radiative forcing (Figure 3) and lower percentage of high level clouds (Figure 4) compared to the other $310 \mathrm{~m}$-Venus simulations at $2.9 \mathrm{Ga}$. This is expected given its faster rotation period, stronger Coriolis force, and less contiguous clouds at the substellar point as discussed in Paper I. 


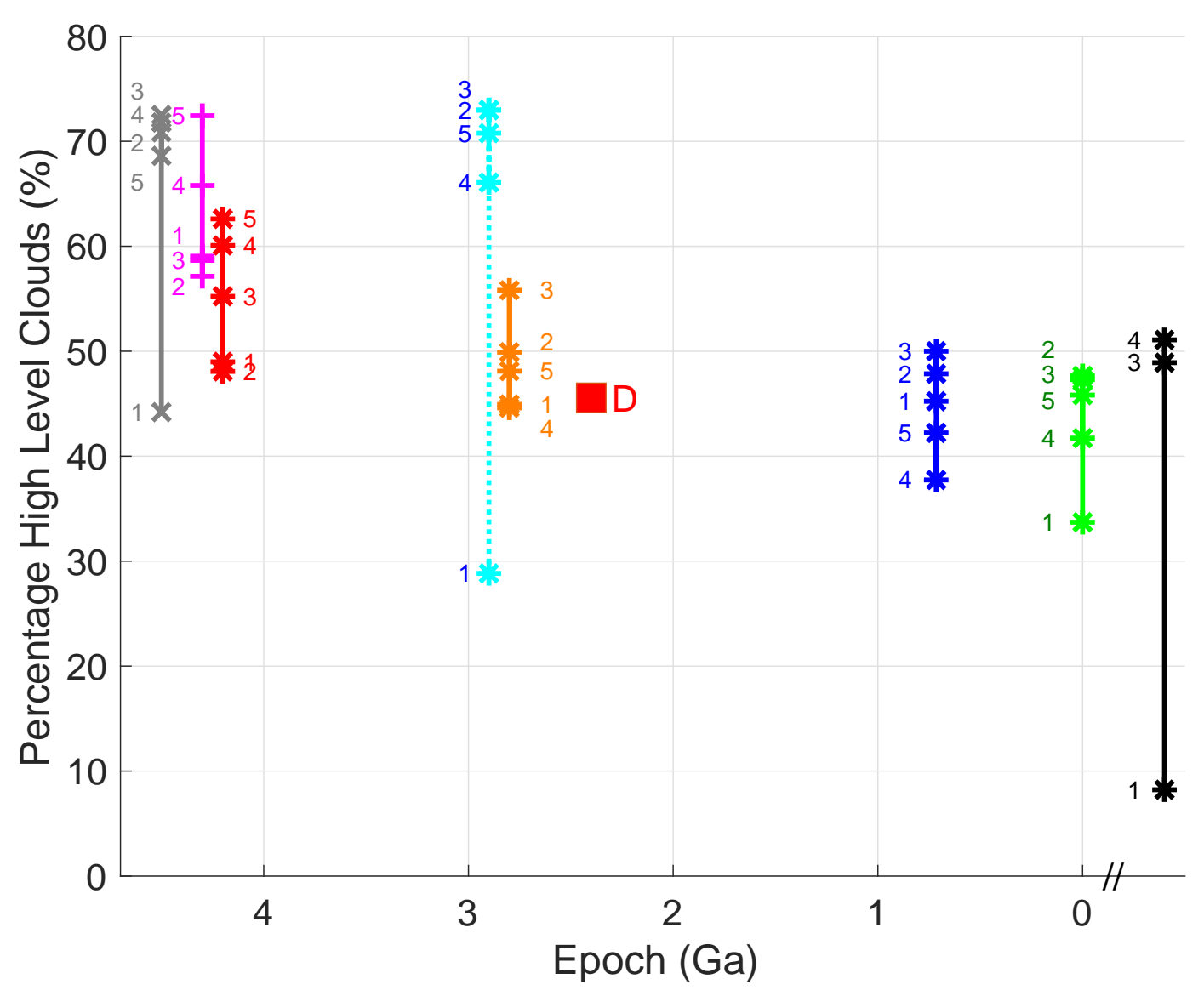

Figure 4. Percentage areal coverage of high level clouds (PCLDH). In Way et al. (2018) it was shown that PCLDH plays a key role in the cloud albedo feedback for slow rotators.

\section{$7.3 \quad 0.715 \mathrm{Ga}$}

This epoch captures a possible final habitable phase on Venus, if the thick $\mathrm{CO}_{2}$ atmosphere we see today was created by volcanic emissions during the global resurfacing event(s). The spread in surface temperatures between simulations remains about the same as in previous epochs, but for all surface types the temperature is warmer than at 2.9 Ga because of the brighter Sun. Again, the Aqua-158m is has the highest surface temperatures with the Arid-Venus close behind as in the $2.9 \mathrm{Ga}$ epoch. The SWCRF is somewhat larger in general, due to both the stronger insolation and slightly reduced high cloud, but again the Arid-Venus has the smaller effect. The spread in high level clouds has shrunk considerably from the 1 bar simulations at $2.9 \mathrm{Ga}$.

\subsection{Present Day}

This suite of simulations at Venus' present day insolation are designed to demonstrate that even under today's Sun the slow rotation cloud feedback effect would have remained strong as Venus' atmospheric pressure and composition remain unchanged. This points to the idea that it was not an increase in insolation that drastically changed Venus' clement climate of earlier epochs, but rather something else, which we speculate to be multiple/simultaneous large igneous provinces. The Arid-Venus simulations again have the highest temperatures and corresponding smallest SWCRF. This is more along lines of what we saw with the simulations at $4.2 \mathrm{Ga}$, with climate forcing by a stronger Sun 


\section{Simulation 28: 310m-Venus : 2.9Ga : $-243 \mathrm{X}: 250 \mathrm{mb}: \mathrm{N} 2$ dominated}

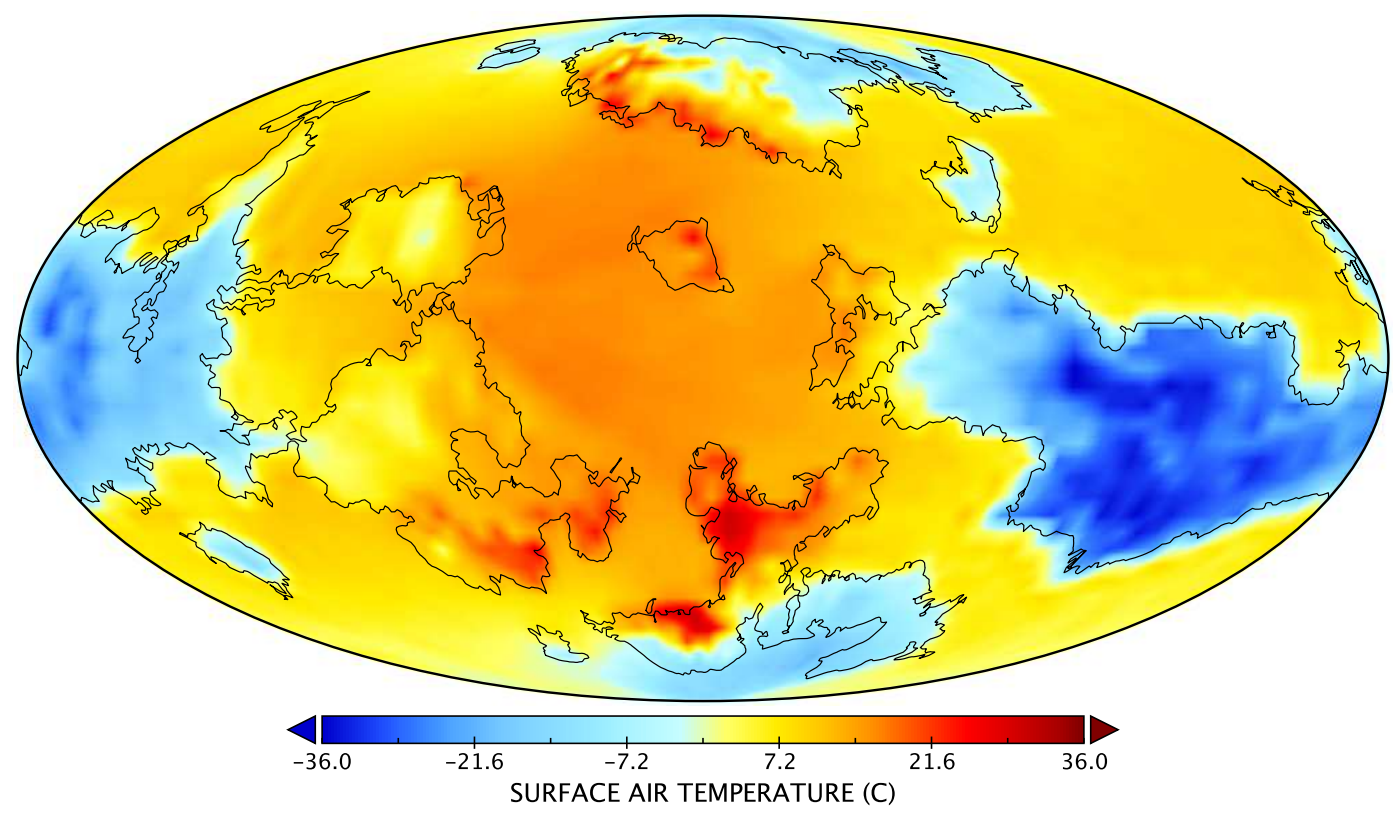

Figure 5. Simulation 28: mean surface temperature over $1 / 6$ th of a diurnal cycle. The substellar point is centered over the middle of the plot.

replacing climate forcing by a thicker greenhouse gas atmosphere as the primary reason for a warm climate.

\subsection{Future}

Our last set of simulations at insolation values 2.4 times that of present day Earth are meant to show how long a temperate Venus-like world could have remained habitable for a given surface type. Our 10m-Venus and 310m-Earth simulations are not in equilibrium and so are not plotted. The Arid-Venus simulation is at nearly $100^{\circ}$ Celsius. It appears to be approaching radiative equilibrium, but the simulation crashed after 20 years so it is difficult to be certain. At this point the cloud/albedo feedback for the Arid-Venus case has decreased to Earth-like values (the SWCRF is a mere $-50 \mathrm{~W} \mathrm{~m}^{-2}$ ). This simulation has the lowest value of PCLDH, which makes it hard to counter the increased insolation at this time in order to keep mean surface temperatures below the boiling point of water.

\subsection{General Trends}

A few relatively consistent trends are apparent from our simulations. First, the AridVenus simulations tend to have the highest surface temperatures, smallest values of SWCRF and lowest percentages of PCLDH. In many cases the 10m-Venus simulations are next, but not always. This may point to the fact that even with $10 \mathrm{~m}$ of available water the cloud/albedo feedback is generally effective at shielding this slowly rotating world from the intense solar radiation at all epochs when considering what modern Earth receives. The simulations with generally higher water availability and similar percentages of landto-sea (310m-Venus and 310m-Earth) tend to cluster together in Figures 2,3,4. The $158 \mathrm{~m}$ Aqua simulations seem to float in between, perhaps because of the lower surface albedo in combination with the cloud albedo feedback. 

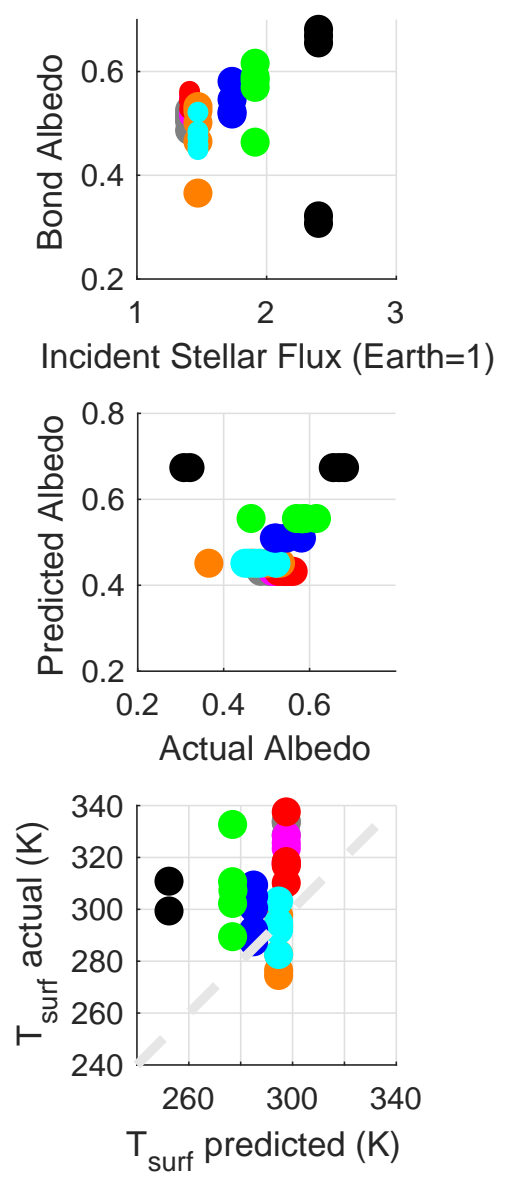

Figure 6. Upper panel: Bond albedo vs. incident solar flux for the planets in Figure 2. Middle panel: Predicted versus actual Bond albedos for the same set of planets after Del Genio, Kiang, et al. (2019). Lower panel: Predicted vs. observed surface temperatures after Del Genio, Kiang, et al. (2019).

Even without a transition to a runaway greenhouse, prior water loss due to the onset of a "moist greenhouse" state may have been important to Venus' evolution. A number of simulations in Table 2 contain stratospheric water concentrations $\left(\mathrm{Q}_{\text {top }}\right)$ greater than $3 \times 10^{-3} \mathrm{~kg} \mathrm{~kg}^{-1}$, the traditional Kasting et al. (1993) limit for onset of the moist greenhouse. However, recent work by Chen et al. (2019) for M-star planets has demonstrated that previous work may have overestimated water loss rates. Hence we should exercise more caution in using $3 \times 10^{-3} \mathrm{~kg} \mathrm{~kg}^{-1}$ as a hard value for the moist greenhouse until similar models are applied to G-star planets. Column $\mathrm{Q}_{\text {surf }}$ is a check on the amount of water vapor at the surface of the model. ROCKE-3D runs with a fixed molecular mass at model start and ignores the spatially/temporally variable mass of water in calculating pressure gradients, so it is important to keep track of whether water becomes a nonnegligible fraction of atmospheric mass (e.g., $20 \%$ of the total or more) as the dynamics in the model will begin to be outside an acceptable range. Only in simulation 45 does this value go over the $20 \%$ limit.

Figure 6 shows calculations for what exoplanet astronomers might find for a population of "exo-Venuses," some of them habitable and some not, in future observations. We use an ensemble of ROCKE-3D simulations of a variety of rocky planet types from which predictors for Bond albedo and surface temperature have been derived using in- 
solation and star temperature as inputs (Del Genio, Kiang, et al., 2019, hereafter DG19). Figure 6 applies the predictor to our Venus evolutionary scenarios to determine the predictability of albedo and surface temperature. In general Bond albedo increases with insolation in the Venus simulations (upper panel), the exceptions being 4 of the Arid-Venus cases with limited surface water, fewer clouds and thus lower albedos than our other simulations. The DG19 predictor (middle panel) works well for all but these 4 cases, since it predicts a high cloud-controlled albedo for the wetter planets that have more and/or thicker clouds than others. For surface temperature (bottom panel), the predictor tends to underestimate the actual temperatures by roughly $20^{\circ}$ or less in most cases, but by up to $50^{\circ}$ for the hotter, drier, marginally habitable Arid-Venus cases.
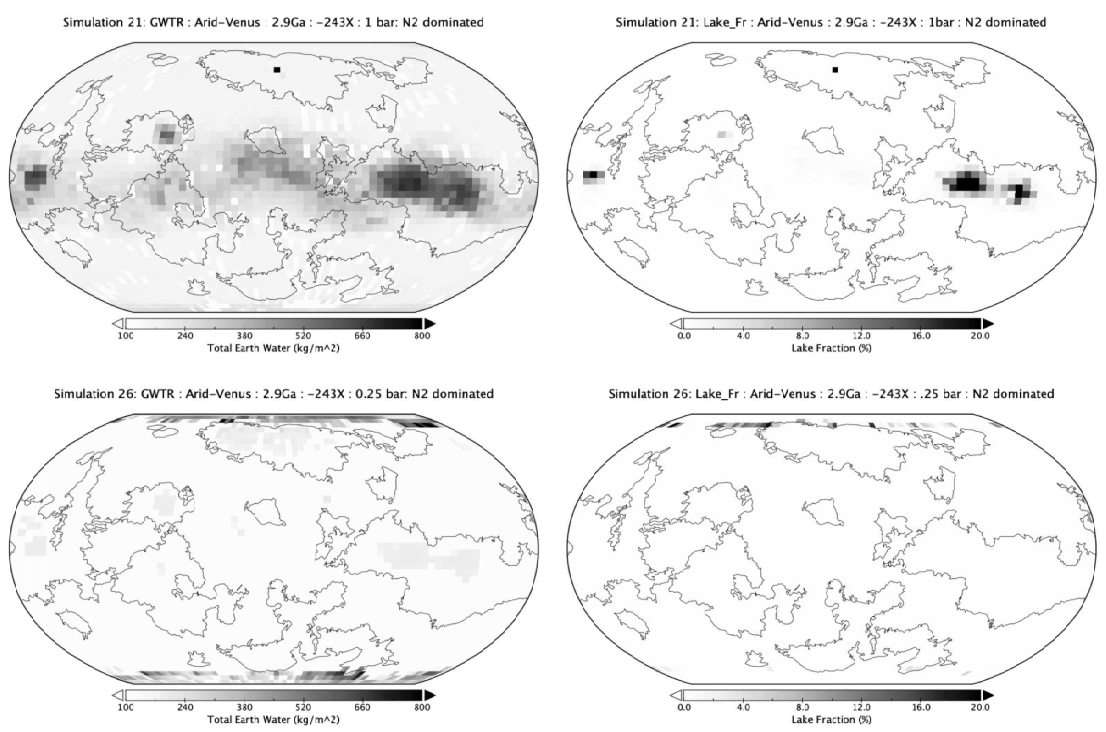

Figure 7. GWTR left panels, LakeFR right panels for Top to Bottom: Simulation 21 and 26 (Arid-Venus).
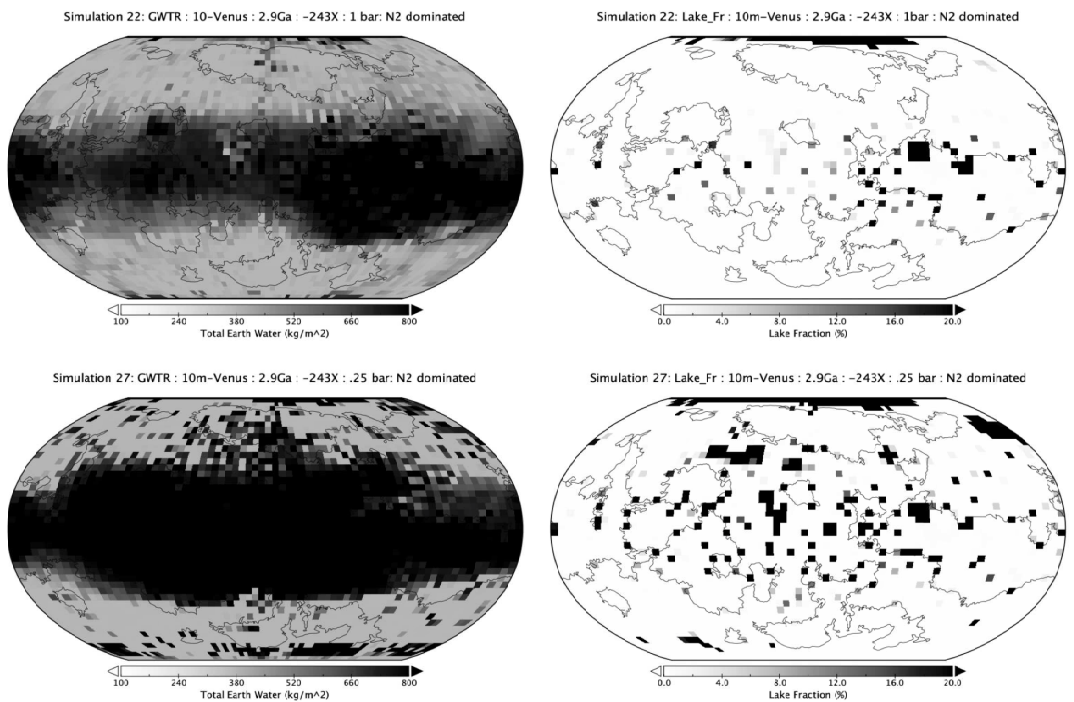

Figure 8. GWTR left panels, LakeFR right panels for Top to Bottom: Simulation 22 and 27 (10m-Venus). 
Figure 7 shows (left panels) the vertically integrated soil moisture and (right panels) lake fraction for two of our Arid-Venus simulations at 2.9 Ga with Earth-like atmospheres: Experiment 21 (1 bar, top panels) and Experiment 26 (250 mb, bottom panels). The Arid-Venus cases are of particular interest because they are initialized with a spatially uniform subsurface soil water reservoir and no standing water bodies, and they then equilibrate to a heterogeneous distribution of surface and subsurface water depending on the climate and circulation and thus the local precipitation-evaporation competition. The 1 bar atmosphere is typical of the behavior of most of the experiments in Table 1: In equilibrium, subsurface water collects primarily in the equatorial region where rising motion and precipitation is prevalent during the daytime, and especially in highland regions such as Aphrodite Terra. Lakes (which are not present in the initial condition) also form preferentially over the equatorial highlands. The 250 mbar simulation is an outlier, with subsurface water and lakes arising primarily at high latitudes. This is reminiscent of what is observed for the methane-ethane lakes on Titan, which Mitchell (2008) is able to reproduce in a GCM when a limited subsurface methane reservoir is assumed.

Figure 8 shows the same quantities for the analogous 10-m Venus simulations (Experiments 22 and 27). These differ from the Arid-Venus cases not only because the planet contains more water, much of it in surface lakes rather than subsurface soil moisture, but also because the lakes fill the lowlands at the start of each simulation rather than being distributed uniformly across the planet. With a larger water reservoir than that for the Arid-Venus planets, soil moisture collects throughout the tropics in the equilibrated climate, but still with a slight preference for the highland regions even though there is no standing water in the highlands in the initial condition. But unlike the Arid-Venus planets, soil moisture also collects at the poles, both for the 1 bar and the $250 \mathrm{mb}$ atmosphere planets. Likewise, lakes in both simulations form in both the tropics and polar region, more so over the highlands for the 1 bar atmosphere but fairly uniformly distributed in longitude for the $250 \mathrm{mb}$ atmosphere.

\section{Conclusion}

Whether Venus' original water survived its initial MO stage, or whether significant water was delivered afterwards, is unknown. It is therefore worth having a theoretical framework that considers the possibility of an early habitable Venus as a starting point for designing future observing strategies that might shed light on Venus' past. In this spirit, we envision the following possible climatic evolution for Venus and provide Figure 9 as a guide:

1.) Toward the end of the accretion period $(\sim 4.2 \mathrm{Ga})$ Venus would have cooled rapidly as did Earth, as shown in the work of J. W. Valley et al. (2002). This would allow surface water to condense and early oceans to form. Early oceans in turn could create significant tidal dissipation that would spin down Venus' rotation rate on a relatively short time scale as shown in work by (Green et al., 2019) and described in Section 5 above. Solid body dissipation may have also been effective, see Section 5. Slow rotation combined with an early ocean would provide the necessary ingredients for a dayside cloud deck to emerge, shielding the planet from high insolation and allowing at least some of the initial surface water to survive despite the planet being well inside the conventional inner edge of the habitable zone, as shown in the work of Yang et al. (2014); Way et al. (2018).

2.) The carbonate-silicate cycle in concert with interior volatile cycling would allow $\mathrm{CO}_{2}$ draw-down while $\mathrm{N}_{2}$ was outgassed, eventually reaching a balance producing an $\mathrm{N}_{2}$-dominated atmosphere with trace amounts of $\mathrm{CO}_{2}$ over gigayears with pressures ranging from several bars to hundreds of millibars. 


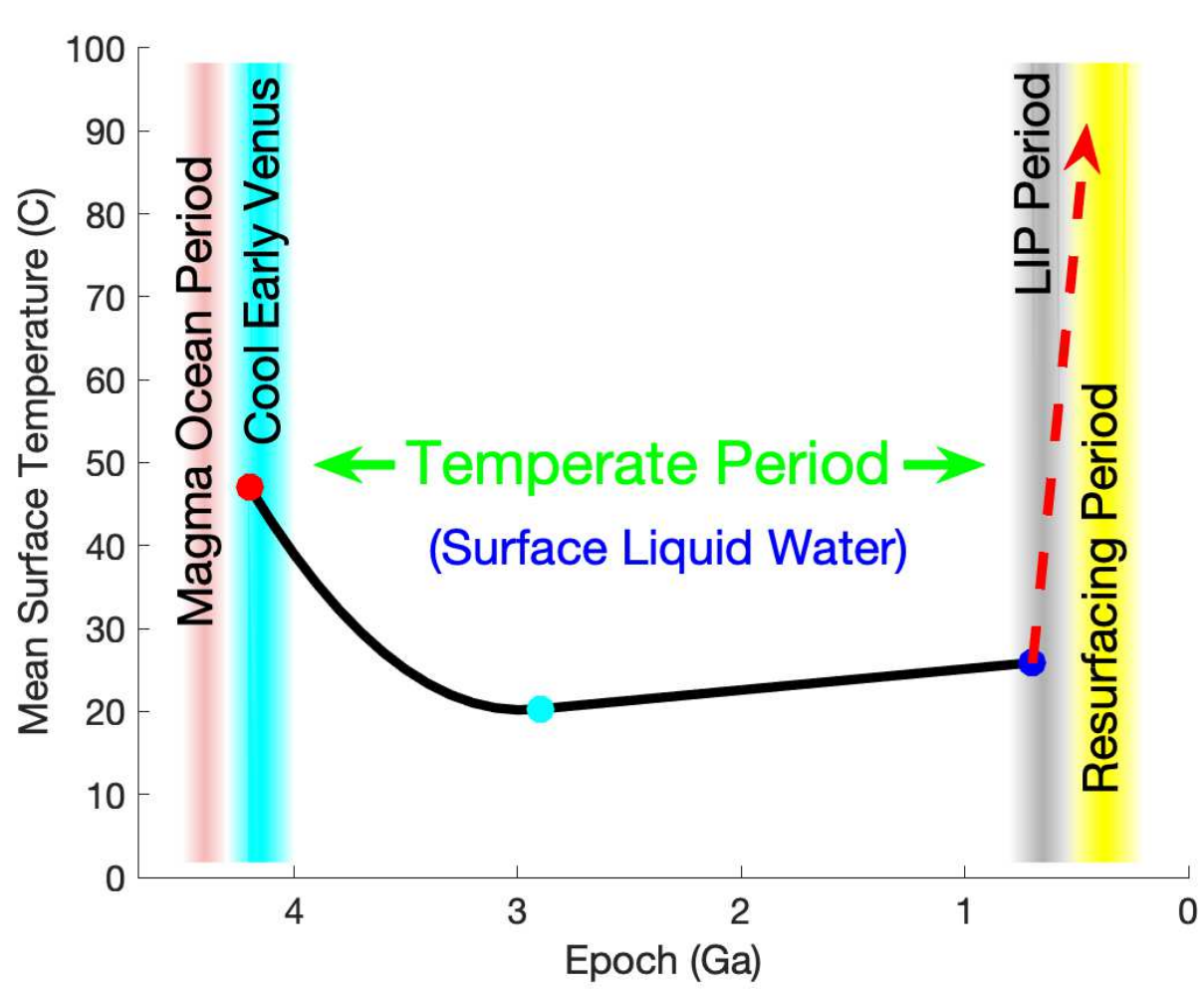

Figure 9. Graphical representation of Venus' possible climate history. The three data points represent the 1 bar atmospheres modeled at those points in time. The red dashed arrow to the right represents the transition to a moist/runaway greenhouse and eventually to Venus' present day surface temperature and atmospheric density.

3.) We propose that any stable Venusian climate period came to an end at some period of time (e.g. $0.2 \mathrm{Ga}$ to $3 \mathrm{Ga}$ ) before the global resurfacing event. As mentioned previously surface age estimates for Venus range from as young as $\sim 180 \mathrm{Ma}$ (Bottke et al., 2016) to $750 \mathrm{Ma}$ (McKinnon et al., 1997). We suggest that the ignition of multiple large igneous provinces (LIPs) became active around that time (over a period of 10s or 100s of millions of years). This would not have been the global LIP as proposed by (Lpez et al., 1998) as it is not necessary and seems to have little support in the community. It is likely that the eruption of LIPs throughout Earth's history (Ernst, 2014; Ernst et al., 2019) is a random stochastic process. This may imply that multiple large scale LIPs have not occurred simultaneously on Earth by purely random chance, which is fortuitous for life as we know it today. Venus may not have been as fortunate. Unfortunately, little is known about Venus' interior structure today, much less its initial state and subsequent evolution, so the question remains as to whether deterministic evolutionary processes in the interiors of Venus-like planets will inevitably lead to catastrophic changes and uninhabitable end states.

4.) Multiple large scale LIPs would have warmed the world markedly via the release of large amounts of $\mathrm{CO}_{2}$ via one or more mechanisms and its greenhouse effect on the climate (e.g., Ogden \& Sleep, 2012) over 10s or 100s of millions of years. It should be noted that degassing $\sim 90$ bars worth of $\mathrm{CO}_{2}$ via this mechanism would be difficult and is an open research topic. 
5.) This warming could have hastened a movement toward the onset of a moist (Kasting et al., 1993) and possibly a runaway greenhouse state in which much of the surface water was lost via photodisassociation accompanied by hydrogen escape and an oxidized surface. Recall that present day Venus D/H measurements (if they are accurate) imply .6 to $16 \%$ of Earth's present day surficial water stores (Donahue et al., 1997). Hence the timescale of total loss would be at least an order of magnitude faster than that described in Kasting et al. (1993), although there is still uncertainty about the stratospheric conditions under which a moist greenhouse occurs (e.g., Chen et al., 2019) and when a runaway greenhouse is achieved (e.g., Kasting \& Ackerman, 1986; Goldblatt et al., 2013; Ramirez, Kopparapu, Lindner, \& Kasting, 2014). Work by Grinspoon (1993) on the D/H ratio may also support this hypothesis as they state: "Thus $(\mathrm{D} / \mathrm{H})_{\text {obs }}$ may be the isotopic signature of a catastrophic resurfacing in the past $0.5-1$ Gyr."

6.) A major issue with any proposed evolutionary scenario with long lived surface water reservoirs then arises: what happened to the large quantities of oxygen expected to be left over from a Venusian ocean? This is the oxygen that would have remained in the atmosphere after the photo-dissociation of $\mathrm{H}_{2} \mathrm{O}$ and the loss of the hydrogen (Watson et al., 1981), but not oxygen, via atmospheric escape. In fact large quantities of abiotically produced $\mathrm{O}_{2}$ (100s to 1000 s of bar) left over in such a scenario has been proposed as an observational signature in exoplanetary atmospheres on planets that have lost their oceans (Luger \& Barnes, 2015). For our Arid-Venus scenario it may be possible to lose much of the oxygen via a combination of atmospheric escape (Persson et al., 2018) and absorption by a surface like that of present day Venus (e.g., M. Gilmore et al., 2017). However, recently submitted work by Persson et al. (2020) demonstrates that $0.3 \mathrm{~m}$ of a global equivalent layer of water could have been lost via atmospheric escape alone in the past $\sim 4 \mathrm{Ga}$. Hence the $0.2 \mathrm{~m}$ global equivalent layer of water in our Arid-Venus scenario fits within this framework. Yet work by Persson et al. (2018); Masunaga et al. (2019); Persson et al. (2020) and their estimates for $\mathrm{O}+$ escape rates shows that atmospheric escape alone is not sufficient to remove larger reservoirs of oxygen left over from the oceans in our other non-Arid-Venus simulations. It should be noted that the escape estimates from Persson et al. (2020) are distinctly lower than previous work by Chassefière $(1996,1997)$ where they are mainly concerned with escape during a more active younger sun. The work of Abe et al. (2011) also gives much higher escape rates estimating that an entire Earth Ocean's volume could be lost in 600Myr to $14 \mathrm{Myr}$ depending on how active the sun is. Some caveats go with this work in that the Venus atmosphere simulated for our temperate period (more akin to an Archean Earth atmosphere than modern day Earth or Venus) is $\mathrm{N}_{2}$ dominated with 400ppmv $\mathrm{CO}_{2}$ and 1 ppmv $\mathrm{CH}_{4}$ and is very different from that of modern Venus with thermospheric and exospheric temperatures likely to be distinct and possibly affecting escape rates (Airapetian et al., 2017).

We propose that the large-scale resurfacing evident on Venus today, which took place over 100s of millions of years, is a possible effective answer. It must be noted that this would be separate from the earlier (in geological time) LIP scenario above. Since the Magellan mission it has been known that $80 \%$ of the surface of Venus is relatively young, with estimates ranging from 300-700Myr old as mentioned in Section 4. These newly exposed basalts would be the ideal sink for large quantities of oxygen (possibly 100s of bars) over 100s of millions of years. According to (Lécuyer et al., 2000) Venus would need to oxydize a rock layer $\sim 50 \mathrm{~km}$ deep to absorb an Earth Ocean's worth of oxygen, and they propose a mechanism for doing so while citing the earlier work of Pieters et al. (1986). Note that none of the oceans proposed herein are close to an Earth's ocean in volume, hence the number could be much smaller. For example, work by Grinspoon (1993) and J. W. Head et al. (1992) note that the volume of magma necessary to cover all pre-existing craters would need to be a global layer $\sim 10 \mathrm{~km}$ deep, and that would be sufficient for the volume of oceans proposed in our models. Some fraction of the oxygen may actually be deep within Venus lithosphere and possibly even within its mantle. This may be consistent with coronae-related subduction hypotheses (Sandwell \& Schubert, 1992; Davaille 
et al., 2017) and other ideas about downwelling-associated highlands (e.g. J. W. Head et al., 1992, see Fig 2), where thicker crustal regions may exhibit orogenesis (e.g., Head et al., 1990) and sinking of parts of the lithosphere into the mantle (e.g., Lenardic et al., 1991; Bindschadler et al., 1992).

7.) The loss of water would in turn change the planet from an initial subductive or mobile plate tectonic mode to more of a stagnant lid mode (as on present day Venus \& Mars) since it is currently believed that water plays a key role in plate tectonics on Earth (e.g., Grove et al., 2012; Lécuyer, 2014). This scenario fits in very nicely with the recent work of (Weller \& Kiefer, 2019) who give a timescale of order 1 Gyr for the transition from a mobile to a stagnant lid mode on Venus in their simplified model. Without a mechanism to efficiently cycle volatiles in a stagnant lid mode (e.g., Tosi et al., 2017; Höning et al., 2019), outgassing would have continued without the major weathering and subduction surface sinks that operate on Earth, hence $\mathrm{CO}_{2}$ and $\mathrm{N}_{2}$ would build up over time to reach the levels we see on Venus today. Some studies have also shown that even in a stagnant lid mode it is possible to cycle volatiles, possibly up to gigayears in time (e.g., Foley \& Smye, 2018; Godolt et al., 2019), but these mechanisms depend on the initial $\mathrm{CO}_{2}$ budget and the retention of at least some water after cooldown.

8.) This stagnant lid mode may then allow very large mantle upwelling and/or downwelling centers that would produce some of the features we see on Venus' surface today produced over hundreds of millions of years, as described most recently in the works of e.g Rolf et al. (2018); Weller and Kiefer (2019).

Our scenario can also fit within the Fortunian, Guineverian \& Atlian periods proposed in the works of Ivanov and Head (2015) and Airey et al. (2017), as it is not possible to constrain the start of the LIP period we propose with the data we have today. Our LIP period could easily have concluded in the pre-Fortunian or Fortunian period $\sim 1.5 \mathrm{Ga}$.

One of the remaining quandaries in our hypothesis is the fact that the 92 bar atmosphere we see on Venus today must go back at least as far as the age of the visible surface because there are fewer small craters ( $<35 \mathrm{~km}$ in diameter) to be seen in the Magellan data (Schaber et al., 1992, see Figure 2). Certainly smaller craters would be visible if the atmosphere had been significantly thinner in the lifetime of the observed surface when atmospheric filtering of smaller impactors would have been less prevalent.

For example, assuming the tesserae are the oldest stratigraphic units why are there no small craters present if the present day atmosphere is not a primordial feature from many eons ago? One resolution to this problem could be that the tesserae are not as old as we think they are, and until we date these units and the basaltic flats we really won't know. Secondly, as mentioned above, there is the possibility that there have been multiple resurfacing events and the tesserae are left-over from one of the previous events. Neither is a terribly optimistic scenario if one is hoping that some of tesserae may be remnant crust from a period of hosting surface water. Finally, a large impactor may be the cause of the catastrophic climate change we propose. This could have also played a role in resetting the clock on the surface of Venus reconciling the lack of small craters. In this scenario the LIP hypothesis plays a partial role in the evolution of Venus' climate. This would be similar to what we have seen in the on-going debate regarding the K-Pg period on Earth (e.g. Hull et al., 2020; Schoene et al., 2019; Sprain et al., 2019). Such an impactor's imprint would have long been lost due to Venus' relatively young surface. Our comments about impactors in Section 4 apply here as well.

Clearly a great deal more modeling work and more observations are required to confirm or refute this hypothesis. Did Venus follow the 'canonical' path with Earth-like conditions in it's early history and then experience a moist-runaway greenhouse due to increasing solar insolation? Did it experience a longer period of habitability throughout 
most of its history, with its demise and present hothouse state the consequence of a series of LIP events releasing $\mathrm{CO}_{2}$ bound up in the crust as on Earth, and/or released from the deep interior where $\mathrm{CO}_{2}$ is more easily sequestered (e.g., Kuramoto \& Matsui, 1996)? Or did it become bone dry in an extended magma ocean phase in the first 100Myr, as described in Hamano et al. (2013) for Type II planets?

We believe the only scenario we can begin to rule out with the present work is the 'canonical path' since there is no evidence that an early period of habitability would have been affected by increasing solar luminosity in the first billion years. In essence, if Venus had habitable surface conditions with surface liquid water $\sim 4 \mathrm{Ga}$ then the same cloud albedo effect that allows such a scenario would continue for eons. On the other hand we will not be able to distinguish between the two remaining scenarios until we return to Venus to make proper noble gas and other elemental and isotopic measurements at the surface (Baines et al., 2013) and better constrain escape processes at the top of the atmosphere through time. The latter will also rely upon how such gases escape from present day Earth given the possibility that Venus may have had a magnetic field in previous epochs, even if it is not clear how important the magnetic field is to escape processes in general (Gunell et al., 2018). Likewise, whether the actual evolution of the one Venus we can visit is the ultimate fate of all highly irradiated rocky planets or an accident of an evolutionary path that might have proceeded differently in other circumstances (e.g. Lenardic et al., 2016) is not known. The stakes are high for answering this question, since many exoplanets have been discovered in the "Venus zone" just inside the traditional inner edge of the habitable zones of other stars (Kane et al., 2014). Efforts to simultaneously characterize the $\mathrm{CO}_{2}$ concentrations and climates of a number of these exoplanets, combined with a focused observational strategy for unveiling the history of the "exoplanet next door" to Earth in our own solar system (Kane et al., 2019), will be our best chance to understand whether the envelope for habitability and the emergence of life is much broader than usually assumed. 
Table 2. Results

\begin{tabular}{|c|c|c|c|c|c|c|c|c|c|c|}
\hline $\mathrm{ID}^{a}$ & $\begin{array}{l}\text { Runtime } \\
\text { years }\end{array}$ & $\begin{array}{l}\text { Temp }^{b} \\
\text { C }\end{array}$ & $\begin{array}{r}\text { Balance }^{c} \\
\mathrm{~W} \mathrm{~m}{ }^{-2}\end{array}$ & $\begin{array}{l}\mathrm{Q}_{t o p}^{d} \\
\mathrm{~kg} / \mathrm{kg}\end{array}$ & $\begin{array}{c}\mathrm{Q}_{\text {surf }}^{e} \\
\%\end{array}$ & $\begin{array}{l}\text { Albedo } \\
\text { Planetary }\end{array}$ & $\begin{array}{l}\text { Albedo } \\
\text { Surface }\end{array}$ & $\begin{array}{l}\text { Clouds } \\
\text { High }\end{array}$ & $\begin{array}{l}\text { Clouds } \\
\text { Medium }\end{array}$ & $\begin{array}{c}\text { Clouds } \\
\text { Low }\end{array}$ \\
\hline 01 & 71 & 262 & 0.01 & $1.36 \mathrm{e}-05$ & 0.08 & 54 & 29 & 54 & 5 & 0 \\
\hline 02 & 111 & 151 & 27.21 & $2.67 \mathrm{e}-05$ & 3.74 & 54 & 18 & 33 & 17 & 33 \\
\hline 03 & 67 & 121 & 21.31 & $4.50 \mathrm{e}-04$ & 7.87 & 52 & 11 & 45 & 23 & 37 \\
\hline 04 & 52 & 120 & 51.28 & $1.74 \mathrm{e}-04$ & 10.01 & 44 & 7 & 36 & 17 & 51 \\
\hline 05 & 56 & 123 & 36.27 & $4.28 \mathrm{e}-04$ & 9.16 & 49 & 10 & 46 & 24 & 44 \\
\hline $06 / 01$ & 100 & 96 & 0.06 & $1.73 \mathrm{e}-03$ & 1.65 & 51 & 29 & 44 & 2 & 0 \\
\hline $07 / 02$ & 100 & 76 & 0.41 & $9.34 \mathrm{e}-03$ & 7.70 & 53 & 16 & 71 & 32 & 21 \\
\hline $08 / 03$ & 53 & 61 & 5.92 & $6.49 \mathrm{e}-03$ & 7.50 & 50 & 10 & 72 & 32 & 47 \\
\hline $09 / 04$ & 100 & 59 & -0.48 & $6.23 \mathrm{e}-03$ & 6.95 & 52 & 7 & 73 & 35 & 62 \\
\hline $10 / 05$ & 60 & 60 & 1.90 & $5.46 \mathrm{e}-03$ & 7.19 & 52 & 9 & 69 & 37 & 53 \\
\hline $11 / 01$ & 200 & 73 & 0.05 & $9.03 \mathrm{e}-04$ & 1.70 & 52 & 29 & 59 & 4 & 1 \\
\hline $12 / 02$ & 500 & 50 & 0.04 & $5.94 \mathrm{e}-04$ & 2.07 & 55 & 16 & 57 & 10 & 10 \\
\hline $13 / 03$ & 200 & 45 & 0.87 & $1.56 \mathrm{e}-03$ & 3.15 & 54 & 10 & 59 & 18 & 43 \\
\hline $14 / 04$ & 156 & 53 & 0.11 & $3.47 \mathrm{e}-03$ & 4.81 & 51 & 7 & 66 & 25 & 60 \\
\hline $15 / 05$ & 200 & 56 & 0.44 & $4.58 \mathrm{e}-03$ & 5.65 & 52 & 9 & 72 & 28 & 49 \\
\hline $16 / 01$ & 300 & 64 & 0.01 & $8.34 \mathrm{e}-04$ & 0.80 & 53 & 28 & 49 & 4 & 1 \\
\hline $17 / 02$ & 500 & 44 & 0.06 & $5.68 \mathrm{e}-04$ & 1.40 & 56 & 16 & 48 & 9 & 8 \\
\hline $18 / 03$ & 1000 & 37 & 0.13 & $8.18 \mathrm{e}-04$ & 2.07 & 56 & 10 & 55 & 15 & 38 \\
\hline $19 / 04$ & 500 & 44 & -0.50 & $1.59 \mathrm{e}-03$ & 3.01 & 54 & 7 & 60 & 17 & 56 \\
\hline $20 / 05$ & 500 & 45 & 0.23 & $1.88 \mathrm{e}-03$ & 3.15 & 54 & 9 & 63 & 19 & 44 \\
\hline $21 / 01$ & 500 & 22 & 0.02 & $2.52 \mathrm{e}-05$ & 0.36 & 46 & 28 & 45 & 6 & 4 \\
\hline $22 / 02$ & 3000 & 21 & -0.04 & $3.08 \mathrm{e}-05$ & 0.61 & 47 & 17 & 50 & 10 & 12 \\
\hline $23 / 03$ & 1000 & 10 & -0.05 & $2.53 \mathrm{e}-06$ & 0.70 & 52 & 10 & 56 & 20 & 48 \\
\hline $24 / 04$ & 500 & 30 & -0.12 & $3.51 \mathrm{e}-05$ & 2.32 & 45 & 6 & 45 & 14 & 37 \\
\hline $25 / 05$ & 1000 & 19 & 0.05 & $5.87 \mathrm{e}-06$ & 1.24 & 48 & 9 & 48 & 22 & 39 \\
\hline $26 / 01$ & 300 & 20 & 0.11 & $5.94 \mathrm{e}-03$ & 0.53 & 37 & 29 & 29 & 5 & 9 \\
\hline $27 / 02$ & 1000 & 8 & -0.14 & $9.98 \mathrm{e}-03$ & 1.26 & 50 & 20 & 73 & 17 & 27 \\
\hline $28 / 03$ & 1000 & 3 & -0.02 & $6.15 \mathrm{e}-03$ & 1.94 & 52 & 13 & 73 & 8 & 13 \\
\hline $29 / 04$ & 1000 & 25 & 0.34 & $2.69 \mathrm{e}-02$ & 6.39 & 47 & 6 & 66 & 1 & 0 \\
\hline $30 / 05$ & 500 & 10 & 0.08 & $8.58 \mathrm{e}-03$ & 2.76 & 50 & 10 & 71 & 7 & 10 \\
\hline $31 / 01$ & 300 & 32 & -0.03 & $1.12 \mathrm{e}-04$ & 0.63 & 52 & 28 & 45 & 7 & 4 \\
\hline $32 / 02$ & 297 & 19 & 0.02 & $8.32 \mathrm{e}-05$ & 0.87 & 2 & 1 & 48 & 20 & 26 \\
\hline $33 / 03$ & 1000 & 15 & -0.03 & $1.18 \mathrm{e}-05$ & 0.95 & 58 & 10 & 50 & 28 & 47 \\
\hline $34 / 04$ & 500 & 36 & -0.03 & $6.41 \mathrm{e}-04$ & 3.32 & 52 & 7 & 38 & 17 & 42 \\
\hline $35 / 05$ & 500 & 28 & 0.27 & $1.11 \mathrm{e}-04$ & 2.04 & 55 & 9 & 42 & 26 & 40 \\
\hline $36 / 01$ & 50 & 60 & -0.09 & $3.05 \mathrm{e}-03$ & 0.58 & 46 & 29 & 34 & 2 & 1 \\
\hline $37 / 02$ & 2000 & 29 & -0.01 & $4.33 \mathrm{e}-04$ & 1.17 & 59 & 17 & 48 & 16 & 23 \\
\hline $38 / 03$ & 1000 & 16 & 0.12 & $3.52 \mathrm{e}-05$ & 1.08 & 62 & 10 & 47 & 33 & 47 \\
\hline $39 / 04$ & 500 & 38 & -0.07 & $1.37 \mathrm{e}-03$ & 3.57 & 57 & 7 & 42 & 21 & 42 \\
\hline $40 / 05$ & 1000 & 34 & 0.35 & $1.10 \mathrm{e}-03$ & 2.92 & 58 & 9 & 46 & 24 & 41 \\
\hline $41 / \mathbf{0 1}$ & 20 & 99 & 0.52 & $3.13 \mathrm{e}-03$ & 0.43 & 32 & 29 & 8 & 0 & 0 \\
\hline $42 / \mathbf{0 2}$ & & 288 & 90.21 & $1.00 \mathrm{e}-01$ & 11.71 & 31 & 17 & 31 & 0 & 0 \\
\hline $43 / \mathbf{0 3}$ & 1000 & 26 & 0.01 & $3.35 \mathrm{e}-03$ & 1.99 & 68 & 11 & 49 & 33 & 54 \\
\hline $44 / 04$ & 500 & 38 & 0.23 & $5.52 \mathrm{e}-03$ & 3.75 & 67 & 8 & 51 & 44 & 54 \\
\hline $45 / 05$ & 35 & 83 & 32.64 & $1.05 \mathrm{e}-01$ & 30.36 & 66 & 10 & 89 & 19 & 16 \\
\hline D & 2000 & 56 & 0.19 & $5.31 \mathrm{e}-03$ & 8.97 & 44 & 10 & 46 & 39 & 45 \\
\hline
\end{tabular}

${ }^{a}$ ID: The colored numbers correspond to those in Figure 2.

${ }^{b}$ Temp: Surface temperature in Celsius.

${ }^{c}$ Balance: These numbers come from 50 year averages unless the Runtime (Column 2) is less than 150 years,

then the average is 10 years.

${ }^{d}$ Specific humidity in top layer of the atmosphere.

${ }^{e}$ Surface humidity as percentage of atmosphere.

\section{Appendix A Energy balance and temperature}

Different simulations reach radiative balance sooner than others, while some never reach it at all. Herein we plot the energy balance (in units of $\mathrm{W} \mathrm{m}^{-2}$ ) and surface temperature (in Celsius) as a function of simulation year. This should allow the reader to have a better grasp of which simulations are appropriate for a given interest. 

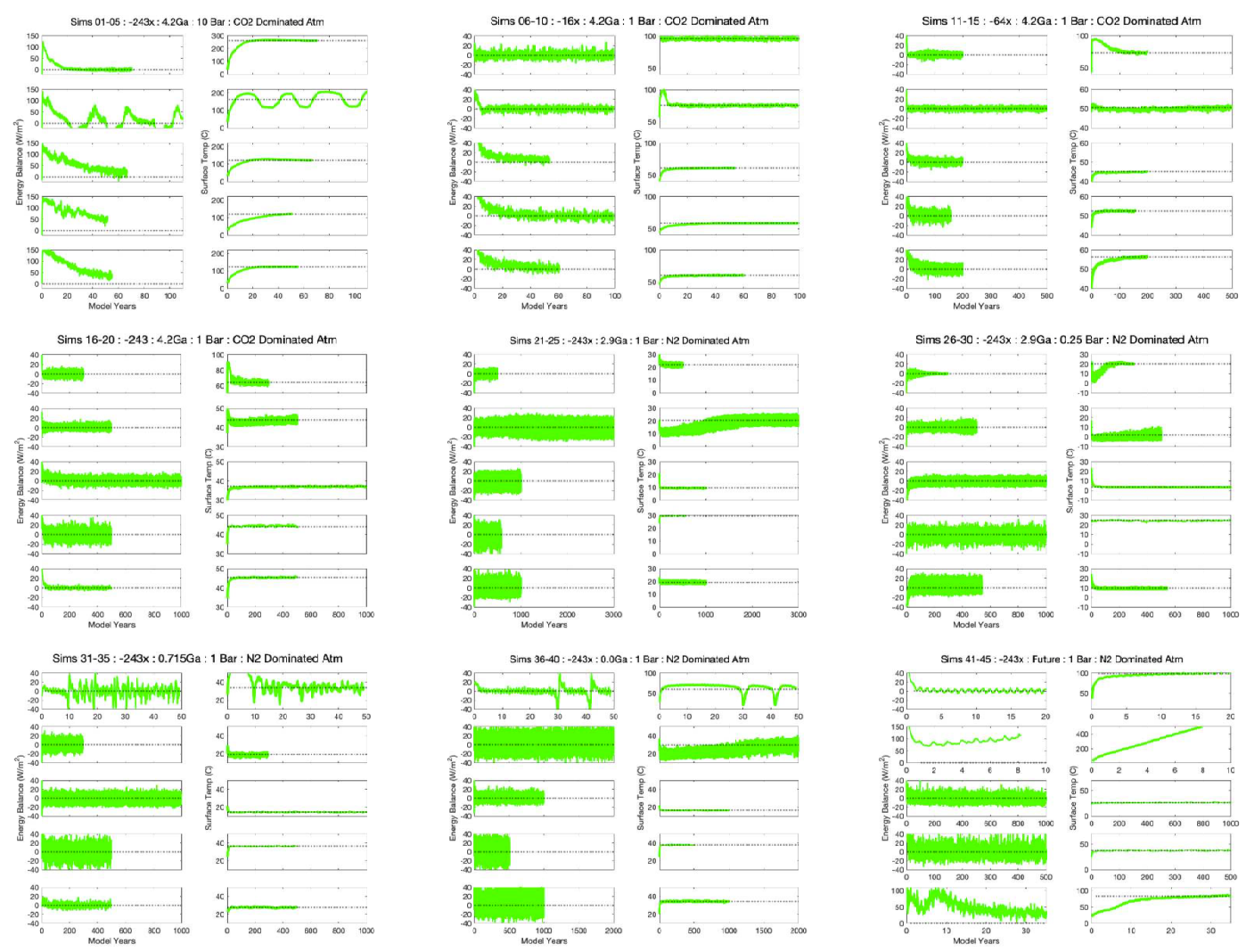

Figure A1. Energy Balance (also called Net Radiative Balance) in the left columns and surface temperature in the right columns as a function of simulation year for all simulations in this study. Note that not all limits on the $\mathrm{x}$ or $\mathrm{y}$ axes are the same.

\section{Acknowledgments}

This work was supported by the NASA Astrobiology Program through collaborations arising from our participation in the Nexus for Exoplanet System Science (NExSS). Resources supporting this work were provided by the NASA High-End Computing (HEC) Program through the NASA Center for Climate Simulation (NCCS) at Goddard Space Flight Center. MJW acknowledges support from the GSFC Sellers Exoplanet Environments Collaboration (SEEC), which is funded by the NASA Planetary Science Divisions Internal Scientist Funding Model. Thanks goes to Rory Barnes for his help with his eqTide program and Eric Wolf for his discussions involving HITRAN and HITEMP. Thanks also to Wade Henning, Tony Dobrovolskis, and Kevin Zahnle for their thoughts on spin evolution. This paper also benefited from useful discussions with Mareike Godolt, Lena Noack, Richard Ernst, Linda Sohl, Matthew Weller, Christine Houser, Kostas Tsigaridis, Igor Aleinov, and Glyn Collinson. This paper also benefited greatly from the detailed comments of three referees: Jim Kasting, David Grinspoon and Cedric Gillmann. All NetCDF data used in this publication can be downloaded from the Zenodo open access data portal:

http://doi.org/10.5281/zenodo.3707251

\section{References}

Abe, Y., Abe-Ouchi, A., Sleep, N. H., \& Zahnle, K. J. (2011, June). Habitable Zone Limits for Dry Planets. Astrobiology, 11, 443-460. doi: 10.1089/ast.2010.0545 
Airapetian, V. S., Glocer, A., Khazanov, G. V., Loyd, R. O. P., France, K., Sojka, J., .. Liemohn, M. W. (2017, Feb). How Hospitable Are Space Weather Affected Habitable Zones? The Role of Ion Escape. Astrophysical Journal Letters, 836(1), L3. doi: 10.3847/2041-8213/836/1/L3

Airey, M. W., Mather, T. A., Pyle, D. M., \& Ghail, R. C. (2017). The distribution of volcanism in the beta-atla-themis region of venus: Its relationship to rifting and implications for global tectonic regimes. Journal of Geophysical Research: Planets, 122(8), 1626-1649. Retrieved from https:// agupubs.onlinelibrary.wiley.com/doi/abs/10.1002/2016JE005205 doi: 10.1002/2016JE005205

Albarède, F. (2009, October). Volatile accretion history of the terrestrial planets and dynamic implications. Nature, 461, 1227-1233. doi: 10.1038/nature08477

Alemi, A., \& Stevenson, D. (2006, Sep). Why Venus has No Moon. In Aas/division for planetary sciences meeting abstracts \#38 (p. 07.03).

Alfvn, H. (1964). On the formation of celestial bodies. Icarus, 3(1), $57-62$. Retrieved from http://www.sciencedirect.com/science/article/pii/ 0019103564900314 doi: https://doi.org/10.1016/0019-1035(64)90031-4

Altwegg, K., Balsiger, H., Bar-Nun, A., Berthelier, J. J., Bieler, A., Bochsler, P., ... Wurz, P. (2015). 67p/churyumov-gerasimenko, a jupiter family comet with a high d/h ratio. Science, 347(6220). Retrieved from https://science.sciencemag.org/content/347/6220/1261952 doi: $10.1126 /$ science. 1261952

Arndt, N. T., \& Nisbet, E. G. (2012). Processes on the young earth and the habitats of early life. Annual Review of Earth and Planetary Sciences, 40(1), 521-549. Retrieved from https://doi.org/10.1146/annurev-earth-042711-105316 doi: 10.1146/annurev-earth-042711-105316

Avice, G., Marty, B., Burgess, R., Hofmann, A., Philippot, P., Zahnle, K., \& Zakharov, D. (2018, July). Evolution of atmospheric xenon and other noble gases inferred from Archean to Paleoproterozoic rocks. Geochim. Cosmochim. Acta, 232, 82-100. doi: 10.1016/j.gca.2018.04.018

Baines, K. H., Atreya, S. K., Bullock, M. A., Grinspoon, D. H., Mahaffy, P., Russell, C. T., ... Zahnle, K. (2013). The Atmospheres of the Terrestrial Planets: Clues to the Origins and Early Evolution of Venus, Earth, and Mars. In Comparative climatology of terrestrial planets, stephen j. mackwell, amy a. simon-miller, jerald w. harder, and mark a. bullock (eds.), university of arizona press, tucson, 610 pp., p.137-160 (p. 137). University of Arizona Press, Tucson. doi: 10.2458/azu_uapress_9780816530595-ch006

Ballentine, C. $(2007,10)$. Geochemistry: Earth holds its breath. Nature, 449, 294-6. doi: $10.1038 / 449294 a$

Barnes, J. W., Quarles, B., Lissauer, J. J., Chambers, J., \& Hedman, M. M. $\quad$ (2016, July). Obliquity Variability of a Potentially Habitable Early Venus. Astrobiology, 16, 487-499. doi: 10.1089/ast.2015.1427

Barnes, R. (2017, December). Tidal locking of habitable exoplanets. Celestial Mechanics and Dynamical Astronomy, 129, 509-536. doi: 10.1007/s10569-017 -9783-7

Barnes, R., Luger, R., Deitrick, R., Driscoll, P., Quinn, T. R., Fleming, D. P., ... Armstrong, J. (2019, May). VPLanet: The Virtual Planet Simulator. arXiv e-prints, arXiv:1905.06367.

Basilevsky, A. T., \& Head, J. W. (1996). Evidence for rapid and widespread emplacement of volcanic plains on Venus: Stratigraphic studies in the

Baltis Vallis Region. Geophysical Research Letters, 23, 1497-1500. doi: 10.1029/96GL00975

Basilevsky, A. T., \& Head, J. W. (1998, April). The geologic history of Venus: A stratigraphic view. Journal of Geophysical Research, 103, 8531-8544. doi: 10 $.1029 / 98 \mathrm{JE} 00487$ 
Basilevsky, A. T., Head, J. W., Schaber, G. G., \& Strom, R. G. (1997). The Resurfacing History of Venus. In S. W. Bougher, D. M. Hunten, \& R. J. Phillips (Eds.), Venus ii: Geology, geophysics, atmosphere, and solar wind environment (p. 1047).

Bierson, C. J., Phillips, R. J., Smith, I. B., Wood, S. E., Putzig, N. E., Nunes, D., \& Byrne, S. (2016). Stratigraphy and evolution of the buried co2 deposit in the martian south polar cap. Geophysical Research Letters, 43(9), 4172 4179. Retrieved from https://agupubs.onlinelibrary.wiley.com/doi/abs/ 10.1002/2016GL068457 doi: 10.1002/2016GL068457

Bindschadler, D. L., Schubert, G., \& Kaula, W. M. （1992). Coldspots and hotspots: Global tectonics and mantle dynamics of venus. Journal of Geophysical Research: Planets, 97(E8), 13495-13532. Retrieved from https : //agupubs . onlinelibrary.wiley.com/doi/abs/10.1029/92JE01165 doi: 10.1029/92JE01165

Bjonnes, E. E., Hansen, V. L., James, B., \& Swenson, J. B. $\quad$ (2012, February). Equilibrium resurfacing of Venus: Results from new Monte Carlo modeling and implications for Venus surface histories. Icarus, 217, 451-461. doi: 10.1016/j.icarus.2011.03.033

Bjoraker, G. L., Larson, H. P., Mumma, M. J., Timmermann, R., \& Montani, J. L. (1992, Jun). Airborne Observations of the Gas Composition of Venus Above the Cloud Tops: Measurements of $\mathrm{H}_{2} \mathrm{O}, \mathrm{HDO}, \mathrm{HF}$, and the $\mathrm{D} / \mathrm{H}$ and ${ }^{18} \mathrm{O} /{ }^{16} \mathrm{O}$ Isotopic Ratios. In Aas/division for planetary sciences meeting abstracts \#24 (Vol. 24, p. 30.04).

Boehnke, P., \& Harrison, T. M. (2016). Illusory late heavy bombardments. Proceedings of the National Academy of Sciences, 113(39), 10802-10806.

Retrieved from https://www.pnas.org/content/113/39/10802 doi: 10.1073/pnas.1611535113

Bottke, W. F., Vokrouhlicky, D., Ghent, B., Mazrouei, S., Robbins, S., \& Marchi, S. (2016, Mar). On Asteroid Impacts, Crater Scaling Laws, and a Proposed Younger Surface Age for Venus. In Lunar and planetary science conference (p. 2036).

Bower, Dan J., Kitzmann, Daniel, Wolf, Aaron S., Sanan, Patrick, Dorn, Caroline, \& Oza, Apurva V. (2019). Linking the evolution of terrestrial interiors and an early outgassed atmosphere to astrophysical observations. Astronomy and Astrophysics, 631, A103. Retrieved from https://doi.org/10.1051/ 0004-6361/201935710 doi: 10.1051/0004-6361/201935710

Brack, A., Horneck, G., Cockell, C. S., Bérces, A., Belisheva, N. K., Eiroa, C., .. . White, G. J. (2010, January). Origin and Evolution of Life on Terrestrial Planets. Astrobiology, 10, 69-76. doi: 10.1089/ast.2009.0374

Brasser, R., Mojzsis, S., Werner, S., Matsumura, S., \& Ida, S. (2016). Late veneer and late accretion to the terrestrial planets. Earth and Planetary Science Letters, 455, 85 - 93. Retrieved from http://www.sciencedirect.com/science/ article/pii/S0012821X16304939 doi: https://doi.org/10.1016/j.epsl.2016.09 .013

Bullock, M. A., \& Grinspoon, D. H. (1999, Mar). Global climate change on Venus. Scientific American, 280(3), 34-41.

Bullock, M. A., \& Grinspoon, D. H. (2001, March). The Recent Evolution of Climate on Venus. Icarus, 150, 19-37. doi: 10.1006/icar.2000.6570

Bullock, M. A., Grinspoon, D. H., \& Head III, J. W. (1993). Venus resurfacing rates: Constraints provided by 3 -d monte carlo simulations. Geophysical Research Letters, 20(19), 2147-2150. Retrieved from https:// agupubs.onlinelibrary.wiley.com/doi/abs/10.1029/93GL02505 doi: 10.1029/93GL02505

Burns, J. A. (1973, Mar). Where are the Satellites of the Inner Planets? Nature Physical Science, 242(115), 23-25. doi: 10.1038/physci242023a0 
Byrne, S. (2009). The polar deposits of mars. Annual Review of Earth and Planetary Sciences, 37(1), 535-560. Retrieved from https://doi.org/10.1146/annurev .earth.031208.100101 doi: 10.1146/annurev.earth.031208.100101

Caldeira, K., \& Rampino, M. R. (1991). The mid-cretaceous super plume, carbon dioxide, and global warming. Geophys. Res. Lett., 18(6), 987-990. doi: 10 .1029/91GL01237

Campbell, I. H., \& Taylor, S. R. (1983, November). No water, no granites-no oceans, no continents. Geophysical Research Letters, 10, 1061-1064. doi: 10.1029/ GL010i011p01061

Canup, R. M. (2004). Simulations of a late lunar-forming impact. Icarus, 168(2), 433 - 456. Retrieved from http://www.sciencedirect.com/ science/article/pii/S0019103503002999 doi: https://doi.org/10.1016/ j.icarus.2003.09.028

Catling, D., \& Kasting, J. (2017). Atmospheric evolution on inhabited and lifeless worlds. Cambridge University Press. Retrieved from https://books.google . se/books?id=dchoDgAAQBAJ

Chapman, S., \& Lindzen, R. (1970). Atmospheric tides: Thermal and gravitational. Gordon and Breach. Retrieved from https://books.google.com/books?id= 9kSR JaL J9EEC

Charnay, B., Forget, F., Wordsworth, R., Leconte, J., Millour, E., Codron, F., \& Spiga, A. (2013, September). Exploring the faint young Sun problem and the possible climates of the Archean Earth with a 3-D GCM. Journal of Geophysical Research (Atmospheres), 118(17), 10. doi: 10.1002/jgrd.50808

Charnay, B., Le Hir, G., Fluteau, F., Forget, F., \& Catling, D. C. ～(2017, September). A warm or a cold early Earth? New insights from a 3-D climatecarbon model. $\quad$ Earth and Planetary Science Letters, 474, 97-109. doi: 10.1016/j.epsl.2017.06.029

Charnley, S. B., \& Rodgers, S. D. (2009, March). Clouds, Clumps, Cores, and Comets - a Cosmic Chemical Connection? Advances in Geosciences, Volume 15: Planetary Science (PS), 15, 211-228. doi: 10.1142/9789812836229_0014

Chassefière, E. (1996, December). Hydrodynamic Escape of Oxygen from Primitive Atmospheres: Applications to the Cases of Venus and Mars. Icarus, 124(2), 537-552. doi: 10.1006/icar.1996.0229

Chassefière, E. (1997, March). NOTE: Loss of Water on the Young Venus: The Effect of a Strong Primitive Solar Wind. Icarus, 126, 229-232. doi: 10.1006/icar .1997 .5677

Chassefière, E., Wieler, R., Marty, B., \& Leblanc, F. (2012, April). The evolution of Venus: Present state of knowledge and future exploration. Planetary Space Science, 63, 15-23. doi: 10.1016/j.pss.2011.04.007

Chen, H., Wolf, E. T., Zhan, Z., \& Horton, D. E. $\quad$ (2019, Jul). Habitability and Spectroscopic Observability of Warm M-dwarf Exoplanets Evaluated with a 3D Chemistry-Climate Model. arXiv e-prints, arXiv:1907.10048.

Claire, M. W., Sheets, J., Cohen, M., Ribas, I., Meadows, V. S., \& Catling, D. C. (2012, September). The Evolution of Solar Flux from $0.1 \mathrm{~nm}$ to $160 \mu \mathrm{m}$ : Quantitative Estimates for Planetary Studies. Astrophysical Journal, 757, 95. doi: 10.1088/0004-637X/757/1/95

Clement, M. S., Morbidelli, A., Raymond, S. N., \& Kaib, N. A. (2019, 12). A record of the final phase of giant planet migration fossilized in the asteroid belts orbital structure. Monthly Notices of the Royal Astronomical Society: Letters, 492(1), L56-L60. Retrieved from https://doi.org/10.1093/mnrasl/slz184 doi: $10.1093 / \mathrm{mnrasl} / \mathrm{slz} 184$

Cockell, C. S. (1999, December). Life on Venus. Planetary Space Science, 47, 14871501. doi: 10.1016/S0032-0633(99)00036-7

Correia, A. C. M., \& Laskar, J. (2001, June). The four final rotation states of Venus. Nature, 411, 767-770. doi: 10.1038/35081000 
Correia, A. C. M., \& Laskar, J. (2003, May). Long-term evolution of the spin of Venus. II. numerical simulations. Icarus, 163, 24-45. doi: 10.1016/ S0019-1035(03)00043-5

Correia, A. C. M., Laskar, J., \& de Surgy, O. N. (2003, May). Long-term evolution of the spin of Venus. I. theory. Icarus, 163, 1-23. doi: 10.1016/S0019-1035(03) 00042-3

Counselman, I., Charles C. (1973, Feb). Outcomes of Tidal Evolution. Astrophysical Journal, 180, 307-316. doi: 10.1086/151964

Cox, G. M., Halverson, G. P., Stevenson, R. K., Vokaty, M., Poirier, A., Kunzmann, M., ... Macdonald, F. A. (2016). Continental flood basalt weathering as a trigger for neoproterozoic snowball earth. Earth and Planetary Science Letters, 446, 89 - 99. Retrieved from http://www.sciencedirect.com/ science/article/pii/S0012821X16301728 doi: https://doi.org/10.1016/ j.epsl.2016.04.016

Cutts, J. A., \& Lewis, B. H. (1982, June). Models of climate cycles recorded in Martian polar layered deposits. Icarus, 50, 216-244. doi: 10.1016/0019-1035(82) 90124-5

Dartnell, L. R., Nordheim, T. A., Patel, M. R., Mason, J. P., Coates, A. J., \& Jones, G. H. (2015). Constraints on a potential aerial biosphere on venus: I. cosmic rays. Icarus, 257, 396 - 405. Retrieved from http:// wWw.sciencedirect.com/science/article/pii/S0019103515002080 doi: https://doi.org/10.1016/j.icarus.2015.05.006

Dauphas, N. (2017, 01). The isotopic nature of the earths accreting material through time. Nature, 541, 521-524. doi: 10.1038/nature20830

Davaille, A., Smrekar, S., \& Tomlinson, S. $\quad$ (2017, 04). Experimental and observational evidence for plume-induced subduction on venus. Nature Geoscience, 10, 1. doi: 10.1038/ngeo2928

Davies, J. H. (2008). Did a mega-collision dry venus' interior? Earth and Planetary Science Letters, 268(3), 376 - 383. Retrieved from http:// www.sciencedirect.com/science/article/pii/S0012821X08000526 doi: https://doi.org/10.1016/j.epsl.2008.01.031

De Bergh, C., Bézard, B., Owen, T., Crisp, D., Maillard, J.-P., \& Lutz, B. L. (1991). Deuterium on venus: Observations from earth. Science, 251(4993), 547-549. Retrieved from https://science.sciencemag.org/content/251/4993/547 doi: $10.1126 /$ science.251.4993.547

Dehant, V., Debaille, V., Dobos, V., Gaillard, F., Gillmann, C., Goderis, S., ... Wünnemann, K. (2019, Aug 20). Geoscience for understanding habitability in the solar system and beyond. Space Science Reviews, 215(6), 42. Retrieved from https://doi.org/10.1007/s11214-019-0608-8 doi: 10.1007/s11214-019-0608-8

Deitrick, R., Barnes, R., Quinn, T. R., Armstrong, J., Charnay, B., \& Wilhelm, C. $\quad(2018$, jan). Exo-milankovitch cycles. i. orbits and rotation states. The Astronomical Journal, 155(2), 60. Retrieved from https://doi.org/ 10.3847\\%2F1538-3881 $\% 2$ Faaa301 doi: 10.3847/1538-3881/aaa301

Del Genio, A. D., Kiang, N. Y., Way, M. J., Amundsen, D. S., Sohl, L. E., Fujii, Y., ... Kelley, M. (2019, oct). Albedos, equilibrium temperatures, and surface temperatures of habitable planets. Astrophysical Journal, $884(1), 75$. Retrieved from https://doi.org/10.3847 $\% 2$ F1538-4357 $\% 2$ Fab3be8 doi: 10.3847/1538-4357/ab3be8

Del Genio, A. D., Way, M. J., Amundsen, D. S., Aleinov, I., Kelley, M., nancy Y. Kiang, \& Clune, T. L. (2019, feb). Habitable climate scenarios for proxima centauri b with as dynamic ocean. Astrobiology, 19(2), 1-27. Retrieved from https://doi.org/10.1089/ast.2017/1760 doi: 10.1089/ast.2017.1760

de Sousa Ribeiro, R., Morbidelli, A., Raymond, S. N., Izidoro, A., Gomes, R., \& Neto, E. V. (2020). Dynamical evidence for an early giant planet instabil- 
ity. Icarus, 339, 113605. Retrieved from http://www.sciencedirect.com/ science/article/pii/S0019103519301332 doi: https://doi.org/10.1016/ j.icarus.2019.113605

Dickson, J. L., Head, J. W., Goudge, T. A., \& Barbieri, L. (2015). Recent climate cycles on mars: Stratigraphic relationships between multiple generations of gullies and the latitude dependent mantle. Icarus, 252, 83 - 94. Retrieved from http://www.sciencedirect.com/science/article/pii/S0019103515000056 doi: https://doi.org/10.1016/j.icarus.2014.12.035

Dobrovolskis, A. R. (1980, January). Atmospheric tides and the rotation of Venus. II - Spin evolution. Icarus, 41, 18-35. doi: 10.1016/0019-1035(80)90157-8

Dobrovolskis, A. R. (1983, October). Atmospheric tides on Venus. III - The planetary boundary layer. Icarus, 56, 165-175. doi: 10.1016/0019-1035(83)90133-1

Dobrovolskis, A. R., \& Ingersoll, A. P. (1980, January). Atmospheric tides and the rotation of Venus. I - Tidal theory and the balance of torques. Icarus, 41, 117. doi: 10.1016/0019-1035(80)90156-6

Donahue, T. M. (1999, Oct). New Analysis of Hydrogen and Deuterium Escape from Venus. Icarus, 141(2), 226-235. doi: 10.1006/icar.1999.6186

Donahue, T. M., Grinspoon, D. H., Hartle, R. E., \& Hodges, R. R., Jr. (1997). Ion/neutral Escape of Hydrogen and Deuterium: Evolution of Water. In S. W. Bougher, D. M. Hunten, \& R. J. Phillips (Eds.), Venus ii: Geology, geophysics, atmosphere, and solar wind environment (p. 385).

Donahue, T. M., Hoffman, J. H., Hodges, R. R., \& Watson, A. J. (1982, May). Venus was wet - A measurement of the ratio of deuterium to hydrogen. Science, 216, 630-633. doi: 10.1126/science.216.4546.630

Donahue, T. M., \& Pollack, J. B. (1983). Origin and evolution of the atmosphere of Venus. In In: Venus (a83-37401 17-91). tucson, az, university of arizona press, 1983, p. 1003-1036. nasa-supported research. (p. 1003-1036). University of Arizona Press.

Donahue, T. M., \& Russell, C. T. (1997, Jan). The Venus Atmosphere and Ionosphere and Their Interaction with the Solar Wind: an Overview. In S. W. Bougher, D. M. Hunten, \& R. J. Phillips (Eds.), Venus ii: Geology, geophysics, atmosphere, and solar wind environment (p. 3).

Dones, L., \& Tremaine, S. (1993, May). On the Origin of Planetary Spins. Icarus, 103(1), 67-92. doi: 10.1006/icar.1993.1059

Dumoulin, C., Tobie, G., Verhoeven, O., Rosenblatt, P., \& Rambaux, N. $\quad$ (2017). Tidal constraints on the interior of venus. Journal of Geophysical Research: Planets, 122(6), 1338-1352. Retrieved from https://agupubs.onlinelibrary .wiley.com/doi/abs/10.1002/2016JE005249 doi: 10.1002/2016JE005249

Efroimsky, M., \& Makarov, V. V. (2013, February). Tidal Friction and Tidal Lagging. Applicability Limitations of a Popular Formula for the Tidal Torque. Astrophysical Journal, 764, 26. doi: 10.1088/0004-637X/764/1/26

Efroimsky, M., \& Williams, J. G. (2009, July). Tidal torques: a critical review of some techniques. Celestial Mechanics and Dynamical Astronomy, 104, 257289. doi: 10.1007/s10569-009-9204-7

Ernst, R. E. (2014). Large igneous provinces. Cambridge University Press. doi: 10 .1017/CBO9781139025300

Ernst, R. E., Bond, D. P. G., Zhang, S., Buchan, K. L., Grasby, S. E., Youbi, N., ... Bekker, A. (2019). LIP record through time and implications for secular environmental changes and GTS boundaries. AGU Books.

Ernst, R. E., Buchan, K. L., Jowitt, S. M., \& Youbi, N. (2017, March). Applying the Terrestrial Large Igneous Provinces (LIPs) Context to Large-Scale Magmatism on Other Planetary Bodies. In Lunar and planetary science conference (Vol. 48, p. 1373).

Ernst, R. E., \& Youbi, N. (2017). How large igneous provinces affect global climate, sometimes cause mass extinctions, and represent natural markers in 
the geological record. Palaeogeography, Palaeoclimatology, Palaeoecology, 478, 30 - 52. Retrieved from http://www.sciencedirect.com/science/ article/pii/S0031018217302857 (Mass Extinction Causality: Records of Anoxia, Acidification, and Global Warming during Earth's Greatest Crises) doi: https://doi.org/10.1016/j.palaeo.2017.03.014

Fedorova, A., Korablev, O., Vandaele, A.-C., Bertaux, J.-L., Belyaev, D., Mahieux, A., ... Villard, E. (2008). Hdo and h2o vertical distributions and isotopic ratio in the venus mesosphere by solar occultation at infrared spectrometer on board venus express. Journal of Geophysical Research: Planets, 113(E5). Retrieved from https://agupubs.onlinelibrary.wiley.com/doi/abs/ 10.1029/2008JE003146 doi: 10.1029/2008JE003146

Feulner, G. (2012, May). The faint young Sun problem. Reviews of Geophysics, 50, RG2006. doi: 10.1029/2011RG000375

Fischer-Gödde, M., \& Kleine, T. (2017, January). Ruthenium isotopic evidence for an inner Solar System origin of the late veneer. Nature, 541, 525-527. doi: 10 $.1038 /$ nature 21045

Foley, B. J., \& Smye, A. J. (2018, Jul). Carbon Cycling and Habitability of EarthSized Stagnant Lid Planets. Astrobiology, 18(7), 873-896. doi: 10.1089/ast .2017 .1695

French, B. M., \& Singer, S. F. (1971, Jul). How Did Venus Lose Its Angular Momentum? Science, 173(3992), 169-170. doi: 10.1126/science.173.3992.169

Gaillard, F., \& Scaillet, B. (2014, Oct). A theoretical framework for volcanic degassing chemistry in a comparative planetology perspective and implications for planetary atmospheres. Earth and Planetary Science Letters, 403, 307-316. doi: $10.1016 /$ j.epsl.2014.07.009

Ganino, C., \& Arndt, N. T. (2009, 04). Climate changes caused by degassing of sediments during the emplacement of large igneous provinces. Geology, 37(4), 323326. Retrieved from https://doi.org/10.1130/G25325A.1 doi: 10.1130/ G25325A.1

Genda, H. (2016). Origin of earths oceans: An assessment of the total amount, history and supply of water. GEOCHEMICAL JOURNAL, 50(1), 27-42. doi: 10 .2343 /geochemj.2.0398

Genda, H., \& Abe, Y. (2005, February). Enhanced atmospheric loss on protoplanets at the giant impact phase in the presence of oceans. Nature, 433, 842-844. doi: 10.1038 /nature03360

Gillmann, C., Chassefière, E., \& Lognonné, P. （2009, September). A consistent picture of early hydrodynamic escape of Venus atmosphere explaining present Ne and Ar isotopic ratios and low oxygen atmospheric content. Earth and Planetary Science Letters, 286, 503-513. doi: 10.1016/j.epsl.2009.07.016

Gillmann, C., Golabek, G., Raymond, S., Tackley, P., Schoenbaechler, M., Dehant, V., \& Debaille, V. (2019, April). The Volatile History of Venus: from Late Veneer to Present-Day. In Egu general assembly conference abstracts (Vol. 21, p. 2308).

Gillmann, C., Golabek, G. J., \& Tackley, P. J. (2016). Effect of a single large impact on the coupled atmosphere-interior evolution of venus. Icarus, 268, 295 312. Retrieved from http://www.sciencedirect.com/science/article/pii/ S0019103515005795 doi: https://doi.org/10.1016/j.icarus.2015.12.024

Gillmann, C., \& Tackley, P. (2014). Atmosphere/mantle coupling and feedbacks on venus. Journal of Geophysical Research: Planets, 119(6), 1189-1217. Retrieved from https://agupubs.onlinelibrary.wiley.com/doi/abs/ 10.1002/2013JE004505 doi: 10.1002/2013JE004505

Gilmore, M., Treiman, A., Helbert, J., \& Smrekar, S. (2017, Nov 01). Venus surface composition constrained by observation and experiment. Space Science Reviews, 212(3), 1511-1540. Retrieved from https://doi.org/10.1007/ s11214-017-0370-8 doi: 10.1007/s11214-017-0370-8 
Gilmore, M. S., Ivanov, M. A., Head III, J. W., \& Basilevsky, A. T. (1997). Duration of tessera deformation on venus. Journal of Geophysical Research: Planets, 102(E6), 13357-13368. Retrieved from https://agupubs.onlinelibrary .wiley.com/doi/abs/10.1029/97JE00965 doi: 10.1029/97JE00965

Gilmore, M. S., Mueller, N., \& Helbert, J. (2015). Virtis emissivity of alpha regio, venus, with implications for tessera composition. Icarus, 254, 350 - 361 . Retrieved from http://www.sciencedirect.com/science/article/pii/ S0019103515001438 doi: https://doi.org/10.1016/j.icarus.2015.04.008

Goddris, Y., Donnadieu, Y., Ndlec, A., Dupr, B., Dessert, C., Grard, A., ... Franois, L. (2003). The sturtian snowball glaciation: fire and ice. Earth and Planetary Science Letters, 211(1), 1 - $12 . \quad$ Retrieved from http:// wWw.sciencedirect.com/science/article/pii/S0012821X03001973 doi: https://doi.org/10.1016/S0012-821X(03)00197-3

Godolt, M., Tosi, N., Stracke, B., Grenfell, J. L., Ruedas, T., Spohn, T., \& Rauer, H. (2019, May). The habitability of stagnant-lid Earths around dwarf stars. Astronomy and Astrophysics, 625, A12. doi: 10.1051/0004-6361/201834658

Gold, T., \& Soter, S. (1969, November). Atmospheric Tides and the Resonant Rotation of Venus. Icarus, 11, 356-366. doi: 10.1016/0019-1035(69)90068-2

Gold, T., \& Soter, S. (1979, January). Theory of the earth-synchronous rotation of Venus. Nature, 277, 280. doi: 10.1038/277280a0

Goldblatt, C., Claire, M. W., Lenton, T. M., Matthews, A. J., Watson, A. J., \& Zahnle, K. J. (2009, December). Nitrogen-enhanced greenhouse warming on early Earth. Nature Geoscience, 2, 891-896. doi: 10.1038/ngeo692

Goldblatt, C., Robinson, T. D., Zahnle, K. J., \& Crisp, D. (2013). Low simulated radiation limit for runaway greenhouse climates. Nature Geoscience, 6(8), 661.

Goldreich, P., \& Peale, S. J. (1966, March). Resonant Rotation for Venus? Nature, 209, 1117-1118. doi: 10.1038/2091117a0

Goldreich, P., \& Peale, S. J. (1970, April). The Obliquity of Venus. Astronomical Journal, 75, 273. doi: 10.1086/110975

Goldreich, P., \& Soter, S. (1966). Q in the Solar System. Icarus, 5, 375-389. doi: 10 .1016/0019-1035(66)90051-0

Goody, R. M., \& Walker, J. C. G. (1972). Atmospheres. Prentice-Hall.

Green, J. A. M., Way, M. J., \& Barnes, R. (2019, March). Consequences of Tidal Dissipation in a Putative Venusian Ocean. arXiv e-prints.

Greenberg, R. (2009, June). Frequency Dependence of Tidal q. Astrophysical Journal, 698, L42-L45. doi: 10.1088/0004-637X/698/1/L42

Greenwood, R. C., Barrat, J.-A., Miller, M. F., Anand, M., Dauphas, N., Franchi, I. A., ... Starkey, N. A. (2018). Oxygen isotopic evidence for accretion of earth's water before a high-energy moon-forming giant impact. Science Advances, 4(3). Retrieved from http://advances.sciencemag.org/content/4/ 3/eaao5928 doi: 10.1126/sciadv.aao5928

Grinspoon, D. (2008). Evolution of Venus: Current knowledge and future prospects. In 37th cospar scientific assembly (Vol. 37, p. 1087).

Grinspoon, D. H. (1987). Was venus wet? deuterium reconsidered. Science, 238(4834), 1702-1704. Retrieved from https://science.sciencemag.org/ content/238/4834/1702 doi: 10.1126/science.238.4834.1702

Grinspoon, D. H. (1993, Jun). Implications of the high D/H ratio for the sources of water in Venus' atmosphere. Nature, 363(6428), 428-431. doi: 10.1038/ $363428 \mathrm{a} 0$

Grinspoon, D. H. (1997). Venus revealed : a new look below the clouds of our mysterious twin planet. Addison-Wesley.

Grinspoon, D. H., \& Bullock, M. A. (2003, May). Did Venus Experience One Great Transition or Two? In Aas/division for planetary sciences meeting abstracts \#35 (Vol. 35, p. 1007).

Grinspoon, D. H., \& Bullock, M. A. (2007). Astrobiology and venus exploration. 
In Exploring venus as a terrestrial planet (p. 191-206). American Geophysical Union (AGU). Retrieved from https://agupubs.onlinelibrary.wiley.com/ doi/abs/10.1029/176GM12 doi: 10.1029/176GM12

Grove, T. L., Till, C. B., \& Krawczynski, M. J. (2012). The role of h2o in subduction zone magmatism. Annual Review of Earth and Planetary Sciences, 40(1), 413-439. Retrieved from https://doi.org/10.1146/annurev-earth-042711 -105310 doi: 10.1146/annurev-earth-042711-105310

Gunell, H., Maggiolo, Romain, Nilsson, Hans, Stenberg Wieser, Gabriella, Slapak, Rikard, Lindkvist, Jesper, ... De Keyser, Johan (2018). Why an intrinsic magnetic field does not protect a planet against atmospheric escape. $A \mathscr{E} A$, 614, L3. Retrieved from https://doi.org/10.1051/0004-6361/201832934 doi: 10.1051/0004-6361/201832934

Gurwell, M. A. (1995, Nov). Evolution of deuterium on Venus. Nature, 378(6552), 22-23. doi: 10.1038/378022b0

Gurwell, M. A., \& Yung, Y. L. (1993, Feb). Fractionation of hydrogen and deuterium on Venus due to collisional ejection. Planetary and Space Science, 41(2), 91-104. doi: 10.1016/0032-0633(93)90037-3

Haberle, R. M., Zahnle, K., Barlow, N. G., \& Steakley, K. E. (2019, Nov). Impact Degassing of $\mathrm{H}_{2}$ on Early Mars and its Effect on the Climate System. Geophysical Research Letters, 46(22), 13,355-13,362. doi: 10.1029/2019GL084733

Halliday, A. N. (2013). The origins of volatiles in the terrestrial planets. Geochimica et Cosmochimica Acta, 105, 146 - 171. Retrieved from http://www.sciencedirect.com/science/article/pii/S0016703712006680 doi: https://doi.org/10.1016/j.gca.2012.11.015

Hamano, K., Abe, Y., \& Genda, H. (2013, May). Emergence of two types of terrestrial planet on solidification of magma ocean. Nature, 497, 607-610. doi: 10 $.1038 /$ nature 12163

Hansen, V., \& López, I. (2010, 04). Venus records a rich early history. Geology, 38(4), 311-314. Retrieved from https://dx.doi.org/10.1130/G30587.1 doi: $10.1130 / \mathrm{G} 30587.1$

Hansen, V., \& Young, D. (2007, 01). Venus's evolution: A synthesis. In Convergent Margin Terranes and Associated Regions: A Tribute to W.G. Ernst (p. 255-

273). Geological Society of America. Retrieved from https://dx.doi.org/ 10.1130/2006.2419(13) doi: 10.1130/2006.2419(13)

Hansen, V. L. (2007). Lips on venus. Chemical Geology, 241(3), $354-374$. Retrieved from http://www.sciencedirect.com/science/article/pii/ S0009254107000745 (The Great Plume Debate: Testing the Plume Theory) doi: https://doi.org/10.1016/j.chemgeo.2007.01.020

Haqq-Misra, J. D., Domagal-Goldman, S. D., Kasting, P. J., \& Kasting, J. F. (2008, December). A Revised, Hazy Methane Greenhouse for the Archean Earth. Astrobiology, 8, 1127-1137. doi: 10.1089/ast.2007.0197

Harris, A. (1978). Satellite formation, ii. Icarus, 34(1), 128 - 145. Retrieved from http://www.sciencedirect.com/science/article/pii/001910357890132X doi: https://doi.org/10.1016/0019-1035(78)90132-X

Harrison, T. M. (2009). The hadean crust: Evidence from ¿4 ga zircons. Annual Review of Earth and Planetary Sciences, 37(1), 479-505. Retrieved from https://doi.org/10.1146/annurev.earth.031208.100151 doi: 10.1146/annurev.earth.031208.100151

Harrison, T. M., Bell, E. A., \& Boehnke, P. (2017, feb). Hadean zircon petrochronology. Reviews in Mineralogy and Geochemistry, 83(1), 329-363. Retrieved from https://doi.org/10.2138\\%2Frmg.2017.83.11 doi: 10.2138/rmg.2017 .83 .11

Hartle, R. E., Donahue, T. M., Grebowsky, J. M., \& Mayr, H. G. (1996). Hydrogen and deuterium in the thermosphere of venus: Solar cycle variations and escape. Journal of Geophysical Research: Planets, 101 (E2), 4525-4538. Retrieved from 
https: //agupubs.onlinelibrary.wiley.com/doi/abs/10.1029/95JE02978 doi: 10.1029/95JE02978

Hashimoto, G. L., Roos-Serote, M., Sugita, S., Gilmore, M. S., Kamp, L. W., Carlson, R. W., \& Baines, K. H. (2008, December). Felsic highland crust on Venus suggested by Galileo Near-Infrared Mapping Spectrometer data. Journal of Geophysical Research (Planets), 113, E00B24. doi: 10.1029/2008JE003134

Hays, J. D., Imbrie, J., \& Shackleton, N. J. (1976). Variations in the earth's orbit: Pacemaker of the ice ages. Science, 194(4270), 1121-1132. Retrieved from http://www.jstor.org/stable/1743620

Head, J. W., \& Basilevsky, A. T. (1998, January). Sequence of tectonic deformation in the history of Venus: Evidence from global stratigraphic relationships. Geology, 26, 35. doi: 10.1130/0091-7613(1998)026〈0035:SOTDIT $\rangle 2.3 . C O ; 2$

Head, J. W., Bruegge, R. W. V., \& Crumpler, L. S. (1990). Venus orogenic belt environments: Architecture and origin. Geophysical Research Letters, 17(9), 1337-1340. Retrieved from https://agupubs.onlinelibrary.wiley.com/ doi/abs/10.1029/GL017i009p01337 doi: 10.1029/GL017i009p01337

Head, J. W., Parmentier, E. M., \& Hess, P. C. (1992, Dec). Chemical Differentiation on One-Plate Planets: Predictions and Geologic Observations for Venus. In International colloquium on venus (Vol. 789, p. 45).

Head, J. W., III, \& Coffin, M. F. (1997). Large igneous provinces: A planetary perspective. Washington DC American Geophysical Union Geophysical Monograph Series, 100, 411-438. doi: 10.1029/GM100p0411

Henning, W. G., \& Hurford, T. (2014, July). Tidal Heating in Multilayered Terrestrial Exoplanets. Astrophysical Journal, 789, 30. doi: 10.1088/0004-637X/789/ $1 / 30$

Herrick, R. R. (1994, August). Resurfacing history of Venus. Geology, 22, 703. doi: 10.1130/0091-7613(1994)022〈0703:RHOV $\rangle 2.3 . \mathrm{CO} ; 2$

Hirschmann, M. M. (2012). Magma ocean influence on early atmosphere mass and composition. Earth and Planetary Science Letters, 341-344, 48 - 57. Retrieved from http://www.sciencedirect.com/science/article/pii/ S0012821X12002993 doi: https://doi.org/10.1016/j.epsl.2012.06.015

Höning, D., Tosi, N., \& Spohn, T. (2019, Jul). Carbon cycling and interior evolution of water-covered plate tectonics and stagnant-lid planets. Astronomy and Astrophysics, 627, A48. doi: 10.1051/0004-6361/201935091

Hoolst, T. V. (2015). 10.04 - rotation of the terrestrial planets. In G. Schubert (Ed.), Treatise on geophysics (second edition) (Second Edition ed., p. 121 -

151). Oxford: Elsevier. Retrieved from http://www.sciencedirect.com/ science/article/pii/B9780444538024001688 doi: https://doi.org/10.1016/ B978-0-444-53802-4.00168-8

Hopkins, M., Mark Harrison, T., \& E Manning, C. $\quad$ (2008, 12). $\quad$ Low heat flow inferred from ¿4 gyr zircons suggests hadean plate boundary interactions. Nature, 456, 493-6. doi: 10.1038/nature07465

Horner, J., Mousis, O., Petit, J.-M., \& Jones, B. (2009). Differences between the impact regimes of the terrestrial planets: Implications for primordial d:h ratios. Planetary and Space Science, 57(12), 1338 - 1345. Retrieved from http://www.sciencedirect.com/science/article/pii/S0032063309001639 doi: https://doi.org/10.1016/j.pss.2009.06.006

Hull, P. M., Bornemann, A., Penman, D. E., Henehan, M. J., Norris, R. D., Wilson, P. A., ... Zachos, J. C. (2020). On impact and volcanism across the cretaceous-paleogene boundary. Science, 367(6475), 266-272. Retrieved from https://science.sciencemag.org/content/367/6475/266 doi: $10.1126 /$ science.aay 5055

Ikoma, M., Elkins-Tanton, L., Hamano, K., \& Suckale, J. (2018, May 08). Water partitioning in planetary embryos and protoplanets with magma oceans. Space Science Reviews, 214(4), 76.

Retrieved from https://doi.org/10.1007/ 
s11214-018-0508-3 doi: 10.1007/s11214-018-0508-3

Imbrie, J., Boyle, E. A., Clemens, S. C., Duffy, A., Howard, W. R., Kukla, G., .. . Toggweiler, J. R. (1992). On the structure and origin of major glaciation cycles 1. linear responses to milankovitch forcing. Paleoceanography, 7(6), 701-738. Retrieved from https://agupubs.onlinelibrary.wiley.com/doi/ abs/10.1029/92PA02253 doi: 10.1029/92PA02253

Ingersoll, A. P. (1969, November). The Runaway Greenhouse: A History of Water on Venus. Journal of Atmospheric Sciences, 26, 1191-1198. doi: 10.1175/1520 -0469(1969)026〈1191:TRGAHO $>2.0 . \mathrm{CO} ; 2$

Ingersoll, A. P., \& Dobrovolskis, A. R. (1978, September). Venus' rotation and atmospheric tides. Nature, 275, 37. doi: 10.1038/275037a0

Irvine, W. M., Schloerb, F. P., Crovisier, J., Fegley, B., Jr., \& Mumma, M. J. (2000, May). Comets: a Link Between Interstellar and Nebular Chemistry. Protostars and Planets IV, 1159.

Ivanov, M. A., \& Basilevsky, A. T. (1993). Density and morphology of impact craters on tessera terrain, venus. Geophysical Research Letters, 20(23), 25792582. Retrieved from https://agupubs.onlinelibrary.wiley.com/doi/abs/ 10.1029/93GL02692 doi: 10.1029/93GL02692

Ivanov, M. A., \& Head, J. W. (2013, August). The history of volcanism on Venus. Planetary Space Science, 84, 66-92. doi: 10.1016/j.pss.2013.04.018

Ivanov, M. A., \& Head, J. W. (2015, August). The history of tectonism on Venus: A stratigraphic analysis. Planetary Space Science, 113, 10-32. doi: 10.1016/j.pss .2015 .03 .016

Jacobson, S. A., Rubie, D. C., Hernlund, J., Morbidelli, A., \& Nakajima, M. (2017). Formation, stratification, and mixing of the cores of earth and venus. Earth and Planetary Science Letters, 474, 375 - 386. Retrieved from http: //www.sciencedirect.com/science/article/pii/S0012821X17303333 doi: https://doi.org/10.1016/j.epsl.2017.06.023

Johnson, B., \& Goldblatt, C. (2015). The nitrogen budget of earth. Earth-Science Reviews, 148, 150 - 173. Retrieved from http://www.sciencedirect.com/ science/article/pii/S0012825215000896 doi: https://doi.org/10.1016/ j.earscirev.2015.05.006

Johnson, N. M., \& Fegley, B. $\quad$ (2000, July). Water on Venus: New Insights from Tremolite Decomposition. Icarus, 146, 301-306. doi: 10.1006/icar.2000.6392

Kane, S. R., Arney, G., \& Crisp, D. e. a. (2019, aug). Venus as a laboratory for exoplanet science. JGRE, 124, 2015-2028.

Kane, S. R., Kopparapu, R. K., \& Domagal-Goldman, S. D. (2014, sep). ON THE FREQUENCY OF POTENTIAL VENUS ANALOGS FROMKEPLERDATA. Astrophysical Journal, 794(1), L5. doi: 10.1088/2041-8205/794/1/15

Kary, D. M., \& Lissauer, J. J. (1995, Sep). Nebular gas drag and planetary accretion. II. Planet on an eccentric orbit. Icarus, 117(1), 1-24. doi: 10.1006/icar .1995 .1139

Kasting, J. (1993). Earth's early atmosphere. Science, 259(5097), 920-926. Retrieved from https://science.sciencemag.org/content/259/5097/920 doi: $10.1126 /$ science.11536547

Kasting, J. (2012). How to find a habitable planet. Princeton University Press. Retrieved from https://books.google.com/books?id=XHh1DwAAQBAJ

Kasting, J. F. (1988, June). Runaway and moist greenhouse atmospheres and the evolution of earth and Venus. Icarus, 74, 472-494. doi: 10.1016/0019-1035(88) 90116-9

Kasting, J. F. (2010, April). Early Earth: Faint young Sun redux. Nature, 464, 687689. doi: $10.1038 / 464687 \mathrm{a}$

Kasting, J. F., \& Ackerman, T. P. (1986, Dec). Climatic Consequences of Very High Carbon Dioxide Levels in the Earth's Early Atmosphere. Science, 234(4782), 1383-1385. doi: 10.1126/science.234.4782.1383 
Kasting, J. F., \& Pollack, J. B. (1983, Mar). Loss of water from Venus. I. Hydrodynamic escape of hydrogen. Icarus, 53(3), 479-508. doi: 10.1016/0019-1035(83) 90212-9

Kasting, J. F., Pollack, J. B., \& Ackerman, T. P. (1984, March). Response of earth's atmosphere to increases in solar flux and implications for loss of water from Venus. Icarus, 57, 335-355. doi: 10.1016/0019-1035(84)90122-2

Kasting, J. F., Whitmire, D. P., \& Reynolds, R. T. (1993). Habitable zones around main sequence stars. Icarus, 101(1), 108 - 128. Retrieved from http://www.sciencedirect.com/science/article/pii/S0019103583710109 doi: https://doi.org/10.1006/icar.1993.1010

Katyal, N., Nikolaou, A., Godolt, M., Grenfell, J. L., Tosi, N., Schreier, F., \& Rauer, H. (2019, Apr). Evolution and Spectral Response of a Steam Atmosphere for Early Earth with a Coupled Climate-Interior Model. Astrophysical Journal, 875(1), 31. doi: 10.3847/1538-4357/ab0d85

Kaula, W. M. (1999, May). Constraints on Venus Evolution from Radiogenic Argon. Icarus, 139, 32-39. doi: 10.1006/icar.1999.6082

Kienert, H., Feulner, G., \& Petoukhov, V. ～(2012, December). Faint young Sun problem more severe due to ice-albedo feedback and higher rotation rate of the early Earth. Geophysical Research Letters, 39, L23710. doi: 10.1029/2012GL054381

King, S. D. (2018). Venus resurfacing constrained by geoid and topography. Journal of Geophysical Research: Planets, 123(5), 1041-1060. Retrieved from https:// agupubs.onlinelibrary.wiley.com/doi/abs/10.1002/2017JE005475 doi: 10.1002/2017JE005475

Kodama, T., Genda, H., O'ishi, R., Abe-Ouchi, A., \& Abe, Y. (2019). Inner edge of habitable zones for earth-sized planets with various surface water distributions. Journal of Geophysical Research: Planets, 0(0). Retrieved from https:// agupubs.onlinelibrary.wiley.com/doi/abs/10.1029/2019JE006037 doi: 10.1029/2019JE006037

Konopliv, A. S., \& Yoder, C. F. (1996). Venusian k 2 tidal Love number from Magellan and PVO tracking data. Geophysical Research Letters, 23, 1857-1860. doi: 10.1029/96GL01589

Kopparapu, R. K., Ramirez, R., Kasting, J. F., Eymet, V., Robinson, T. D., Mahadevan, S., .. Deshpande, R. (2013, March). Habitable Zones around Main-sequence Stars: New Estimates. Astrophysical Journal, 765, 131. doi: 10.1088/0004-637X/765/2/131

Korenaga, J. (2013). Initiation and evolution of plate tectonics on earth: Theories and observations. Annual Review of Earth and Planetary Sciences, 41(1), 117-151. Retrieved from https://doi.org/10.1146/annurev-earth-050212 -124208 doi: 10.1146/annurev-earth-050212-124208

Korenaga, J. (2018). Crustal evolution and mantle dynamics through earth history. Philosophical Transactions of the Royal Society A: Mathematical, Physical and Engineering Sciences, 376(2132), 20170408. Retrieved from https:// royalsocietypublishing.org/doi/abs/10.1098/rsta.2017.0408 doi: 10 $.1098 /$ rsta.2017.0408

Krissansen-Totton, J., Arney, G. N., \& Catling, D. C. (2018, April). Constraining the climate and ocean $\mathrm{pH}$ of the early Earth with a geological carbon cycle model. Proceedings of the National Academy of Science, 115, 4105-4110. doi: 10.1073/pnas.1721296115

Kunze, M., Godolt, M., Langematz, U., Grenfell, J. L., Hamann-Reinus, A., \& Rauer, H. (2014, August). Investigating the early Earth faint young Sun problem with a general circulation model. Planetary Space Science, 98, 77-92. doi: 10.1016/j.pss.2013.09.011

Kuramoto, K., \& Matsui, T. (1996). Partitioning of h and c between the mantle and core during the core formation in the earth: Its implications for 
the atmospheric evolution and redox state of early mantle.

Journal of

Geophysical Research: Planets, 101 (E6), 14909-14932.

Retrieved from

https: //agupubs . onlinelibrary.wiley.com/doi/abs/10.1029/96JE00940

doi: 10.1029/96JE00940

Kusky, T. M., Windley, B. F., \& Polat, A. （2018, Dec 01). Geological evidence for the operation of plate tectonics throughout the archean: Records from archean paleo-plate boundaries. Journal of Earth Science, 29(6), 12911303. Retrieved from https://doi.org/10.1007/s12583-018-0999-6 doi: 10.1007/s12583-018-0999-6

Lago, B., \& Cazenave, A. (1979, October). Possible dynamical evolution of the rotation of Venus since formation. Moon and Planets, 21, 127-154. doi: 10.1007/ BF00897084

Lammer, H., Zerkle, A. L., Gebauer, S., Tosi, N., Noack, L., Scherf, M., .. . Nikolaou, A. (2018, May). Origin and evolution of the atmospheres of early Venus, Earth and Mars. Astronomy and Astrophysics Reviews, 26, 2. doi: 10.1007/s00159-018-0108-y

Larson, R. L. (1991, 06). Latest pulse of Earth: Evidence for a mid-Cretaceous superplume. Geology, 19(6), 547-550. Retrieved from https://dx.doi.org/ 10.1130/0091-7613(1991)019<0547:LPOEEF>2.3.C0;2 doi: $10.1130 /$ 0091-7613(1991)019〈0547:LPOEEF $\rangle 2.3 . \mathrm{CO} ; 2$

Laskar, J., Correia, A. C. M., Gastineau, M., Joutel, F., Levrard, B., \& Robutel, P. (2004, August). Long term evolution and chaotic diffusion of the insolation quantities of Mars. Icarus, 170, 343-364. doi: 10.1016/j.icarus.2004.04.005

Laskar, J., Levrard, B., \& Mustard, J. F. ～(2002, September). Orbital forcing of the martian polar layered deposits. $\quad$ Nature, 419, 375-377. doi: 10.1038/nature01066

Le Hir, G., Teitler, Y., Fluteau, F., Donnadieu, Y., \& Philippot, P. ～(2014, April). The faint young Sun problem revisited with a 3-D climate-carbon model - Part 1. Climate of the Past, 10, 697-713. doi: 10.5194/cp-10-697-2014

Lebrun, T., Massol, H., ChassefièRe, E., Davaille, A., Marcq, E., Sarda, P., ... Brandeis, G. (2013, June). Thermal evolution of an early magma ocean in interaction with the atmosphere. Journal of Geophysical Research (Planets), 118, 1155-1176. doi: 10.1002/jgre.20068

Leconte, J. (2018, March). Continuous reorientation of synchronous terrestrial planets due to mantle convection. Nature Geoscience, 11, 168-172. doi: 10.1038/ s41561-018-0071-2

Leconte, J., Forget, F., Charnay, B., Wordsworth, R., Selsis, F., Millour, E., \& Spiga, A. (2013, June). 3D climate modeling of close-in land planets: Circulation patterns, climate moist bistability, and habitability. Astronomy and Astrophysics, 554, A69. doi: 10.1051/0004-6361/201321042

Leconte, J., Wu, H., Menou, K., \& Murray, N. (2015, February). Asynchronous rotation of Earth-mass planets in the habitable zone of lower-mass stars. Science, 347, 632-635. doi: 10.1126/science.1258686

Lécuyer, C. (2014). Water and plate tectonics. In Water on earth (p. 113-154). John Wiley \& Sons, Ltd. Retrieved from https://onlinelibrary.wiley.com/doi/ abs/10.1002/9781118574928.ch4 doi: 10.1002/9781118574928.ch4

Lécuyer, C., Simon, L., \& Guyot, F. (2000). Comparison of carbon, nitrogen and water budgets on venus and the earth. Earth and Planetary Science Letters, 181(1), 33 - 40. Retrieved from http://www.sciencedirect.com/ science/article/pii/S0012821X00001953 doi: https://doi.org/10.1016/ S0012-821X(00)00195-3

Lenardic, A., Jellinek, A. M., Foley, B., O’Neill, C., \& Moore, W. B. (2016). Climatetectonic coupling: Variations in the mean, variations about the mean, and variations in mode. Journal of Geophysical Research: Planets, 121(10), 18311864. Retrieved from https://agupubs.onlinelibrary.wiley.com/doi/abs/ 
10.1002/2016 JE005089 doi: 10.1002/2016JE005089

Lenardic, A., Kaula, W. M., \& Bindschadler, D. L. (1991). The tectonic evolution of western ishtar terra, venus. Geophysical Research Letters, 18(12), 22092212. Retrieved from https://agupubs.onlinelibrary.wiley.com/doi/abs/ 10.1029/91GL02734 doi: 10.1029/91GL02734

Lenardic, A., Weller, M., Hink, T., \& Seales, J. (2019). Toward a boot strap hypothesis of plate tectonics: Feedbacks between plates, the asthenosphere, and the wavelength of mantle convection. Physics of the Earth and Planetary Interiors, 296, 106299. Retrieved from http://www.sciencedirect.com/ science/article/pii/S0031920118300888 doi: https://doi.org/10.1016/ j.pepi.2019.106299

Lichtenegger, H. I. M., Kislyakova, K. G., Odert, P., Erkaev, N. V., Lammer, H., Gröller, H., .. . Holmström, M. (2016, May). Solar XUV and ENA-driven water loss from early Venus' steam atmosphere. Journal of Geophysical Research (Space Physics), 121, 4718-4732. doi: 10.1002/2015JA022226

Limaye, S. S., Mogul, R., Smith, D. J., Ansari, A. H., Sowik, G. P., \& Vaishampayan, P. (2018). Venus' spectral signatures and the potential for life in the clouds. Astrobiology, 18(9), 1181-1198. Retrieved from https://doi.org/ 10.1089/ast.2017.1783 (PMID: 29600875) doi: 10.1089/ast.2017.1783

Lissauer, B. J. W., J. J., \& Chambers, J. E. (2011). Obliquity variations of a moonless earth. Icarus, 217, 77-87.

Lissauer, J. J., \& Kary, D. M. (1991, Nov). The origin of the systematic component of planetary rotation I. Planet on a circular orbit. Icarus, 94(1), 126-159. doi: 10.1016/0019-1035(91)90145-J

Liu, L.-g. (2004). The inception of the oceans and co2-atmosphere in the early history of the earth. Earth and Planetary Science Letters, 227(3), 179 - 184. Retrieved from http://www.sciencedirect.com/science/article/pii/ S0012821X04005345 doi: https://doi.org/10.1016/j.epsl.2004.09.006

Luger, R., \& Barnes, R. (2015). Extreme water loss and abiotic o2 buildup on planets throughout the habitable zones of m dwarfs. Astrobiology, 15(2), 119143. Retrieved from https://doi.org/10.1089/ast.2014.1231 (PMID: 25629240) doi: 10.1089/ast.2014.1231

Lpez, I., Oyarzun, R., Mrquez, A., Doblas-Reyes, F., \& Laurrieta, A. (1998, 10). Progressive build up of co2in the atmosphereof venus through multiple volcanic resurfacing events. Earth Moon and Planets, 81, 187-192. doi: 10.1023/A:1006369831384

Macdonald, F. A., \& Wordsworth, R. (2017). Initiation of snowball earth with volcanic sulfur aerosol emissions. Geophysical Research Letters, 44(4), 19381946. Retrieved from https://agupubs.onlinelibrary.wiley.com/doi/abs/ 10.1002/2016GL072335 doi: 10.1002/2016GL072335

MacDonald, G. J. F. $\quad$ (1962, July). On the Internal Constitution of the Inner Planets. Journal of Geophysical Research, 67, 2945-2974. doi: 10.1029/JZ067i007p02945

Mallik, A., Li, Y., \& Wiedenbeck, M. ～(2018, January). Nitrogen evolution within the Earth's atmosphere-mantle system assessed by recycling in subduction zones. $\quad$ Earth and Planetary Science Letters, 482, 556-566. doi: 10.1016/j.epsl.2017.11.045

Mann, A. (2018, jan). Bashing holes in the tale of earth's troubled youth. Nature, 553. doi: 10.1038/d41586-018-01074-6

Marcq, E. (2006). Prelude to the Venus Express mission : a study of the atmosphere using infrared spectral imaging. (Theses, Université Paris-Diderot - Paris VII). Retrieved from https://tel.archives-ouvertes.fr/tel-00126105

Marcq, E., Mills, F. P., Parkinson, C. D., \& Vandaele, A. C. $\quad$ (2017, Nov 30). Composition and chemistry of the neutral atmosphere of venus. Space Science Reviews, 214(1), 10. Retrieved from https://doi.org/10.1007/ 
s11214-017-0438-5 doi: 10.1007/s11214-017-0438-5

Marty, B., Altwegg, K., Balsiger, H., Bar-Nun, A., Bekaert, D. V., Berthelier, J.-J., ... Wurz, P. (2017). Xenon isotopes in $67 \mathrm{p} /$ churyumov-gerasimenko show that comets contributed to earth's atmosphere. Science, 356 (6342), 1069-1072. Retrieved from https://science.sciencemag.org/content/356/6342/1069 doi: 10.1126/science.aal3496

Marty, B., Zimmermann, L., Pujol, M., Burgess, R., \& Philippot, P. (2013). Nitrogen isotopic composition and density of the archean atmosphere. Science, 342(6154), 101-104. Retrieved from http://science.sciencemag.org/ content/342/6154/101 doi: 10.1126/science.1240971

Maruyama, S., Santosh, M., \& Azuma, S. (2018). Initiation of plate tectonics in the hadean: Eclogitization triggered by the abel bombardment. Geoscience Frontiers, 9(4), 1033 - 1048. Retrieved from http://www.sciencedirect.com/ science/article/pii/S1674987116302079 doi: https://doi.org/10.1016/ j.gsf.2016.11.009

Masunaga, K., Futaana, Y., Persson, M., Barabash, S., Zhang, T., Rong, Z., \& Fedorov, A. (2019). Effects of the solar wind and the solar euv flux on o+ escape rates from venus. Icarus, 321, 379 - 387. Retrieved from http://www.sciencedirect.com/science/article/pii/S0019103518304433 doi: https://doi.org/10.1016/j.icarus.2018.11.017

Matsui, T., \& Abe, Y. (1986, August). Impact-induced atmospheres and oceans on earth and Venus. Nature, 322, 526-528. doi: 10.1038/322526a0

Matthews, R. K., Frohlich, C., \& Duffy, A. (1997, September). Orbital forcing of global change throughout the Phanerozoic: A possible stratigraphic solution to the eccentricity phase problem. Geology, 25, 807. doi: 10.1130/0091-7613(1997)025〈0807:OFOGCT $\rangle 2.3 . C O ; 2$

McCord, T. B. (1968). The loss of retrograde satellites in the solar system. Journal of Geophysical Research (1896-1977), 73(4), 1497-1500. Retrieved from https://agupubs.onlinelibrary.wiley.com/doi/abs/10.1029/ JB073i004p01497 doi: 10.1029/JB073i004p01497

McCubbin, F. M., \& Barnes, J. J. (2019, Nov). Origin and abundances of $\mathrm{H}_{2} \mathrm{O}$ in the terrestrial planets, Moon, and asteroids. Earth and Planetary Science Letters, 526, 115771. doi: 10.1016/j.epsl.2019.115771

McKinnon, W. B., Zahnle, K. J., Ivanov, B. A., \& Melosh, H. J. (1997). Cratering on Venus: Models and Observations. In S. W. Bougher, D. M. Hunten, \& R. J. Phillips (Eds.), Venus ii: Geology, geophysics, atmosphere, and solar wind environment (p. 969).

Mello, F. d. S., \& Friaa, A. C. S. (2019). The end of life on earth is not the end of the world: converging to an estimate of life span of the biosphere? International Journal of Astrobiology, 118. doi: 10.1017/S1473550419000120

Mitchell, J. L. (2008). The drying of titan's dunes: Titan's methane hydrology and its impact on atmospheric circulation. JGRE(E08015). doi: 10.1029/ 2007HE003017

Mojzsis, S., Mark Harrison, T., \& Pidgeon, R. (2001, 02). Oxygen-isotope evidence from ancient zircons for liquid water at the earth's surface 4,300 myr ago. $\mathrm{Na}$ ture, 409, 178-81. doi: 10.1038/35051557

Mojzsis, S. J., Brasser, R., Kelly, N. M., Abramov, O., \& Werner, S. C. $\quad$ (2019, aug). Onset of giant planet migration before 4480 million years ago. Astrophysical Journal, 881(1), $44 . \quad$ Retrieved from https://doi.org/ 10.3847\\%2F1538-4357\\%2Fab2c03 doi: 10.3847/1538-4357/ab2c03

Morbidelli, A., Chambers, J., Lunine, J. I., Petit, J. M., Robert, F., Valsecchi, G. B., \& Cyr, K. E. (2000, November). Source regions and time scales for the delivery of water to Earth. Meteoritics and Planetary Science, 35, 1309-1320. doi: 10.1111/j.1945-5100.2000.tb01518.x

Morbidelli, A., Nesvorny, D., Laurenz, V., Marchi, S., Rubie, D., Elkins-Tanton, L., 
... Jacobson, S. (2018). The timeline of the lunar bombardment: Revisited. Icarus, 305, 262 - $276 . \quad$ Retrieved from http://www.sciencedirect.com/ science/article/pii/S0019103517303408 doi: https://doi.org/10.1016/ j.icarus.2017.12.046

Morbidelli, A., \& Wood, B. J. (2015). Late accretion and the late veneer. In The early earth (p. 71-82). American Geophysical Union (AGU). Retrieved from https://agupubs.onlinelibrary.wiley.com/doi/abs/10.1002/ 9781118860359.ch4 doi: 10.1002/9781118860359.ch4

Morowitz, H., \& Sagan, C. (1967, September). Life in the Clouds of Venus? Nature, 215, 1259-1260. doi: 10.1038/2151259a0

Mueller, N., Helbert, J., Hashimoto, G. L., Tsang, C. C. C., Erard, S., Piccioni, G., \& Drossart, P. (2008). Venus surface thermal emission at $1 \mathrm{um}$ in virtis imaging observations: Evidence for variation of crust and mantle differentiation conditions. Journal of Geophysical Research: Planets, 113(E5). Retrieved from https://agupubs.onlinelibrary.wiley.com/doi/abs/10.1029/ 2008JE003118 doi: 10.1029/2008JE003118

Munk, W. H., \& MacDonald, G. J. F. (1960). The rotation of the earth; a geophysical discussion. Cambridge University Press.

Namiki, N., \& Solomon, S. C. (1998). Volcanic degassing of argon and helium and the history of crustal production on venus. Journal of Geophysical Research: Planets, 103(E2), 3655-3677. Retrieved from https:// agupubs.onlinelibrary.wiley.com/doi/abs/10.1029/97JE03032 doi: 10.1029/97JE03032

Nesvorny, D., Vokrouhlick, D., Bottke, W., \& Levison, H. $\quad(2018,11) . \quad$ Evidence for very early migration of the solar system planets from the patroclusmenoetius binary jupiter trojan. Nature Astronomy, 2, 878-882. doi: 10.1038/s41550-018-0564-3

Nikolaou, A., Katyal, N., Tosi, N., Godolt, M., Grenfell, J. L., \& Rauer, H. $\quad$ (2019, Apr). What Factors Affect the Duration and Outgassing of the Terrestrial Magma Ocean? Astrophysical Journal, 875(1), 11. doi: 10.3847/1538-4357/ ab08ed

Nikolayeva, O. V. (1990, Jul 01). Geochemistry of the venera 8 material demonstrates the presence of continental crust on venus. Earth, Moon, and Planets, 50(1), 329-341. Retrieved from https://doi.org/10.1007/BF00142398 doi: $10.1007 / \mathrm{BF} 00142398$

Nishizawa, M., Sano, Y., Ueno, Y., \& Maruyama, S. (2007). Speciation and isotope ratios of nitrogen in fluid inclusions from seafloor hydrothermal deposits at $\sim 3.5 \mathrm{ga} . \quad \quad$ Earth and Planetary Science Letters, 254(3), 332 - 344. Retrieved from http://www.sciencedirect.com/science/article/pii/ S0012821X06008600 doi: https://doi.org/10.1016/j.epsl.2006.11.044

Noack, L., Breuer, D., \& Spohn, T. (2012). Coupling the atmosphere with interior dynamics: Implications for the resurfacing of venus. Icarus, 217(2), 484 498. Retrieved from http://www.sciencedirect.com/science/article/pii/ S0019103511003435 (Advances in Venus Science) doi: https://doi.org/10 $.1016 /$ j.icarus.2011.08.026

Ogden, D. E., \& Sleep, N. H. (2012). Explosive eruption of coal and basalt and the end-permian mass extinction. Proceedings of the National Academy of Sciences, 109(1), 59-62. Retrieved from https://www.pnas.org/content/109/ 1/59 doi: 10.1073/pnas.1118675109

Olsen, P. E., Laskar, J., Kent, D. V., Kinney, S. T., Reynolds, D. J., Sha, J., \& Whiteside, J. H. (2019). Mapping solar system chaos with the geological orrery. $\quad$ Proceedings of the National Academy of Sciences, 116 (22), 1066410673. Retrieved from https://www.pnas.org/content/116/22/10664 doi: $10.1073 /$ pnas. 1813901116

O'Neill, C., Marchi, S., Zhang, S., \& Bottke, W. (2017, Oct). Impact-driven sub- 
duction on the Hadean Earth. Nature Geoscience, 10, 793-797. doi: 10.1038/ ngeo3029

Owen, T., Cess, R. D., \& Ramanathan, V. (1979, February). Enhanced $\mathrm{CO}_{2}$ greenhouse to compensate for reduced solar luminosity on early Earth. Nature, 277, 640-642. doi: 10.1038/277640a0

ORourke, J. G., \& Korenaga, J. (2015). Thermal evolution of venus with argon degassing. Icarus, 260,128-140. Retrieved from http:// ww. sciencedirect.com/science/article/pii/S0019103515003000 doi: https://doi.org/10.1016/j.icarus.2015.07.009

Pälike, H., Laskar, J., \& Shackleton, N. J. (2004, November). Geologic constraints on the chaotic diffusion of the solar system. Geology, 32, 929. doi: 10.1130/ G20750.1

Pälike, H., \& Shackleton, N. J. (2000, October). Constraints on astronomical parameters from the geological record for the last $25 \mathrm{Myr}$. Earth and Planetary Science Letters, 182, 1-14. doi: 10.1016/S0012-821X(00)00229-6

Park, J., \& Herbert, T. D. (1987, December). Hunting for Paleoclimatic Periodicities in a Geologic Time Series With an Uncertain Time Scale. Journal of Geophysical Research, 92, 14. doi: 10.1029/JB092iB13p14027

Persson, M., Futaana, Y., Fedorov, A., Nilsson, H., Hamrin, M., \& Barabash, S. (2018). $\quad \mathrm{H}+/ \mathrm{o}+$ escape rate ratio in the venus magnetotail and its dependence on the solar cycle. Geophysical Research Letters, 45(20), 10,805-10,811. Retrieved from https://agupubs.onlinelibrary.wiley.com/doi/abs/ 10.1029/2018GL079454 doi: 10.1029/2018GL079454

Persson, M., Futaana, Y. F., Ramstad, R., Masunaga, K., Nilsson, H., Hamrin, M., ... Barabash, S. (2020). The venusian atmospheric oxygen ion escape: Extrapolation to the early solar system. Earth and Space Science Open Archive. Retrieved from https://www.essoar.org/doi/abs/10.1002/ essoar.10501914.1 doi: 10.1002/essoar.10501914.1

Petit, J. R., Jouzel, J., Raynaud, D., Barkov, N. I., Barnola, J.-M., Basile, I., ... Stievenard, M. (1999, June). Climate and atmospheric history of the past 420,000 years from the Vostok ice core, Antarctica. Nature, 399, 429-436. doi: $10.1038 / 20859$

Pham, L. B. S., Karatekin, Ö., \& Dehant, V. (2011, August). Effects of impacts on the atmospheric evolution: Comparison between Mars, Earth, and Venus. Planetary Space Science, 59, 1087-1092. doi: 10.1016/j.pss.2010.11.010

Phillips, R. J., Raubertas, R. F., Arvidson, R. E., Sarkar, I. C., Herrick, R. R., Izenberg, N., \& Grimm, R. E. (1992). Impact craters and venus resurfacing history. Journal of Geophysical Research: Planets, $97(\mathrm{E} 10), 15923-15948$. Retrieved from https://agupubs.onlinelibrary.wiley.com/doi/abs/ 10.1029/92JE01696 doi: 10.1029/92JE01696

Pieters, C. M., Head, J. W., Pratt, S., Patterson, W., Garvin, J., Barsukov, V. L., ... Narayeva, Y. M. (1986). The color of the surface of venus. Science, 234(4782), 1379-1383. Retrieved from https://science.sciencemag.org/ content/234/4782/1379 doi: 10.1126/science.234.4782.1379

Pollack, J. B. (1971, June). A Nongrey Calculation of the Runaway Greenhouse: Implications for Venus' Past and Present. Icarus, 14, 295-306. doi: 10.1016/0019 -1035(71)90001-7

Quarles, B., \& Kaib, N. (2019, jan). Instabilities in the early solar system due to a self-gravitating disk. The Astronomical Journal, 157(2), 67. Retrieved from https://doi.org/10.3847\%2F1538-3881\%2Faafa71 doi: 10.3847/1538-3881/ aafa71

Ramirez, R., \& Craddock, R. (2018, 04). The geological and climatological case for a warmer and wetter early mars. Nature Geoscience, 11, 230. doi: 10.1038/ s41561-018-0093-9

Ramirez, R. M., Kopparapu, R., Zugger, M. E., Robinson, T. D., Freedman, R., \& 
Kasting, J. F. (2014, Jan). Warming early Mars with $\mathrm{CO}_{2}$ and $\mathrm{H}_{2}$. Nature Geoscience, 7(1), 59-63. doi: 10.1038/ngeo2000

Ramirez, R. M., Kopparapu, R. K., Lindner, V., \& Kasting, J. F. (2014, Aug). Can Increased Atmospheric CO2 Levels Trigger a Runaway Greenhouse? Astrobiology, 14(8), 714-731. doi: 10.1089/ast.2014.1153

Rampino, M. R., \& Caldeira, K. (1994). The Goldilocks Problem: Climatic Evolution and Long-Term Habitability of Terrestrial Planets. Annual Review of Astronomy and Astrophysics, 32, 83-114. doi: 10.1146/annurev.aa.32.090194 .000503

Rasool, S. I., \& de Bergh, C. (1970, June). The Runaway Greenhouse and the Accumulation of $\mathrm{CO}_{2}$ in the Venus Atmosphere. Nature, 226, 1037-1039. doi: 10 $.1038 / 2261037 \mathrm{a} 0$

Raymond, S. N., Quinn, T., \& Lunine, J. I. (2004). Making other earths: dynamical simulations of terrestrial planet formation and water delivery. Icarus, 168(1), 1 - 17. Retrieved from http://www.sciencedirect.com/science/article/ pii/S0019103503003981 doi: https://doi.org/10.1016/j.icarus.2003.11.019

Raymond, S. N., Quinn, T., \& Lunine, J. I. (2006, August). High-resolution simulations of the final assembly of Earth-like planets I. Terrestrial accretion and dynamics. Icarus, 183, 265-282. doi: 10.1016/j.icarus.2006.03.011

Ringwood, A., \& Anderson, D. L. (1977). Earth and venus: A comparative study. Icarus, 30(2), 243 - 253. Retrieved from http://www.sciencedirect.com/ science/article/pii/0019103577901567 doi: https://doi.org/10.1016/ 0019-1035(77)90156-7

Rolf, T., Steinberger, B., Sruthi, U., \& Werner, S. (2018). Inferences on the mantle viscosity structure and the post-overturn evolutionary state of venus.

Icarus, 313, 107 - 123. Retrieved from http://www.sciencedirect.com/ science/article/pii/S0019103517308400 doi: https://doi.org/10.1016/ j.icarus.2018.05.014

Rozel, A. B., Golabek, G. J., Jain, C., Tackley, P. J., \& Gerya, T. (2017, May). Continental crust formation on early Earth controlled by intrusive magmatism. Nature, 545 (7654), 332-335. doi: 10.1038/nature22042

Rubie, D., Jacobson, S., Morbidelli, A., OBrien, D., Young, E., de Vries, J., ...

Frost, D. (2015). Accretion and differentiation of the terrestrial planets with implications for the compositions of early-formed solar system

bodies and accretion of water. Icarus, 248,89-108. Retrieved from http://www.sciencedirect.com/science/article/pii/S0019103514005545 doi: https://doi.org/10.1016/j.icarus.2014.10.015

Sakuraba, H., Kurokawa, H., \& Genda, H. (2019, January). Impact degassing and atmospheric erosion on Venus, Earth, and Mars during the late accretion. Icarus, 317, 48-58. doi: 10.1016/j.icarus.2018.05.035

Salvador, A., Massol, H., Davaille, A., Marcq, E., Sarda, P., \& Chassefière, E. (2017, Jul). The relative influence of $\mathrm{H}_{2} \mathrm{O}$ and $\mathrm{CO}_{2}$ on the primitive surface conditions and evolution of rocky planets. Journal of Geophysical Research (Planets), 122(7), 1458-1486. doi: 10.1002/2017JE005286

Sandwell, D. T., \& Schubert, G. (1992). Evidence for retrograde lithospheric subduction on venus. Science, 257(5071), 766-770. Retrieved from https:// science.sciencemag.org/content/257/5071/766 doi: 10.1126/science. 257 .5071 .766

Schaber, G. G., Strom, R. G., Moore, H. J., Soderblom, L. A., Kirk, R. L., Chadwick, D. J., ... Russell, J. (1992). Geology and distribution of impact craters on venus: What are they telling us? Journal of Geophysical Research: Planets, 97(E8), 13257-13301. Retrieved from https:// agupubs.onlinelibrary.wiley.com/doi/abs/10.1029/92JE01246 doi: 10.1029/92JE01246

Schmandt, B., Jacobsen, S. D., Becker, T. W., Liu, Z., \& Dueker, K. G. (2014). De- 
hydration melting at the top of the lower mantle. Science, $344(6189), 1265-$ 1268. Retrieved from https://science.sciencemag.org/content/344/6189/ 1265 doi: 10.1126/science. 1253358

Schoene, B., Eddy, M. P., Samperton, K. M., Keller, C. B., Keller, G., Adatte, T., \& Khadri, S. F. R. (2019). U-pb constraints on pulsed eruption of the deccan traps across the end-cretaceous mass extinction. Science, 363(6429), 862-866. Retrieved from http://science.sciencemag.org/content/363/6429/862 doi: $10.1126 /$ science.aau2422

Schulze-Makuch, D., Grinspoon, D. H., Abbas, O., Irwin, L. N., \& Bullock, M. A. (2004, March). A Sulfur-Based Survival Strategy for Putative Phototrophic Life in the Venusian Atmosphere. Astrobiology, 4, 11-18. doi: $10.1089 / 153110704773600203$

Schulze-Makuch, D., \& Irwin, L. N. (2002, June). Reassessing the Possibility of Life on Venus: Proposal for an Astrobiology Mission. Astrobiology, 2, 197-202. doi: $10.1089 / 15311070260192264$

Shaw, G. H. (2018). Comment on batalha et al.: Climate cycling on early mars caused by the carbonatesilicate cycle. Earth and Planetary Science Letters, 484, 412 - 414. Retrieved from http://www.sciencedirect.com/ science/article/pii/S0012821X1730540X doi: https://doi.org/10.1016/ j.epsl.2017.09.038

Shellnutt, J. G. (2019, March). The curious case of the rock at Venera 8. Icarus, 321, 50-61. doi: 10.1016/j.icarus.2018.11.001

Singer, S. F. (1970, Dec). How Did Venus Lose Its Angular Momentum? Science, 170(3963), 1196-1198. doi: 10.1126/science.170.3963.1196

Smrekar, S. E., Davaille, A., \& Sotin, C. (2018, Jul 16). Venus interior structure and dynamics. Space Science Reviews, 214(5), 88. Retrieved from https://doi .org/10.1007/s11214-018-0518-1 doi: 10.1007/s11214-018-0518-1

Som, D., S. Catling, Harnmeijer, J., Polivka, P., \& Buick, R. (2012, March). Air density 2.7 billion years ago limited to less than twice modern levels by fossil raindrop imprints. Nature, 484, 359. doi: 10.1038/nature10890

Som, S., Buick, R., Hagadorn, J., Blake, T., Perreault, J., Harnmeijer, J., \& Catling, D. (2016, May). Earth's air pressure 2.7 billion years ago constrained to less than half of modern levels. Nat.Geo., 9, 448. doi: 10.1038/ngeo2713

Spencer, J. (2019, 01). The faint young sun problem revisited. GSA Today, 1. doi: 10.1130/GSATG403A.1

Sprain, C. J., Renne, P. R., Vanderkluysen, L., Pande, K., Self, S., \& Mittal, T. (2019). The eruptive tempo of deccan volcanism in relation to the cretaceous-paleogene boundary. Science, 363(6429), 866-870. Retrieved from http://science.sciencemag.org/content/363/6429/866 doi: 10.1126/science.aav1446

Stewart, E., Ague, J. J., Ferry, J. M., Schiffries, C. M., Tao, R.-B., Isson, T. T., \& Planavsky, N. J. $\quad(2019,10)$ Carbonation and decarbonation reactions: Implications for planetary habitability. American Mineralogist, 104(10), 1369-1380. Retrieved from https://doi.org/10.2138/am-2019-6884 doi: 10.2138/am-2019-6884

Strom, R. G., Schaber, G. G., \& Dawsow, D. D. (1994, May). The global resurfacing of Venus. Journal of Geophysical Research, 99, 10. doi: 10.1029/94JE00388

Taylor, F., \& Grinspoon, D. (2009, May). Climate evolution of Venus. Journal of Geophysical Research (Planets), 114, E00B40. doi: 10.1029/2008JE003316

Thomson, W. (1882). 2. on the thermodynamic acceleration of the earth's rotation. Proceedings of the Royal Society of Edinburgh, 11, 396405. doi: 10.1017/ S037016460004757X

Tosi, N., Godolt, M., Stracke, B., Ruedas, T., Grenfell, J. L., Höning, D., ... Spohn, T. (2017, Sep). The habitability of a stagnant-lid Earth. Astronomy and Astrophysics, 605, A71. doi: 10.1051/0004-6361/201730728 
Touma, J., \& Wisdom, J. (1994, November). Evolution of the Earth-Moon system. Astronomical Journal, 108, 1943-1961. doi: 10.1086/117209

Treiman, A. H. (2009, Feb). Venus - Bulk and Mantle Compositions: Are Venus and Earth Really Twins? In Venus geochemistry: Progress, prospects, and new missions (Vol. 1470, p. 47-48).

Tsang, C., Encrenaz, T., DeWitt, C. N., Richter, M., \& Irwin, P. (2017, Oct). Airborne Measurements of Venus Cloud-top $\mathrm{H}_{2} \mathrm{O}$ and HDO from NASA's SOFIA in the Mid-Infrared. In Aas/division for planetary sciences meeting abstracts \#49 (p. 502.04).

Turcotte, D. L. (1993, September). An episodic hypothesis for venusian tectonics. Journal of Geophysical Research, 98, 17061-17068. doi: 10.1029/93JE01775

Valley, J. (2005, 11). A cool early earth? Scientific American, 293, 58-65. doi: 10 $.1038 /$ scientificamerican1005-58

Valley, J. W., Cavosie, A. J., Ushikubo, T., Reinhard, D. A., Lawrence, D. F., Larson, D. J., ... Spicuzza, M. J. (2014, March). Hadean age for a post-magmaocean zircon confirmed by atom-probe tomography. Nature Geoscience, 7, 219-223. doi: 10.1038/ngeo2075

Valley, J. W., Peck, W. H., King, E. M., \& Wilde, S. A. $\quad(2002,04) . \quad$ A cool early Earth. Geology, 30(4), 351-354. Retrieved from https://doi.org/ 10.1130/0091-7613(2002)030<0351:ACEE>2.0.CO;2 doi: $10.1130 /$ 0091-7613(2002)030<0351:ACEE $\rangle$ 2.0.CO;2

Varas-Reus, M. I., KÃ $\llbracket$ nig, S., Yierpan, A., Lorand, J.-P., \& Schoenberg, R. (2019). Selenium isotopes as tracers of a late volatile contribution to earth from the outer solar system. Nature Geoscience, 12(9), 779-782. Retrieved from https://doi.org/10.1038/s41561-019-0414-7 doi: 10.1038/s41561-019-0414-7

Voosen, P. (2020, jan). Cataclysmic bashing from giant planets occurred early in our solar system's history. Science, 367(6458), $10 . \quad$ Retrieved from https://www. sciencemag.org/news/2020/01/cataclysmic-bashing -giant-planets-occurred-early-our-solar-systems-history doi: doi:10.1126/science.aba9938

Walker, J. C. G. (1975). Evolution of the atmosphere of venus. Journal of the Atmospheric Sciences, 32(6), 1248-1256. Retrieved from https:// doi.org/10.1175/1520-0469(1975)032<1248:EOTAOV>2.0.CO;2 doi: 10.1175/1520-0469(1975)032〈1248:EOTAOV $\rangle 2.0 . \mathrm{CO} ; 2$

Walker, J. C. G., Hays, P. B., \& Kasting, J. F. ～(1981, October). I negative feedback mechanism for the long-term stabilization of the earth's surface temperature. Journal of Geophysical Research, 86, 9776-9782. doi: 10.1029/JC086iC10p09776

Ward, W. R., \& Reid, M. J. $\quad$ (1973, Jan). Solar tidal friction and satellite loss. Monthly Notices of the Royal Astronomical Society, 164, 21. doi: $10.1093 / \mathrm{mnras} / 164.1 .21$

Watson, A. J., Donahue, T. M., \& Walker, J. C. G. $\quad$ (1981, Nov). The dynamics of a rapidly escaping atmosphere: Applications to the evolution of Earth and Venus. Icarus, 48(2), 150-166. doi: 10.1016/0019-1035(81)90101-9

Watson, E., Thomas, J., \& Cherniak, D. (2007, 10). 40ar retention in the terrestrial planets. Nature, 449, 299-304. doi: 10.1038/nature06144

Way, M. J., Aleinov, I., Amundsen, D. S., Chandler, M. A., Clune, T. L., Del Genio, A. D., ... Tsigaridis, K. (2017, July). Resolving Orbital and Climate Keys of Earth and Extraterrestrial Environments with Dynamics (ROCKE-3D) 1.0: A General Circulation Model for Simulating the Climates of Rocky Planets. Astrophysical Journals, 231, 12. doi: 10.3847/1538-4365/aa7a06

Way, M. J., Del Genio, A. D., Aleinov, I., Clune, T. L., Kelley, M., \& Kiang, N. Y. (2018, August). Climates of Warm Earth-like Planets I: 3-D Model Simulations. ArXiv e-prints. 
Way, M. J., Del Genio, A. D., Kiang, N. Y., Sohl, L. E., Grinspoon, D. H., Aleinov, I., ... Clune, T. (2016, August). Was Venus the first habitable world of our solar system? Geophysical Research Letters, 43, 8376-8383. doi: 10.1002/2016GL069790

Weller, M. B., \& Kiefer, W. S. (2019). The physics of changing tectonic regimes: Implications for the temporal evolution of mantle convection and the thermal history of venus. Journal of Geophysical Research: Planets, $n / a(\mathrm{n} / \mathrm{a})$. Retrieved from https://agupubs.onlinelibrary.wiley.com/doi/abs/ 10.1029/2019JE005960 doi: 10.1029/2019JE005960

Weller, M. B., Lenardic, A., \& Jellinek, M. (2018, March). Life Potential on Early Venus Connected to Climate and Geologic History. In Lunar and planetary science conference (Vol. 49, p. 2808).

Wolf, E. T., \& Toon, O. B. (2013, July). Hospitable Archean Climates Simulated by a General Circulation Model. Astrobiology, 13, 656-673. doi: 10.1089/ast.2012 .0936

Wordsworth, R., Kalugina, Y., Lokshtanov, S., Vigasin, A., Ehlmann, B., Head, J., ... Wang, H. (2017, Jan). Transient reducing greenhouse warming on early Mars. Geophysical Research Letters, 44(2), 665-671. doi: 10.1002/2016GL071766

Wordsworth, R. D. (2016a, August). Atmospheric nitrogen evolution on Earth and Venus. Earth and Planetary Science Letters, 447, 103-111. doi: 10.1016/j.epsl .2016 .04 .002

Wordsworth, R. D. (2016b, June). The Climate of Early Mars. Annual Review of Earth and Planetary Sciences, 44, 381-408. doi: 10.1146/annurev-earth-060115 $-012355$

Wroblewski, F. B., Treiman, A. H., Bhiravarasu, S., \& Gregg, T. K. P. Ovda fluctus, the festoon lava flow on ovda regio, venus: Not silica-rich. Journal of Geophysical Research: Planets, 0(0). Retrieved from https:// agupubs.onlinelibrary.wiley.com/doi/abs/10.1029/2019JE006039 doi: 10.1029/2019JE006039

Xia, Y. F., \& Xiao, N. Y. (2002, April). Love Numbers And Elastic Energy Of Deformation For Venus. Earth Moon and Planets, 88, 75-87. doi: 10.1023/A: 1015808809889

Yang, J., Boué, G., Fabrycky, D. C., \& Abbot, D. S. (2014, May). Strong Dependence of the Inner Edge of the Habitable Zone on Planetary Rotation Rate. Astrophysical Journal, 787, L2. doi: 10.1088/2041-8205/787/1/L2

Yoder, C. F. (1997). Venusian Spin Dynamics. In S. W. Bougher, D. M. Hunten, \& R. J. Phillips (Eds.), Venus ii: Geology, geophysics, atmosphere, and solar wind environment (p. 1087).

Zahnle, K., Lupu, R., \& Catling, D. $\quad$ (2019, Dec). Creation and Evolution of Impact-generated Reduced Atmospheres of Early Earth. arXiv e-prints, arXiv:2001.00095.

Zahnle, K., Schaefer, L., \& Fegley, B. $\quad$ (2010). Earths earliest atmospheres. Cold Spring Harbor Perspectives in Biology, 2(10). Retrieved from http://cshperspectives.cshlp.org/content/2/10/a004895. abstract doi: $10.1101 /$ cshperspect.a004895

Zahnle, K., \& Sleep, N. H. (2002, 01). Carbon dioxide cycling through the mantle and implications for the climate of ancient Earth. In The Early Earth: Physical, Chemical and Biological Development (p. 231-257). Geological Society of London. Retrieved from https://doi.org/10.1144/GSL.SP.2002.199.01.12 doi: 10.1144/GSL.SP.2002.199.01.12

Zahnle, K., \& Walker, J. C. G. (1987). A consistent daylength during the precambrian era? Precambrian Res., 37, 95-105.

Zahnle, K. J. (2006, 08). Earth's Earliest Atmosphere. Elements, 2(4), 217-222. Retrieved from https://doi.org/10.2113/gselements.2.4.217 doi: 10.2113/ 
gselements.2.4.217

Zellner, N. E. B. (2017, Sep 01). Cataclysm no more: New views on the timing and delivery of lunar impactors. Origins of Life and Evolution of Biospheres, 47(3), 261-280. Retrieved from https://doi.org/10.1007/s11084-017-9536 -3 doi: 10.1007/s11084-017-9536-3

Zhang, C. Z. (1992, March). Love numbers of the moon and of the terrestrial planets. Earth Moon and Planets, 56, 193-207. doi: 10.1007/BF00116287

Zolotov, M. Y., Fegley, B., \& Lodders, K. (1997). Hydrous silicates and water on venus. Icarus, 130(2), 475 - 494. Retrieved from http:// www.sciencedirect.com/science/article/pii/S0019103597958383 doi: https://doi.org/10.1006/icar.1997.5838 